JORGE VON ATZINGEN DOS REIS

\title{
HEURÍSTICAS BASEADAS EM \\ BUSCA EM VIZINHANÇA VARIÁVEL PARA \\ O PROBLEMA DE PROGRAMAÇÃO INTEGRADA \\ DE VEÍCULOS E TRIPULAÇÕES NO \\ TRANSPORTE COLETIVO URBANO POR ÔNIBUS
}

Dissertação apresentada à Escola Politécnica da Universidade de São Paulo para obtenção do Título de Mestre em Engenharia. 
JORGE VON ATZINGEN DOS REIS

\title{
HEURÍSTICAS BASEADAS EM BUSCA EM VIZINHANÇA VARIÁVEL PARA O PROBLEMA DE PROGRAMAÇÃO INTEGRADA DE VEÍCULOS E TRIPULAÇÕES NO TRANSPORTE COLETIVO URBANO POR ÔNIBUS
}

\author{
Dissertação apresentada à Escola \\ Politécnica da Universidade de São Paulo \\ para obtenção do Título de Mestre em \\ Engenharia. \\ Área de Concentração: \\ Engenharia de Transportes. \\ Orientador: \\ Prof. Dr. \\ Claudio Barbieri da Cunha.
}


Este exemplar foi revisado e alterado em relação à versão original sob responsabilidade única do autor e com a anuência de seu orientador.

São Paulo, 23 de julho de 2008.

Assinatura do autor

Assinatura do orientador

\section{FICHA CATALOGRÁFICA}

Reis, Jorge von Atzingen dos

Heurísticas Baseadas em Busca em Vizinhança Variável para o Problema de Programação Integrada de Veículos e Tripulações no Transporte Coletivo Urbano por Ônibus / J. V. A. dos Reis. -- ed. Rev. -São Paulo, 2008.

$108 p$.

Dissertação (Mestrado) - Escola Politécnica da Universidade de São Paulo. Departamento de Engenharia de Transportes.

1. Heurística 2. Transporte Coletivo 3. Ônibus 4. Mão-de-obra

I. Universidade de São Paulo. Escola Politécnica. Departamento de Engenharia de Transportes II.t. 
Dedico este trabalho a Deus, à minha familia, principalmente aos meus pais Vitor e Yara, às minhas irmãs Marina e Laís, à minha esposa Deborah, e a todos os meus irmãos da República Calamidade Pública. 


\section{AGRADECIMENTOS}

Agradeço à Escola Politécnica da Universidade de São Paulo, à Fundação de Amparo à Pesquisa do Estado de São Paulo, ao meu orientador Prof. Dr. Claudio Barbieri da Cunha pela orientação fornecida durante o desenvolvimento deste trabalho e ao Prof. Dr. Gustavo Peixoto Silva pela sua contribuição ao trabalho, bem como a todos que, direta ou indiretamente, colaboraram na execução do mesmo. 


\section{RESUMO}

Na maioria das cidades brasileiras, o ônibus é o principal, senão o único meio de transporte público de passageiros, atendendo àqueles que não possuem carro, mas também contribuindo para reduzir os congestionamentos e, dessa forma, melhorando a qualidade de vida. A fim de incentivar a sua utilização em muitas cidades, inúmeras medidas devem ser tomadas, incluindo um esforço para reduzir custos e, em decorrência, as tarifas pagas pelos usuários, definindo uma tarifa justa que privilegie a população de baixa renda, na qual estão inseridos uma grande parcela dos seus usuários. Nesse contexto, a programação eficiente de veículos e tripulações é essencial para essa redução de custos, uma vez que representa uma parcela significativa dos mesmos. Este trabalho trata do Problema de Programação de Veículos e de Tripulantes de Ônibus, em que ambas as programações são determinadas simultaneamente e de maneira integrada. Durante a realização deste trabalho, foi desenvolvido um programa computacional em $\mathrm{C}++$, o qual implementa a metaheurística Busca em Vizinhança Variável (VNS) utilizada para resolver esse problema complexo. São apresentados resultados de experimentos computacionais com dados reais de uma empresa de transporte coletivo. Os resultados obtidos comprovam a eficácia da abordagem integrada em comparação com quatro outras abordagens encontradas na literatura. 


\begin{abstract}
In most Brazilian cities, bus has become the main, and oftentimes the only mean of public transportation, not only servicing those who cannot afford to have a car, but also helping to reduce traffic congestion and thus improving quality of life. In order to encourage the bus usage in many cities, several measures must be taken, including an effort to reduce overall costs and, as a result, fares paid by the users, thus benefit mainly low income users which represent a major part of its users. In this context, an efficient scheduling of vehicles and crews is essential to achieve cost reduction, since it accounts for a major part of overall costs. In this paper, we deal with the Bus Vehicle Crew Scheduling Problem, in which bus and crew schedules are simultaneously determined in an integrated approach. We propose an approach based on Variable Neighborhood search to solve this complex problem, which was implemented in $\mathrm{C}++$. Computational results for real-world problems are presented, showing the effectiveness of this novel approach in comparison with other four approaches found in the literature.
\end{abstract}




\section{SUMÁRIO}

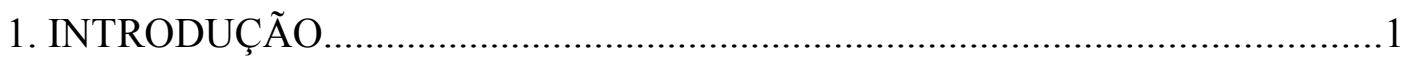

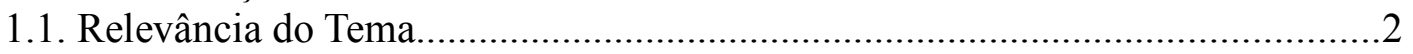

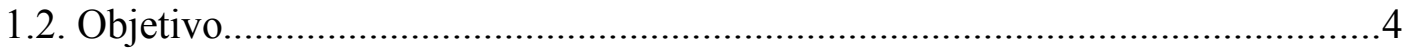

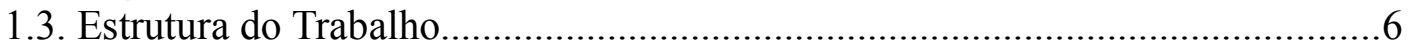

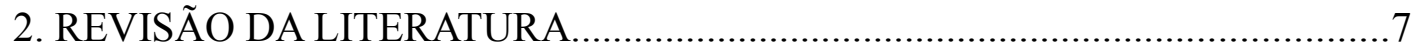

2.1. O Sistema de Transporte Coletivo..................................................................

2.2. O Problema de Programação de Veículos e Tripulantes....................................... 10

3. CARACTERIZAÇÃO DO PROBLEMA DE PROGRAMAÇÃO E INTEGRADA DE VEÍCULOS E TRIPULAÇÕES......................................................................

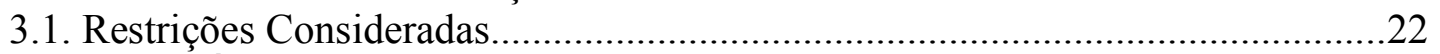

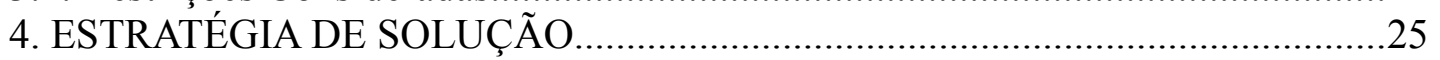

4.1. Metaheurística Variable Neighborhood Search....................................................26

4.2. Heurística Construtiva para a Solução Inicial...……………………………….....29

4.3. Função de Avaliação.....................................................................................

4.4. Estruturas de Vizinhança.....................................................................................4

5. ABORDAGENS IMPLEMENTADAS PARA O PPVT.......................................4

5.1. Abordagem Seqüencial Tradicional................................................................... 44

5.2. Abordagem Seqüencial Inversa.....................................................................5

5.3. Abordagem Independente ................................................................................5

5.4. Abordagem Integrada Nível 1.....................................................................58

5.5. Abordagem Integrada Nível 2.........................................................................62

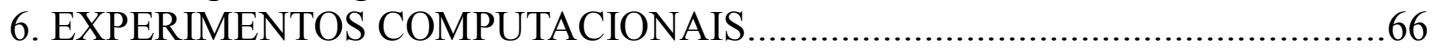

6.1. Resultados Obtidos Utilizando Custo Monetário...................................................72

6.2. Comparativo entre Pesos Empíricos e Monetários................................................77

6.3. Testes dos Métodos de Exploração da Vizinhança...................................................78

6.4. Evolução da Função de Avaliação.................................................................79

6.5. Variação nos Resultados Obtidos........................................................................ 81

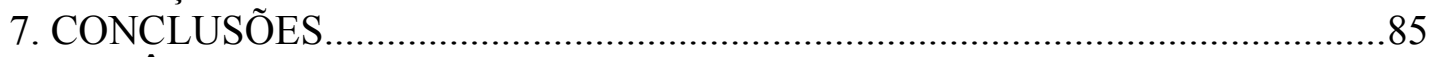

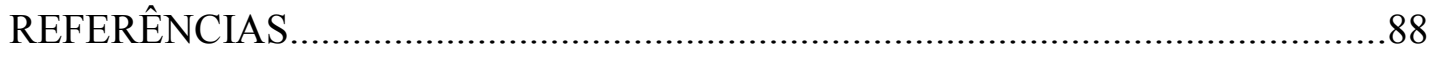

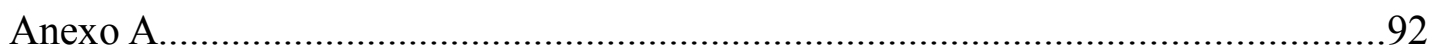

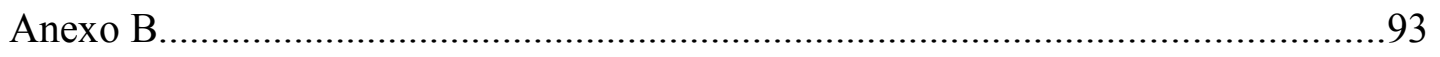

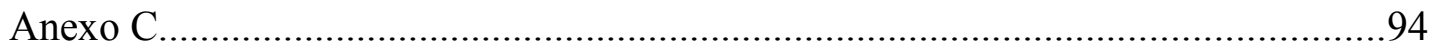




\section{LISTA DE TABELAS}

Tabela 4.1 - Valores limites de restrições e pesos determinados empiricamente......34

Tabela 4.2 - Valores limites de restrições e pesos considerando custo monetário......38

Tabela 4.3 - Dados utilizados no cálculo dos pesos................................................39

Tabela 6.1 - Resultados obtidos para o dia útil utilizando peso empírico.................67

Tabela 6.2 - Sumário de resultados obtidos utilizando peso empírico.......................68

Tabela 6.3 - Resultados obtidos para o sábado utilizando peso empírico..................70

Tabela 6.4 - Resultados obtidos para o domingo utilizando peso empírico...............71

Tabela 6.5 - Resultados obtidos utilizando custo monetário....................................72

Tabela 6.6 - Resultados obtidos para o dia útil utilizando custo monetário..............73

Tabela 6.7 - Resultados obtidos para o sábado utilizando custo monetário..............75

Tabela 6.8 - Resultados obtidos para o domingo utilizando custo monetário............76

Tabela 6.9 - Peso empírico versus peso monetário....................................................77

Tabela 6.10 - Variação nos resultados obtidos para o dia útil..................................82

Tabela 6.11 - Variação nos resultados obtidos para o sábado..................................83

Tabela 6.12 - Variação nos resultados obtidos para o domingo.................................84

Tabela B.1 - Peso empírico versus custo monetário.................................................93

Tabela C.1 - Resultados para o dia útil utilizando a abordagem seqüencial

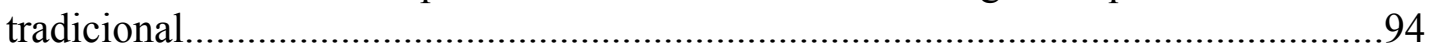

Tabela C. 2 - Resultados para o domingo utilizando a abordagem seqüencial

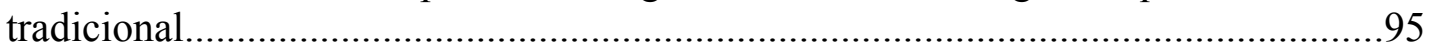

Tabela C.3 - Resultados para o sábado utilizando a abordagem seqüencial

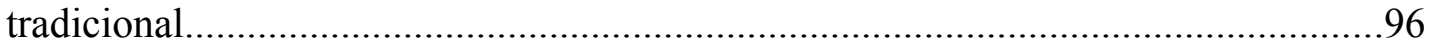

Tabela C. 4 - Resultados para o dia útil utilizando a abordagem seqüencial inversa. 97

Tabela C.5 - Resultados para o domingo utilizando a abordagem seqüencial inversa.

Tabela C.6 - Resultados para o sábado utilizando a abordagem seqüencial inversa. 99

Tabela C.7 - Resultados para o dia útil utilizando a abordagem independente........100

Tabela C.8 - Resultados para o domingo utilizando a abordagem independente.....101

Tabela C.9 - Resultados para o sábado utilizando a abordagem independente........102

Tabela C.10 - Resultados para o dia útil utilizando a abordagem integrada nível 1.

Tabela C.11 - Resultados para o domingo utilizando a abordagem integrada nível 1.

Tabela C.12 - Resultados para o sábado utilizando a abordagem integrada nível 1.

Tabela C.13 - Resultados para o dia útil utilizando a abordagem integrada nível 2.

Tabela C.14 - Resultados para o domingo utilizando a abordagem integrada nível 2.

Tabela C.15 - Resultados para o sábado utilizando a abordagem integrada nível 2. 


\section{LISTA DE FIGURAS}

Figura 2.1 - As Quatro Etapas do Problema de Planejamento Operacional..............11

Figura 4.1 - Pseudocódigo VND para Problema de Minimização............................26

Figura 4.2 - Pseudocódigo VNS para Problema de Minimização............................27

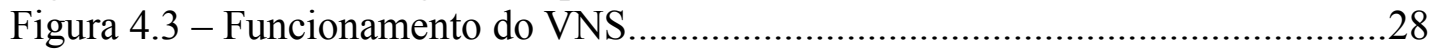

Figura 4.4 - Pseudocódigo da heurística construtiva.............................................29

Figura 4.5 - Movimento de Realocação para o PPT...................................................40

Figura 4.6 - Movimento de Troca para o PPT............................................................41

Figura 4.7 - Movimento de Realocação para o PPV..................................................42

Figura 4.8 - Movimento de Troca para o PPV.........................................................42

Figura 5.1 - Geração da solução inicial do PPV......................................................45

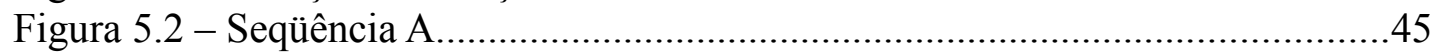

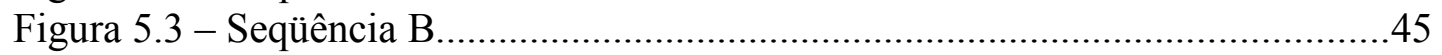

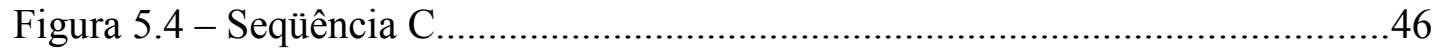

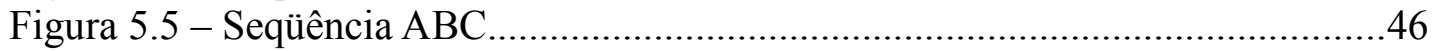

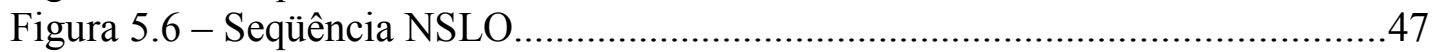

Figura 5.7 - Geração da solução inicial do PPT.....................................................48

Figura 5.8 - Geração da solução inicial do PPT....................................................50

Figura 5.9 - Geração da solução inicial do PPV....................................................52

Figura 5.10 - Geração da solução inicial do PPT....................................................65

Figura 6.1 - Influência da seqüência de movimentos sobre a FA..............................78

Figura 6.2 - Divisão do tempo entre o PPV e o PPT...............................................79

Figura 6.3 - Evolução do valor da melhor solução na abordagem integrada nível 2.81

Figura A.1 - Planilha Tarifária 2007 de Natal-RN..................................................92 


\section{LISTA DE ABREVIATURAS E SIGLAS}

ANTP

IBGE

IPK

NTU

OSO

OT

PPT

PPV

PPVT

SPTRANS

STC

VND

VNS
- Associação Nacional de Transportes Públicos

- Instituto Brasileiro de Geografia e Estatística

- Índice de Passageiros por Quilômetro

- Associação Nacional das Empresas de Transportes Urbanos

- Ordem de Serviço e Operação

- Oportunidade de Troca

- Problema de Programação de Tripulantes

- Problema de Programação de Veículos

- Problema de Programação de Veículos e Tripulantes

- São Paulo Transportes SA

- Sistema de Transporte Coletivo

- Variable Neighborhood Descent

- Variable Neighborhood Search 


\section{INTRODUÇÃO}

Este documento apresenta a dissertação de mestrado desenvolvida por Jorge von Atzingen dos Reis, no âmbito do Programa de Mestrado em Engenharia de Transportes da Escola Politécnica da Universidade de São Paulo. O projeto foi desenvolvido sob a orientação do Prof. Dr. Claudio Barbieri da Cunha, do Departamento de Engenharia de Transportes.

Neste trabalho é abordado o Problema de Programação Integrada de Veículos e de Tripulações (PPVT) de um sistema de transporte coletivo por ônibus urbano. O PPVT consiste em resolver simultaneamente a programação dos veículos (PPV) e das tripulações (PPT), isto é, atribuir as viagens a cada um dos veículos e as tarefas a cada um dos tripulantes, de tal modo que o custo operacional total, englobando as parcelas referentes aos veículos e às tripulações, seja mínimo.

Este trabalho contribui no sentido de colocar em prática técnicas de otimização, acumular conhecimentos e desenvolver ferramentas que permitem reduzir os custos com a programação dos veículos e das tripulações e, conseqüentemente, do sistema de transporte público como um todo. Mais especificamente, estão sendo propostas heurísticas baseadas na metaheurística denominada Busca em Vizinhança Variável para resolver o PPVT, as quais são testadas e avaliadas considerando dados reais.

Esta pesquisa de mestrado corresponde à continuidade dos projetos de iniciação científica desenvolvidos pelo candidato durante a sua graduação. Em Reis (2006) foi proposta uma metodologia para resolver o PPVT, na qual a programação dos veículos é realizada considerando características das tripulações. No presente trabalho é desenvolvido um modelo computacional que possui uma estrutura de vizinhança com capacidade de exploração das características das interações entre o PPV e o PPT, ou seja, resolver a programação dos veículos simultaneamente à programação das tripulações. 


\subsection{RelevânCIA do Tema}

No Brasil, o transporte coletivo urbano por ônibus é o principal meio de transporte público utilizado pelas pessoas que residem em áreas urbanas nos seus deslocamentos para realização das suas atividades diárias cotidianas, incluindo trabalho, escola, compras, lazer, etc.

Segundo dados do IBGE (2007), cerca de 135 milhões de pessoas vivem nas cidades brasileiras, o que corresponde a três em cada quatro habitantes de uma população que atinge 180 milhões de habitantes. Destas pessoas, cerca de $75 \%$ vive em áreas urbanas de médio e grande porte, com mais de 100 mil habitantes, e que possui algum tipo de transporte público urbano, normalmente o serviço de transporte coletivo por ônibus. De acordo com dados da ANTP - Associação Nacional dos Transportes Públicos (2007), o transporte por ônibus atende cerca de 95\% dos deslocamentos por transporte coletivo urbano no Brasil, contando com uma frota de 95 mil veículos.

Um sistema de transporte coletivo eficiente e eficaz corresponde a uma importante alternativa para a melhoria da qualidade de vida nos centros urbanos, pois permite reduzir as viagens realizadas por automóvel, acarreta diminuição dos congestionamentos, da poluição ambiental, dos acidentes e da queima de combustíveis fósseis que contribuem para o aquecimento global.

Por outro lado, existe uma percepção mais ou menos generalizada entre os diversos agentes, poder público, operadoras e usuários, que o transporte coletivo urbano por ônibus vem enfrentando dificuldades, consubstanciada por uma perda de demanda e de produtividade, entre outros fatores. Segundo dados recentes da NTU Associação Nacional das Empresas de Transportes Urbanos (2008), na média nacional, os sistemas de transporte público transportam hoje cerca de $35 \%$ menos passageiros do que transportavam nos anos 90. Contribuem para essa situação diversos fatores, entre os quais os valores elevados das tarifas, os crescentes congestionamentos urbanos e a falta de prioridade para o transporte coletivo, o que leva as pessoas a trocar o transporte coletivo pelo individual. Essa situação é acentuada pela atual fase de crescimento da economia brasileira.

Os congestionamentos urbanos aumentam o tempo de viagem do 
transporte coletivo urbano sobre pneus e, devido ao aumento do tempo de viagem, torna-se necessário um número maior de ônibus e seus correlatos (vans e microônibus) para realizar as viagens diárias necessárias. Esta situação aumenta o custo do transporte coletivo por ônibus ao mesmo tempo em que diminui a qualidade do serviço oferecido aos usuários (aumento do tempo de viagem e redução do conforto).

O custo impacta na tarifa do transporte coletivo por ônibus, que corresponde ao valor pago pelos usuários, ou à contrapartida financeira dos usuários, pelos serviços ofertados. No Brasil, é sempre definida pela autoridade governamental que opera, diretamente ou por delegação, o serviço de transporte público, sendo determinada com base no custo médio por passageiro pagante transportado, apurado através de uma planilha tarifária.

Dentre os itens que compõem o valor da tarifa, os custos da frota de veículos (englobando depreciação e remuneração de capital) e salário das tripulações (motoristas e cobradores), em conjunto com o custo do combustível, representam uma parcela significativa do valor total da tarifa. Assim, uma alocação eficiente dos veículos às linhas, de forma a atender à programação de viagens em cada linha, e das tripulações aos veículos, são essenciais para a obtenção de uma tarifa justa, privilegiando os usuários do transporte público, os quais na sua maioria são pessoas de baixa renda, que não dispõem de outra alternativa para seus deslocamentos diários.

Existem, basicamente, dois tipos de agentes em um sistema de transporte coletivo por ônibus urbano: o poder público e as empresas operadoras. O poder público, geralmente através de uma empresa reguladora, possui como atribuições: definir e aprovar linhas e seus itinerários, estabelecer as freqüências de acordo com a demanda de cada linha e estabelecer uma tabela de horários para as viagens diárias que devem ser realizadas por cada empresa operadora do sistema. As empresas operadoras devem alocar os recursos necessários para a realização das viagens diárias e oferecer o serviço ao usuário dentro das normas estabelecidas pelo poder público tanto em relação aos veículos como em relação às tripulações.

Desta forma, a programação eficiente e eficaz de veículos e tripulações no transporte coletivo por ônibus é essencial para assegurar e preservar as melhores 
condições operacionais do serviço ao mesmo tempo em que se garante os menores custos. Uma vez que o sistema, em tese, deve ser mantido pelos seus usuários, uma redução no custo de mão-de-obra pode significar um benefício para milhares de pessoas.

A programação dos veículos e a programação das tripulações interferem uma na outra, deste modo a abordagem integrada das programações (PPVT Problema de Programação Integrada de Veículos e Tripulações) pode utilizar-se dessas interações e reduzir os custos operacionais da programação. A definição de uma escala de tripulações econômica é um problema de otimização e várias técnicas têm sido desenvolvidas para resolver o PPVT. Pela sua importância e grau de dificuldade, este problema desperta grande interesse no meio científico.

\subsection{Objetivo}

O principal objetivo desta dissertação é resolver o Problema Integrado de Programação de Veículos e Tripulantes. O escopo de pesquisa engloba a formulação e implantação de diversas heurísticas de solução baseadas na metaheurística Variable Neighborhood Search. Pretende-se obter uma heurística de solução eficiente, capaz de gerar uma escala de trabalho de custo mínimo juntamente com uma escala de veículos, que atenda a todas as restrições operacionais e trabalhistas, isto é, um conjunto de jornadas viáveis com custo mínimo para uma empresa de transporte coletivo.

Entre as principais restrições operacionais que serão aplicadas aos veículos é possível citar: (i) todas as viagens diárias serão alocadas, sendo que cada viagem será alocada a um único veículo; (ii) todo veículo será operado por uma única tripulação (motorista e cobrador) durante cada viagem; (iii) o veículo deverá possuir um intervalo diário mínimo estacionado na garagem para manutenção preventiva e limpeza; (iv) um veículo não pode executar duas ou mais viagens simultaneamente; (v) a escala de trabalho do veículo deve iniciar e terminar em uma garagem.

As restrições operacionais aplicadas aos tripulantes são mais complexas 
que as restrições aplicadas aos veículos. As principais restrições consideradas são: (i) cada tripulação possuirá um intervalo diário para descanso e/ou alimentação; (ii) cada tripulação possuirá um tempo máximo de trabalho; (iii) uma tripulação não pode operar simultaneamente dois ou mais veículos; (iv) uma tripulação não pode deslocar-se sem um veículo; (v) a jornada de trabalho deve iniciar e terminar em um terminal ou uma garagem.

O custo da tripulação, devido aos encargos trabalhistas brasileiros, é um dos principais custos a serem considerados durante a operação de um sistema de transporte coletivo por ônibus urbano em uma cidade brasileira. Desta forma, uma restrição importante a ser atendida é a redução do número de horas ociosas de trabalho das tripulações, isto é, o tempo remunerado durante a jornada de trabalho no qual a tripulação não está operando um veículo ou em um intervalo de descanso previsto pela legislação trabalhista.

Segundo Huisman e Wagelmans (2006), o PPVT é um problema da classe NP-difícil, isto é, uma classe de problemas cuja função de tempo computacional necessário para a resolução é não polinomial. Desta forma, a resolução do PPVT através de algoritmos exatos para instâncias com dados reais é inviável e, a única forma de abordar esse problema da classe $N P$-dificil é através da utilização de métodos heurísticos.

O levantamento bibliográfico realizado durante o desenvolvimento deste trabalho não encontrou referências bibliográficas sobre a resolução do PPVT em instâncias de grande porte, o que configura que esta é uma abordagem inédita no meio científico. É necessário ressaltar que o problema de programação integrado de veículos e tripulações no contexto do transporte por ônibus é um problema não amplamente explorado na literatura.

Este trabalho pretende abordar a programação diária de tripulantes e de veículos para o problema com uma única garagem. Como objetivos específicos podem ser citados: $(i)$ um levantamento bibliográfico sobre o tema, para melhor entendimento do problema proposto e conhecimento das metodologias que têm sido utilizadas na abordagem do PPVT; (ii) descrever uma modelagem integrada para a programação de veículos e tripulantes, especificando todas as restrições operacionais e trabalhistas envolvidas. 
Os resultados deste trabalho podem ser utilizados tanto pelas empresas operadoras de ônibus (objetivando reduzir os seus custos operacionais e, conseqüentemente ampliando a sua margem de lucro) quanto pelo poder público, o qual pode verificar a eficiência do serviço prestado pelas empresas operadoras e reduzir o custo operacional das mesmas, permitindo uma redução nos subsídios pagos a essas empresas.

\subsection{Estrutura do Trabalho}

Este trabalho tem a seguinte organização:

O presente capítulo correspondeu a uma introdução ao tema, relatando suas origens e importância, assim como objetivos e limitações.

No segundo capítulo, é apresentado o Sistema de Transporte Coletivo e seus principais problemas, destacando os de natureza de políticas públicas, operacionais e econômico-financeiros. No referido capítulo, também é descrito o estado da arte do PPVT e as metaheurísticas utilizadas para abordar este tipo de problema.

O terceiro capítulo descreve o problema abordado, apresenta as restrições e as características referentes à empresa de transporte coletivo, a qual forneceu os dados para este trabalho.

O quarto capítulo apresenta a metodologia utilizada e a aplicação da metaheurística proposta para o PPVT, juntamente com as suas estruturas de vizinhança.

No quinto capítulo, é detalhada a implementação computacional de cada uma das abordagens utilizadas.

O sexto capítulo apresentado os resultados computacionais obtidos pelas metodologias propostas para o PPVT, assim como os tempos computacionais utilizados.

No sétimo capítulo, são destacadas as conclusões e recomendações acerca do estudo de caso e do resultado obtido pelas metodologias propostas. Também é apresentada uma proposta de continuação da presente pesquisa. 


\section{REVISÃO DA LITERATURA}

\subsection{O Sistema de Transporte Coletivo}

O Sistema de Transporte Coletivo (STC) é composto por todo e qualquer modo de transporte, que permita o deslocamento coletivo de indivíduos, a fim de permitir a realização das atividades diárias de cada indivíduo. Como exemplos de sistemas de transporte coletivo de passageiros, pode-se citar o ferroviário, o metroviário e o rodoviário.

A estrutura do sistema de transporte coletivo compreende os tipos de serviços prestados e linhas oferecidas, a política de cálculo e cobrança de tarifas, as integrações entre os diversos modos, os equipamentos necessários e o sistema de informações aos passageiros.

De uma forma geral, o poder público, através da administração direta ou de empresas estatais, assume a responsabilidade de definir as linhas e os itinerários do transporte coletivo urbano de passageiros de modo a cobrir toda a região de abrangência do município e também determina a freqüência das linhas de forma a atender a demanda diária de passageiros. Além disso, realiza a concessão da operação das linhas para as empresas operadoras, fiscaliza e gerencia os serviços prestados, administra as câmaras de compensação tarifária e/ou outros mecanismos de gestão de receita quando esses existirem.

As empresas operadoras são os agentes do sistema de transporte coletivo responsáveis pela operação dos serviços, incluindo a alocação dos veículos e das tripulações. Cabe às empresas operadoras a determinação do número de veículos e de tripulantes necessários para operar cada linha de ônibus e a execução das viagens diárias conforme estabelecido pelo poder concedente.

As desigualdades econômicas e sociais, presentes em várias cidades brasileiras, se expressam na ocupação e uso do solo, segregando, na periferia e nas áreas mais distantes e carentes de infra-estrutura, a parcela mais pobre da população. Ao se concentrar a maior parte das oportunidades de trabalho na região central das cidades, criou-se a necessidade de transportar, diariamente, muitas pessoas para o local de realização de suas atividades diárias, gerando uma grande demanda pelo uso 
do sistema de transporte coletivo.

A priorização pelo transporte individual, nas últimas décadas caracterizada pelos investimentos realizados no sistema viário visando reduzir os congestionamentos, levou as grandes metrópoles a enfrentar uma crise de mobilidade. A conseqüência desta preferência pelo transporte individual é que a parcela das viagens motorizadas, realizadas por meio de transporte individual, vem crescendo a cada ano (SPTRANS, 2006).

A metrópole de São Paulo é uma das poucas do mundo, na qual o principal meio de transporte é o ônibus e seus similares, como microônibus e vans (SPTRANS, 2006). Segundo dados da SPTRANS (2006), 77\% das viagens coletivas diárias, dentro da cidade de São Paulo, são realizadas por ônibus e seus correlatos microônibus e vans, o que equivale a, aproximadamente, 6,8 milhões de viagens diárias. O transporte coletivo sobre trilhos atende a apenas 10\% das viagens coletivas metropolitanas, apesar de seus $270 \mathrm{~km}$ de extensão, sendo $134 \mathrm{~km}$ dentro do município de São Paulo (SPTRANS, 2006).

Devido à reduzida infra-estrutura do transporte coletivo metro-ferroviário brasileiro, os ônibus representam o principal meio de transporte, na maioria das cidades brasileiras. A opção pela implantação de sistemas de transporte coletivo sobre pneus decorre, ao contrário dos altos investimentos envolvidos na instalação e/ ou expansão da malha ferroviária, de sua grande flexibilidade e o menor custo dos ônibus; o transporte coletivo por ônibus urbano permite o atendimento de uma grande área urbana, sem a obrigatoriedade de implantação de uma estrutura específica, possibilitando uma maior cobertura espacial da sua rede.

A falta de vias com prioridade para a circulação de ônibus, os quais dividem o mesmo espaço com os automóveis nos congestionamentos e problemas relativos à organização e estrutura do sistema, reduzem a qualidade do serviço prestado e elevam o custo operacional do sistema de transporte coletivo.

Investimentos escassos, descontínuos e lentos nos transportes públicos, especialmente em relação ao metrô, corredores de ônibus e trens, tornaram o sistema de transporte coletivo ineficaz, para atender às necessidades dos usuários, muito dos quais, migraram para o uso do automóvel particular, que proporciona conforto, flexibilidade e permite viagens mais rápidas que o transporte coletivo, mesmo em 
congestionamentos. $\mathrm{O}$ aumento do uso do automóvel teve como conseqüência o aumento do tráfego urbano e gerou um dos principais problemas de transporte: os congestionamentos, os quais desgastam os motoristas, reduzem a produtividade e acarretam enormes prejuízos para muitos setores da economia (FREITAS et al., 2001).

A cidade de São Paulo é um exemplo de como os congestionamentos podem ser prejudiciais à qualidade de vida. São Paulo se caracteriza por um crescimento desordenado, que ocorreu sem a implantação simultânea de uma estrutura de transporte coletivo de maior capacidade, como trens urbanos e metrô.

Outro grande problema de um sistema de transporte público é a definição de sua política tarifária, a qual visa determinar o preço dos serviços prestados pelos agentes operacionais, isto é, determinar a contrapartida financeira do usuário. Esta contrapartida depende da forma como o Estado e os empregadores participam do financiamento dos serviços e da forma como certos grupos de usuários (idosos, estudantes, deficientes físicos) tenham direito a concessões de descontos e gratuidades (AGUIAR, 2001).

As políticas tarifárias não se limitam apenas à definição do valor da tarifa, mas também sobre a forma como a tarifa é cobrada e as eventuais formas de subsídios e contribuições sociais. Conforme Aguiar (2001), existem três conjuntos de fatores ou instrumentos sobre os quais as decisões e ações da política tarifária são realizadas:

- Nível da tarifa: os valores monetários pelos quais as tarifas são cobradas;

- Estrutura tarifária: os elementos espaciais e funcionais que servem de base para a cobrança da tarifa;

- Concessões especiais: os descontos e gratuidades atribuídos a alguns grupos de usuários.

O cálculo do valor da tarifa a ser cobrada do usuário considera que, caso não exista uma política de subsídios, o valor estabelecido deve cobrir os custos do sistema de transporte coletivo por ônibus. Isto é, no valor da tarifa devem estar incluídos, além do custo de transporte daquele usuário que está usufruindo do 
serviço, os custos das gratuidades (idosos e deficientes) e dos descontos concedidos a certas classes de usuários (por exemplo, estudantes).

No Brasil, é comum utilizar-se da política de tarifa única, na qual existe uma tarifa única cobrada independentemente da distância percorrida. Este tipo de política tarifária cria um grande problema devido à existência de linhas cujo percurso é longo e o usuário entra no ponto inicial e desce somente no ponto final. Este tipo de linha é comum no trajeto da periferia para o centro das cidades. Essas linhas longas muitas vezes não cobrem os seus custos, visto que o seu índice de passageiros por quilômetro é muito baixo. Em um outro extremo, existem linhas cujo índice de passageiros por quilômetros é elevado, criando trajetos altamente lucrativos.

O custo operacional de um sistema de transporte coletivo por ônibus urbano pode ser reduzido através de uma operação mais eficiente da frota, como proposto neste trabalho, ou através da melhoria do sistema de transporte como um todo. Uma redução nos congestionamentos urbanos possibilita um aumento da velocidade média dos ônibus, reduzindo o tempo necessário para a execução das viagens o que aumenta a utilização dos veículos devido ao aumento da produtividade. Desta forma será necessário um número menor de veículos e de tripulantes para operar a mesma quantidade de viagens diárias, reduzindo o custo operacional do sistema de transporte coletivo por ônibus urbano.

O poder público é o órgão responsável pela definição do tipo e do tamanho dos veículos a serem utilizados pelas empresas operadoras em cada linha e serviço. Entretanto, não é atribuição do poder público definir a alocação dos veículos para a realização das viagens diárias, na maioria dos casos limitando-se a indicar a frota necessária para cada linha. No entanto, é interessante para o poder público reduzir a frota de veículos necessários como uma forma de reduzir os custos operacionais e os repasses de subsídios às empresas operadoras.

\subsection{O Problema de Programação de Veículos e Tripulantes}

Em um sistema de transporte coletivo urbano por ônibus, o planejamento operacional e a programação dos serviços, incluindo veículos e tripulantes (motoristas e cobradores), são, devido à sua grande complexidade, geralmente 
decompostos em quatro etapas. As decisões sobre a estrutura dos serviços, isto é, as linhas que compõem cada serviço, seus respectivos itinerários e freqüências, assim como o tipo de veículo utilizado, são de atribuição do poder público. Estas decisões devem ser tomadas com base nas demandas de passageiros, nos serviços requeridos, na infra-estrutura viária disponível e nas condições de tráfego e de circulação dos veículos.

Como resultado, é definida uma Ordem de Serviço de Operação (OSO) para cada linha, contendo todas as informações operacionais, incluindo itinerários de ida e volta, pontos terminais, frota a ser alocada e tabela de viagens, que indica as viagens correspondentes a cada horário e respectivos locais de partida e de chegada. Com base nas programações das viagens a serem cumpridas diariamente, cabe à empresa operadora a programação de veículos e de tripulantes.

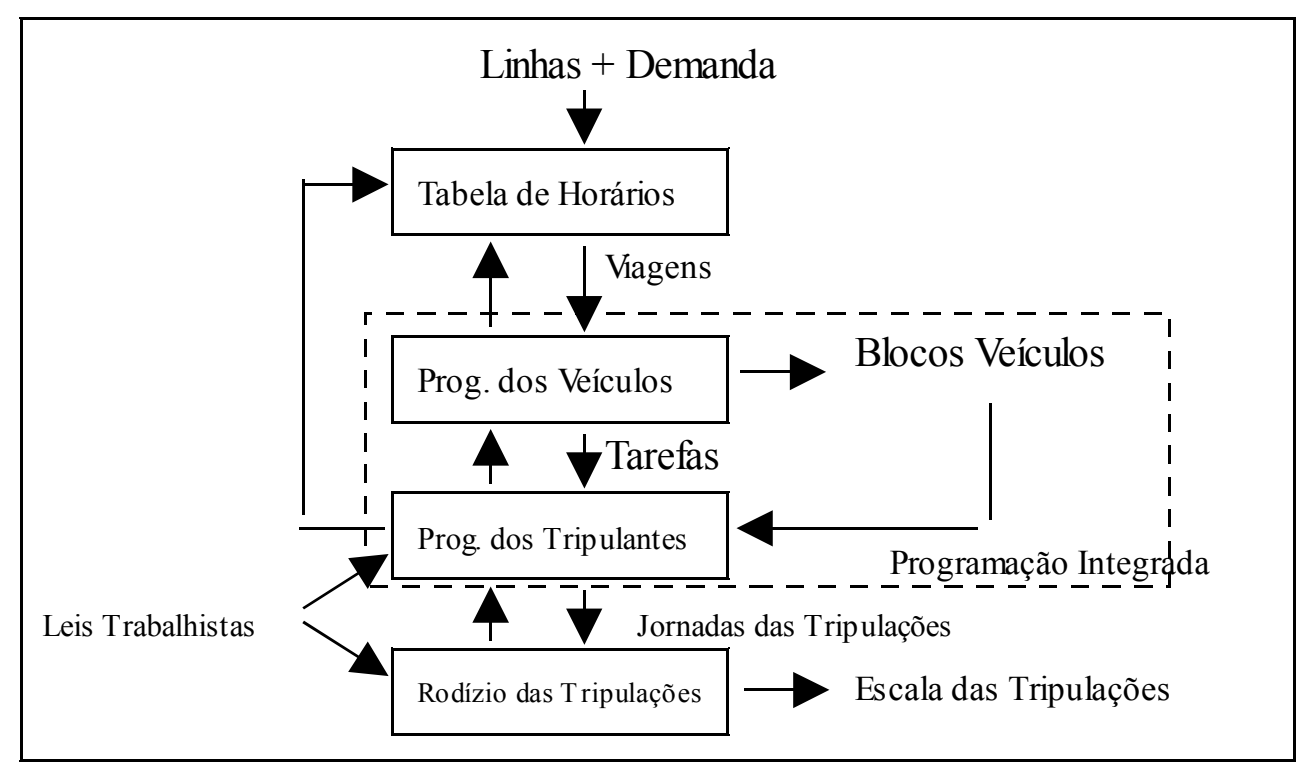

Figura 2.1 - As Quatro Etapas do Problema de Planejamento Operacional.

O problema de programação dos veículos (PPV) consiste em definir quantos e quais veículos serão utilizados nas linhas a serem operadas, bem como a alocação de cada veículo às viagens diárias programadas. Como resultado, obtém-se, para cada veículo, o chamado "bloco", ou seja, o conjunto de viagens designadas a cada veículo ao longo do dia, começando e terminando na garagem, sua seqüência, e todos os aspectos espaciais e temporais relacionados, incluindo locais e horários de 
partidas e chegadas das viagens a serem realizadas, assim como os eventuais percursos ociosos nos deslocamentos entre viagens consecutivas. Cada bloco mostra também as Oportunidades de Troca (OT). Uma OT é um intervalo de tempo suficiente, em um ponto apropriado, para haver a troca das tripulações.

O problema de programação dos tripulantes (PPT) consiste em formar tarefas a partir dos blocos dos veículos e atribuir essas tarefas aos tripulantes (motoristas e cobradores), definindo assim as jornadas de trabalho dos mesmos. Cada tarefa corresponde a um conjunto de viagens compreendidas entre duas OT's: uma no início e outra no final da tarefa. Assim, durante a realização da tarefa, não é possível que haja troca de tripulação. A programação de uma tripulação é formada por um conjunto de tarefas, denominado jornada de trabalho ou somente jornada. Uma jornada de trabalho corresponde à chamada escala de um tripulante (ou de uma dupla, motorista/cobrador).

Com base na situação encontrada na empresa que forneceu os dados para este trabalho, as jornadas podem ser divididas em dois tipos: pegada simples ou dupla pegada, conforme o tempo ocioso existente entre as tarefas. No primeiro tipo, as tarefas são realizadas de uma única vez e os intervalos de tempo entre as tarefas consecutivas são inferiores a duas horas. Caso ocorra um intervalo entre uma tarefa e a seguinte igual ou superior a duas horas, a jornada é classificada como do tipo dupla pegada. Este intervalo não é contabilizado na remuneração da tripulação, que fica liberada durante este tempo. Após o término do intervalo, a tripulação deve retornar ao trabalho para realizar as tarefas remanescentes.

Vários métodos de resolução do PPV são apresentados na literatura por diversos autores e os resultados comprovam que existe uma redução significativa no custo operacional quando métodos heurísticos ou de otimização são aplicados a casos reais (Smith e Wren, 1981; Wren e Gualda, 1999; Silva e Gualda, 2000; Silva, 2001; Silva e Gualda, 2001).

Silva (2001) resolve o PPV utilizando uma abordagem de geração de arcos para resolver uma representação de rede do problema. O princípio da geração de arcos é derivado da abordagem de geração de colunas por programação linear. Com esta técnica é possível reduzir o número de arcos na rede que representa o problema, reduzindo o tempo de processamento necessário para resolver o problema 
de fluxo de rede subjacente. Também é possível introduzir algumas restrições laterais que descrevem características práticas do problema, fazendo a rede mostrar uma representação mais compatível com casos reais.

No trabalho de Silva e Gualda (2000) problemas testes baseados em dados reais da cidade de Reading no Reino Unido e da cidade de Sorocaba no Brasil foram resolvidos usando a abordagem de geração de arcos e os resultados foram comparados com os obtidos pelo sistema heurístico BOOST, o qual foi testado e comercializado no Reino Unido. Na maioria dos casos o método heurístico e o algoritmo de fluxo em redes encontraram a mesma solução e, em algumas instâncias de grande porte, o algoritmo de fluxo em redes encontra o ótimo global que o método heurístico não consegue alcançar. Silva e Gualda (2001) utilizam a abordagem de geração de arcos para resolver o problema de programação dos veículos usando dados reais da cidade de Belo Horizonte.

A programação de tripulações, tipicamente aplicada em sistemas de transporte público, envolve a seleção do melhor conjunto de jornadas de trabalho. $\mathrm{O}$ PPT está relacionado com a geração de jornadas de trabalho viáveis. A construção de jornadas de trabalho, geralmente, é bastante complicada, pois várias regras trabalhistas e operacionais precisam ser atendidas. A programação de tripulações é uma das áreas dominantes na programação e roteamento de pessoal. Muitos artigos têm sido publicados abordando diversas técnicas para a programação de tripulações em aviões, trens e ônibus.

Esse tema tem sido largamente estudado e seus resultados, geralmente, são utilizados nos países mais desenvolvidos. A abordagem mais explorada é aquela que formula o PPT como um problema de recobrimento ou de particionamento (set covering ou set partitioning model) e utiliza a técnica de geração de colunas para resolvê-lo (Smith e Wren 1988, Desrochers e Soumis 1989, Desrochers et al. 1992, Barnhart et al. 1998, Fores et al. 1999). A variedade de trabalhos deriva das diferentes maneiras de gerar as colunas e diferentes metodologias para resolver o problema, tais como: branch-and-bound, branch-and-price e a relaxação lagrangeana.

O método proposto por Ball et al. (1981) consiste em uma solução iterativa que resolve o problema combinando pequenos pedaços de trabalho em 
pedaços maiores, e estes pedaços maiores são transformados em jornadas de trabalho. Em várias partes do algoritmo, o usuário possui a oportunidade de eliminar combinações inviáveis ou fazer outros ajustes manuais.

Um modelo matemático para resolver o PPT é apresentado no trabalho de Ball et al. (1983). Isto inclui a duração e a colocação de pontos de troca. O problema, o qual é formulado usando uma representação de redes, é modelado como um problema de particionamento em um grafo acíclico. É usada uma decomposição do problema para a sua resolução. Um emparelhamento de um subproblema é acompanhado de uma fase de melhoramento e combinação de tarefas de trabalho de forma a determinar uma jornada.

O artigo de Blais et al. (1990) apresenta uma visão de uma aplicação orientada de sofisticados métodos de programação utilizando o HASTUS, um sistema de apoio à decisão para a programação de veículos e de tripulações. $\mathrm{O}$ artigo trata da implementação em uma empresa de transporte coletivo de Montreal. Devido à implementação de vários algoritmos inteligentes para o desenvolvimento da escala de tripulação e de veículos, os modelos implementados utilizando o sistema HASTUS economizaram aproximadamente US\$4 milhões para o operador de transporte coletivo de Montreal.

Bodin et al. (1983) apresentam uma revisão de modelos e métodos utilizados para resolver problemas de programação de linhas aéreas, tripulação de ônibus e roteamento de veículos. Uma classificação por categorias é apresentada segundo uma revisão de modelos, algoritmos e métodos.

O trabalho de Ceder et al. (1988) descreve um sistema computadorizado que integra o desenvolvimento da escala de horários de ônibus, escala de veículos e escala de tripulação. Depois de determinar a tabela de horários, escala de veículos e oportunidades de trocas, o sistema determina as escala das tripulações utilizando uma heurística.

O trabalho de Freling et al. (2001) formula o PPT como um problema de recobrimento e o resolve combinando a técnica de relaxação lagrangeana com a de geração de colunas. Haase et al. (2001) usam uma aproximação exata para resolver o problema de programação da tripulação integrado com o problema de programação de veículos. O problema é resolvido usando o método branch-and-bound e o método 
de planos de cortes juntamente com a geração de colunas.

Pedrosa e Constantino (2001) apresentam um modelo de recobrimento no qual a mão-de-obra é dividida em grupos usando uma lista circular e o PPT é resolvido usando uma heurística construtiva com geração de colunas. Valouxis e Housos (2002) dividem a tripulação em níveis de forma a reduzir as dimensões do PPT. Estes níveis são baseados em um algoritmo de emparelhamento das trocas de tripulação. Moura et al. (2000) utilizam programação inteira e geração de colunas para resolver o PPT formulado como um problema de particionamento.

Um caso especial do problema de programação integrada da escala de veículos e tripulantes é considerado por Fischetti et al. (2001). O problema é modelado com programação inteira ao invés de um problema de recobrimento. A modelagem inteira resultante tem uma relaxação linear muito livre, mas pode ser apertada por meio de novas famílias de desigualdades válidas (cortes). Estes cortes são baseados em um algoritmo branch-and-cut. Testes numéricos com um conjunto de problemas de testes gerados aleatoriamente e um conjunto de características reais mostram como o método é competitivo em alguns tipos de problemas testes.

Segundo Freling et al. (1999), os tipos de abordagens para a resolução do problema de programação de veículos e de tripulantes podem ser classificados em: seqüencial, independente e integrada. A abordagem seqüencial pode ser subdividida em tradicional e inversa, enquanto que a abordagem integrada pode ser subdividida em nível um e nível dois.

A abordagem seqüencial tradicional foi a primeira a ser utilizada e consiste em resolver o PPV e em seguida o PPT. A abordagem seqüencial inversa é uma variação desta abordagem, a qual consiste em inverter a ordem de resolução dos problemas, isto é, resolver primeiramente o PPT e em seguida o PPV (Marinho et al., 2004; Silva et al., 2004; Souza et al., 2004; , 2006).

As principais vantagens das abordagens seqüenciais (tradicional e inversa) são a facilidade de implementação e a diminuição da complexidade do problema. A abordagem seqüencial tradicional é recomendada para os casos em que a programação dos veículos possui um custo operacional superior ao custo operacional da programação dos tripulantes e a abordagem seqüencial inversa é indicada para o caso oposto, ou seja, quando o custo operacional do PPT é superior ao do PPV. A 
desvantagem das abordagens seqüenciais (tradicional e inversa) é o não aproveitamento das interações existentes entre o PPT e o PPV o que torna o custo operacional destas abordagens superiores ao custo operacional das abordagens integradas.

$\mathrm{Na}$ abordagem independente, a programação dos veículos é resolvida ignorando-se a programação dos tripulantes; na seqüência, a programação dos tripulantes é determinada independentemente dos resultados obtidos pela programação dos veículos. O grande problema dessa abordagem é que os resultados obtidos resultam, na maioria dos casos, inviáveis do ponto de vista prático, pois apesar de se obter a solução ótima para o PPV e para o PPT, dificilmente essas duas soluções são compatíveis entre si, o que impede a sua aplicação (Freling et al., 1999).

A abordagem integrada começou a ser estudada mais recentemente, tendo em vista a evolução dos computadores, uma vez que devido à sua grande complexidade, o custo computacional desta abordagem era proibitivo. Existem dois níveis de abordagem integrada.

O primeiro é baseado na resolução do PPV considerando características dos tripulantes, de tal forma que a programação dos tripulantes é facilitada pela programação dos veículos. Os artigos científicos encontrados na literatura mostram diversos casos de aplicação deste tipo de abordagem a problemas com dados reais (Freling et al. 2001, Freling et al., 2003, Huisman et al., 2001, Huisman et al., 2003, Huisman e Wagelmans, 2004; Reis, 2006; Reis et al., 2006).

O segundo tipo de abordagem integrada consiste em resolver simultaneamente a programação dos veículos e dos tripulantes, o qual é um problema complexo devido às suas grandes dimensões. Existem alguns modelos computacionais para a sua resolução que não podem ser aplicados a problemas de grandes dimensões devido às limitações computacionais existentes (Freling et al., 1999; Friberg e Haase, 1999; Haase et al., 2001). Huisman e Wagelmans (2006) apresentam resultados de um modelo matemático exato o qual considera o segundo nível de abordagem integrada para problemas com aproximadamente 300 viagens diárias.

Entretanto, esse número é bastante reduzido considerando-se o porte 
médio das empresas de ônibus que operam nas grandes cidades brasileiras, as quais normalmente são responsáveis por mais de 1.000 viagens diárias (conforme observado nos dados coletados para o desenvolvimento deste presente trabalho). Como o PPVT corresponde a um problema de natureza combinatória, no qual o número de combinações, em termos de blocos de veículos e escalas de tripulantes, cresce exponencialmente com o tamanho do problema, torna-se impossível resolver instâncias reais através de modelos exatos de programação linear inteira usando os pacotes ("solvers") disponíveis comercialmente.

Freling et al. (2001) aplicam uma abordagem integrada para os problemas de programação de veículos e de programação de tripulações de ônibus urbano. Esta abordagem integrada foi originalmente proposta em Freling et al. (1999) e adaptada de forma a considerar restrições complexas presentes em aplicações reais. Tradicionalmente estes problemas são abordados seqüencialmente.

No caso seqüencial, a programação de veículos é resolvida utilizando relaxação lagrangeana. A programação da tripulação é resolvida como um problema de recobrimento (set covering). Freling et al. (2001) apresenta uma formulação inteira para a programação de veículos e tripulações, a qual é resolvida com uma combinação de relaxação lagrangeana e geração de colunas.

Com o objetivo de avaliar a utilidade desta abordagem integrada, Freling et al. (2003) comparam diversas soluções obtidas com a abordagem integrada e com a abordagem seqüencial tradicional. São propostos modelos matemáticos para o problema integrado e para o problema seqüencial. Relaxação lagrangeana e heurísticas lagrangeanas foram desenvolvidas para o problema integrado. O modelo associado de recobrimento foi resolvido usando geração de colunas. Os resultados obtidos demonstram que caso o custo fixo com as tripulações seja muito maior que o custo fixo com os veículos a abordagem mais adequada para o PPVT é a integrada, caso contrário é a seqüencial.

O artigo de Gaffi e Nonato (1999) apresenta uma heurística lagrangeana para o problema integrado. O procedimento heurístico para o subproblema de recobrimento é proposto utilizando restrições simplificadas e abordagem baseada em tarefas.

Uma modelagem matemática para o PPVT com uma única garagem e 
restrições de recursos no grafo de escalonamento é apresentada por Haase e Friberg (1999). A modelagem proposta é suficientemente genérica para ser estendida para múltiplos depósitos e receber restrições adicionais. O modelo é resolvido usando geração de colunas formulando um problema de particionamento (set partitioning). A geração de colunas é usada para desenvolver baixos valores em um algoritmo branch-and-bound.

Uma abordagem exata é apresentada por Haase et al. (2001) para resolver o PPVT. O problema é formulado como um problema de particionamento para a escala de motoristas com restrições laterais para o itinerário dos veículos. Isto é resolvido usando o método branch-and-bound em conjunto com geração de colunas e o método de planos de cortes. Definida a escala de tripulantes, a resolução de um problema de fluxo em rede determina o itinerário dos veículos.

De acordo com Freling et al. (2003), a abordagem integrada do PPT e do PPV sempre permitirá obter resultados superiores ou iguais aos resultados da abordagem seqüencial, e resultados inferiores ou iguais aos resultados da abordagem independente, tendo em vista que essa última considera cada problema de forma independente, e retorna soluções inviáveis. Entretanto, a abordagem independente é útil, pois permite determinar os limitantes inferiores para a solução ótima do PPVT.

Em Reis (2006) foi proposta uma metodologia para resolver o PPVT, na qual é utilizado o primeiro tipo de abordagem integrada, isto é, considera-se na programação dos veículos características pertinentes aos tripulantes como tempo de folga e hora-extra. Desta forma, é obtida uma programação dos veículos capaz de facilitar a resolução da programação dos tripulantes, reduzindo o custo operacional total.

Outro tipo de problema que envolve a programação de veículos e tripulações é o Airline Crew Scheduling Problem (Problema de Programação de Tripulações Aéreas). Este problema envolve restrições muito distintas do PPVT, não sendo possível fazer analogias e aproveitar os mesmos métodos e abordagens desenvolvidos entre os dois problemas. Essa incompatibilidade entre a programação aérea e a de ônibus decorre das restrições presentes no transporte aéreo, como tempo de duração da jornada, tipo de vôo, autonomia, tipo de aeronave e configurações do vôo. 
Segundo Gopalakrishnan e Johnson (2005), o problema de programação de tripulações aéreas (PPTA) pode ser dividido em cinco estágios de planejamentos: (i) programação dos vôos, com a definição de todos os vôos que serão realizados; (ii) alocação da frota de aviões, com a alocação das viagens aos aviões satisfazendo as restrições referentes ao tipo de aeronave; (iii) roteamento dos aviões, com a alocação das viagens aos aviões satisfazendo as restrições referentes à manutenção; (iv) emparelhamento dos tripulantes, com a alocação dos vôos aos tripulantes, satisfazendo as restrições referentes ao tipo de tripulação necessária para operar cada aeronave; e (v) roteamento dos tripulantes, com a definição da escala mensal ou semanal de trabalho da tripulação satisfazendo as restrições referentes a intervalos de descansos e folgas. Boas referências e conceitos sobre este problema do transporte aéreo podem ser encontradas em Arabeyre (1969), Ball e Roberts (1985), Etschmaier e Mathaisel (1985), Klabjan et al. (2002) e Vance et al. (1995).

O levantamento bibliográfico mostrou que a maioria dos trabalhos estrangeiros geralmente utilizam métodos exatos (principalmente relaxação lagrangeana e geração de colunas) para resolver problemas de menor porte devido ao PPV e ao PPT serem resolvidos em cidades pequenas. Também existem diversos trabalhos estrangeiros utilizando métodos heurísticos (inclusive sistemas comerciais) para resolver a programação dos veículos e das tripulações aplicados, geralmente nas grandes cidades, nas quais os métodos exatos não são adequados para a utilização.

Os trabalhos desenvolvidos no Brasil, estão no mesmo nível técnico dos trabalhos estrangeiros. A principal diferença é que os trabalhos nacionais priorizam a utilização de métodos heurísticos (Simulated Annealing, Busca TABU, VNS, ILS, GRASP) devido a normalmente serem abordados problemas de grandes dimensões. Devido ao problema ser resolvido no presente trabalho possuir instâncias de grande porte (até 3.654 viagens diárias), será utilizado um método heurístico para a resolução do problema de programação integrada de veículos e tripulações. 


\section{CARACTERIZAÇÃO DO PROBLEMA DE PROGRAMAÇÃo INTEGRADA DE VEÍCULOS E TRIPULAÇÕES}

O Problema de Programação Integrada de Veículos e Tripulações (PPVT) consiste em elaborar a programação dos veículos e dos tripulantes no transporte coletivo por ônibus urbano, isto é, alocar de forma eficaz e eficiente todas as viagens diárias aos veículos e as tarefas aos tripulantes. As tarefas são definidas como um conjunto de viagens consecutivas realizadas por um mesmo veículo, entre as quais não existe nenhuma oportunidade para a troca de tripulações.

As programações para os veículos e os tripulantes normalmente podem variar conforme três tipos de dias existentes: dias úteis, sábados e domingos. $\mathrm{Na}$ programação relativa aos dias úteis, o número de viagens e a frota usualmente são maiores do que nos demais tipos de dias, em virtude da maior demanda de passageiros dado que as viagens preponderantes na maioria dos sistemas de transporte são as por motivo de trabalho. Conseqüentemente, a programação de veículos e tripulantes para os dias úteis são as de maior interesse, não só devido à sua maior complexidade, como também pelo fato de que ela define a necessidade de recursos para a operação de transporte, tanto em termos de frota quanto de mão-deobra.

A programação referente aos sábados, para o caso estudado, é aproximadamente $28 \%$ menor. A programação referente ao domingo normalmente é a programação com o menor número de viagens diárias a serem realizadas. No caso estudado é aproximadamente $50 \%$ menor que a programação referente ao dia útil. Em alguns casos a programação pode ser elaborada para dias específicos (por exemplo, feriados) e, em algumas localidades a programação é diferente em períodos de férias escolares.

Ao se reunirem as tarefas formando as jornadas de trabalho (ou escalas) dos tripulantes, deve-se levar em conta inúmeras restrições operacionais e trabalhistas. As restrições trabalhistas decorrem da legislação vigente e de acordos coletivos negociados entre trabalhadores e empresas, já as operacionais representam as práticas operacionais e de gestão estabelecidas pela empresa, bem como acordo 
com seus funcionários. Essas restrições podem ser classificadas em dois tipos: restrições essenciais, ou seja, aquelas de caráter obrigatório e que devem ser necessariamente satisfeitas para gerar uma escala viável (por exemplo, um veículo não pode executar duas viagens ao mesmo tempo); e restrições não essenciais, aquelas cujo atendimento resulta em uma melhora na qualidade da escala gerada, mas que, se não satisfeitas, não geram escalas inviáveis (como por exemplo, o tempo que um veículo permanece parado em um terminal entre duas viagens consecutivas).

Algumas restrições variam conforme a cultura da empresa. Por exemplo, na Inglaterra é desejável que um motorista troque de linha diariamente a fim de que o trabalho não se torne monótono e repetitivo; por outro lado, na maioria das empresas brasileiras é desejável que o motorista permaneça sempre na mesma linha devido ao conhecimento do percurso, evitando assim o aumento do tempo de viagem além de facilitar o estabelecimento das relações interpessoais entre a tripulação e os passageiros que utilizam a linha.

Adicionalmente, acredita-se que o fato de o motorista conduzir sempre o mesmo veículo resulta em um maior cuidado com a manutenção do mesmo, devido não apenas a uma condução mais cuidadosa, como também na identificação mais prematura de problemas mecânicos.

A diferença entre a programação dos tripulantes e o rodízio de tripulantes é que a primeira refere-se à programação de um dado dia, que pode ser dia útil, sábado ou domingo, e o segundo termo refere-se à programação individual para um período maior, normalmente um mês, considerando folgas, descansos aos domingos e férias, respeitando a legislação trabalhista. Assim, enquanto na programação de tripulação definem-se as viagens que compõem a jornada de trabalho de um dado dia para cada tripulante ou dupla, sem identificá-lo, o rodízio ou roteamento corresponde a uma seqüência de programações a serem cumpridas por cada indivíduo, de modo a contemplar as folgas, descansos e outros afastamentos previstos na legislação (férias, licença paternidade, etc.).

O Problema de Programação Integrada dos Veículos e Tripulantes (PPVT) consiste em resolver simultaneamente o PPV e o PPT, isto é, atribuir as viagens a cada um dos veículos e as tarefas a cada um dos tripulantes, de tal modo que o custo operacional total seja mínimo. 
$\mathrm{Na}$ maioria das situações práticas, a programação dos veículos afeta a programação das tripulações e vice-versa. Por exemplo, um veículo que possua um maior número de oportunidades de troca, isto é, locais e horários onde a troca de tripulantes pode ocorrer, permite uma maior flexibilidade na programação dos tripulantes e, conseqüentemente, uma possível redução do custo operacional desta tripulação. Portanto, pode-se presumir que uma abordagem integrada do problema pode proporcionar melhores resultados do que uma abordagem seqüencial, em que geralmente é feita primeiro a programação dos veículos e depois da tripulação.

Entretanto, como foi visto anteriormente, devido à complexidade das formulações matemáticas que consideram o problema como um todo, a maioria dos trabalhos encontrados na literatura aborda os problemas de forma seqüencial e independente, sendo a resolução integrada dos problemas de programação dos veículos e das tripulações relativamente recente e ainda com poucos trabalhos. Isso se deve à sua magnitude, o que torna a sua resolução fortemente dependente de equipamentos computacionais de grande capacidade.

\subsection{Restrições Consideradas}

As restrições de designação e alocação dos veículos e de escala das tripulações são tais que permitem definir o problema através das regras operacionais adotadas pelas empresas, assim como as leis trabalhistas. Com base na experiência prática e na interação com as empresas operadoras, foram consideradas, no processo de resolução do PPVT as seguintes restrições operacionais ditas essenciais, isto é, que não podem ser violadas:

Para os veículos:

- Um veículo não pode realizar duas ou mais viagens ao mesmo tempo, isto é, não pode haver sobreposição de viagens alocadas ao mesmo veículo;

- Um veículo deve iniciar e terminar a sua jornada diária de trabalho na garagem;

- Um veículo deve ficar na garagem por no mínimo 1 hora por dia para 
manutenção;

- Para um veículo ser considerado como fazendo uma jornada de tripulação denominada dupla pegada (jornadas compostas por dois períodos distintos de trabalho, por exemplo, de manhã e de tarde) deve haver um intervalo entre duas viagens superior a 2 horas somado com o tempo de deslocamento do veículo até a garagem;

- O número de veículos com programação de tripulação em jornada de trabalho do tipo dupla pegada estará limitado a um determinado limite superior máximo admissível.

\section{Para as tripulações:}

- Uma tripulação não pode realizar mais de uma tarefa ao mesmo tempo, ou seja, não pode haver sobreposição de tarefas;

- As trocas das tripulações só podem ocorrer nos locais correspondentes às oportunidades de trocas, ou seja, em determinados pontos e entre viagens com mais do que um dado intervalo de tempo;

- As trocas das tripulações só podem ocorrer entre tripulantes que operem grupos de linhas com as mesmas características (por exemplo, linhas da mesma região geográfica);

- Existem dois tipos de jornadas, ditas pegada simples e dupla pegada. A jornada tipo pegada simples tem duração de 7 horas e 10 minutos com direito a uma pausa para descanso e/ou alimentação. A dupla pegada tem duração total de 6 horas e 40 minutos dividida em duas etapas separadas por pelo menos duas horas de interrupção. Neste caso, a tripulação não tem direito a pausa para descanso/alimentação;

- A pausa na jornada do tipo pegada simples deve ser no mínimo de 20 minutos podendo este intervalo ser fracionado, desde que pelo menos um deles seja maior ou igual a 10 minutos;

- O número de tripulações com dupla pegada deve estar limitado a um certo valor;

- Podem ser acrescidas até duas horas extras às jornadas diárias de trabalho. 
As restrições ditas não-essenciais, isto é, que correspondem a características desejáveis para a programação resultante da resolução do PPVT, pois melhoram a eficiência do serviço. As restrições não-essenciais consideradas são:

Para os veículos:

- O tempo ocioso de um veículo deve ser minimizado;

- O número de veículos utilizados deve ser o menor possível;

- O número de vezes que um veículo realiza uma troca de linha deve ser mínimo;

- O tempo total de viagem vazia, ou seja, com o veículo fora de operação, deve ser o menor possível.

Para as tripulações:

- O tempo ocioso de uma tripulação deve ser o menor possível;

- O número de horas extras deve ser minimizado;

- O número de tripulações deve ser mínimo;

- O número de vezes que uma tripulação troca de veículo deve ser reduzido;

- O número de vezes que uma tripulação com dupla pegada finaliza a primeira pegada em um ponto e inicia a segunda pegada em um outro ponto deve ser reduzido.

As restrições não-essenciais não são exatamente restrições do PPVT, pois definem metas ou alvos desejáveis e o não atendimento dessas não torna a solução obtida inviável do ponto de vista prático. O PPVT pode ser formulado como um problema de múltiplos objetivos como minimizar tempo de viagem morta, minimizar frota, minimizar o número de horas extras, minimizar o número de tripulações, etc. $\mathrm{E}$ estes objetivos podem ser conflitantes, por exemplo, reduzir o número de tripulações pode implicar em aumento do número de horas extras, o que torna necessário a definição de uma função de avaliação calibrada com pesos para cada restrição do problema. Isto será abordado no próximo capítulo, juntamente com os pseudocódigos das heurísticas utilizadas e as estruturas de vizinhança. 


\section{ESTRATÉGIA DE SOLUÇÃO}

Tendo em vista que o PPVT é um problema de natureza combinatória, cujo esforço computacional é não polinomial (Huisman e Wagelmans, 2006), ou seja, cresce exponencialmente com o tamanho do problema. Considerando que as instâncias reais encontradas na prática, em particular no caso do transporte coletivo urbano por ônibus no Brasil, poderem usualmente representar mais de mil viagens (mais de cem veículos) a serem realizadas em um único dia, torna-se necessária uma abordagem heurística para a sua solução, uma vez que os algoritmos exatos, apesar de todos os avanços observados, são incapazes de obter soluções ótimas em tempos de processamento viáveis do ponto de vista prático.

Estratégias de solução heurísticas apóiam-se, em geral, em alguma abordagem intuitiva, na qual a estrutura particular do problema pode ser considerada e explorada de forma inteligente, a fim de se obter uma solução satisfatória, considerando-se o compromisso qualidade versus esforço computacional para obtê-la (Silver, 2004).

Segundo Cunha (2006), o termo metaheurística, introduzido pela primeira vez por Glover (1986), é a união de duas palavras gregas: heurística, derivada do verbo heuriskein ( $\varepsilon v \rho \imath \sigma \kappa \varepsilon l v)$, que significa "encontrar", e o prefixo meta, que significa "além, acima" (no sentido de superior). Assim, as metaheurísticas podem ser definidas como as estratégias e técnicas mais recentes e avançadas, que guiam outras heurísticas com o objetivo de se encontrar soluções melhores, ultrapassando o ponto de parada das heurísticas tradicionais.

Entre as metaheurísticas mais conhecidas e amplamente utilizadas com sucesso pode-se citar, entre outras, algoritmos genéticos, busca tabu, têmpera simulada (simulated annealing), busca em vizinhança de grande porte (do inglês "very large-scale neighborhood search"), GRASP ("Greedy Randomized Adaptive Search Procedure"), busca em vizinhança variável (do inglês "variable neighborhood search" - VNS) e "scatter search".

Neste capítulo é apresentada a metaheurística VNS (Variable Neighborhood Search) a qual foi escolhida, neste trabalho, para resolver o PPVT. Também serão apresentadas a função de avaliação utilizada e as estruturas de 
vizinhança desenvolvidas, bem como as definições necessárias.

\subsection{Metaheurística Variable Neighborhood Search}

O VNS (Método de Busca em Vizinhança Variável) é uma evolução do VND (Método de Descida em Vizinhança Variável). O VND, proposto em Mladenovic \& Hansen (1997), é um método de busca local que explora o espaço de soluções através de trocas de estruturas de vizinhança, aceitando somente soluções de melhora da solução corrente e retornando à primeira estrutura quando uma solução melhor é encontrada.

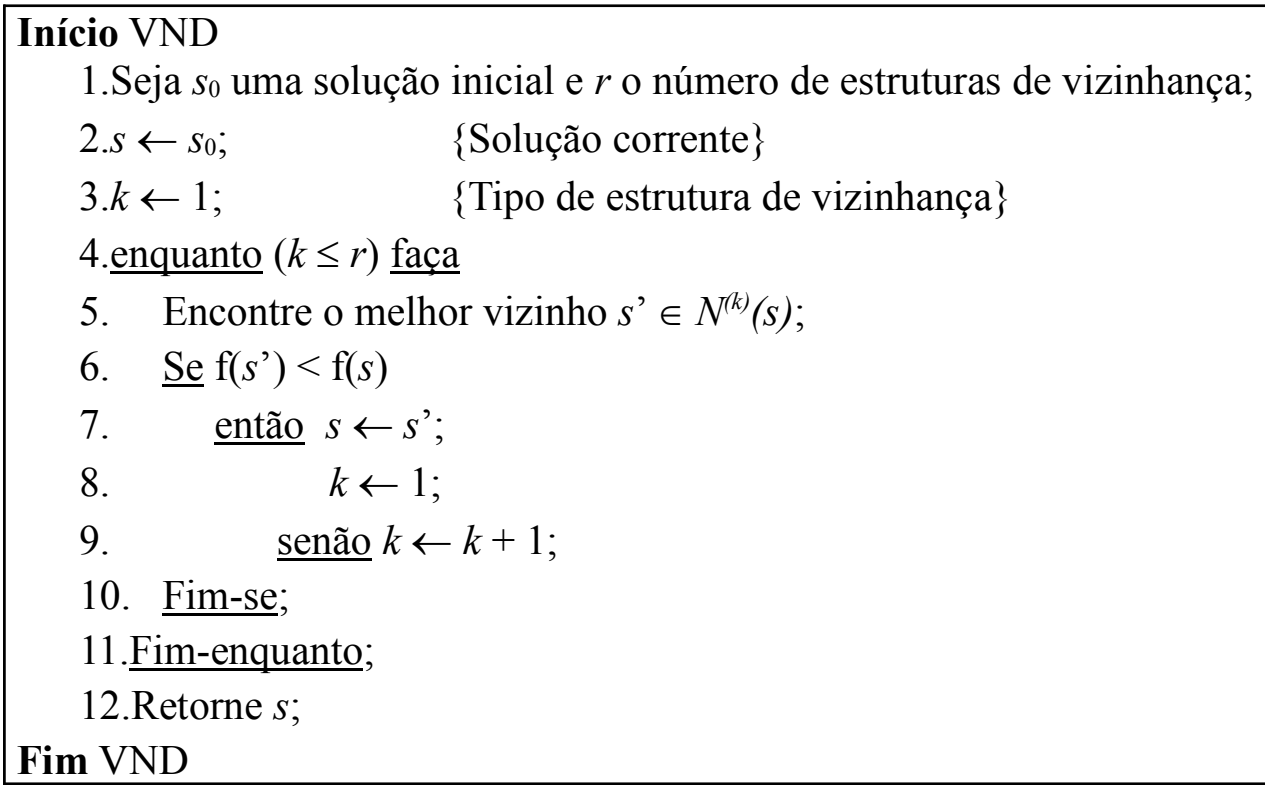

Figura 4.1 - Pseudocódigo VND para Problema de Minimização.

O VNS, a partir de uma solução corrente, realiza uma busca local na sua vizinhança igual ao VND. No caso de não encontrar uma solução de melhora, escolhe-se aleatoriamente uma vizinhança cada vez mais distante da solução corrente; caso se encontra uma solução melhor, inicia-se uma nova busca local similar ao VND.

O VNS (Método de Pesquisa em Vizinhança Variável) é um método de busca local que consiste em explorar o espaço de soluções através de trocas 
sistemáticas de estruturas de vizinhança. Contrariamente a outras metaheurísticas baseadas em métodos de busca local, o método VNS não segue uma trajetória, mas sim explora vizinhanças gradativamente mais "distantes" da solução corrente e focaliza a busca em torno de uma nova solução se, e somente se, um movimento de melhora é realizado. O método inclui, também, um procedimento de busca local a ser aplicado sobre a solução corrente. Esta rotina de busca local também pode usar diferentes estruturas de vizinhança. O pseudocódigo da metaheurística é apresentado na Figura 4.2. Detalhes adicionais desse algoritmo podem ser encontrados em Mladenovic \& Hansen (1997).

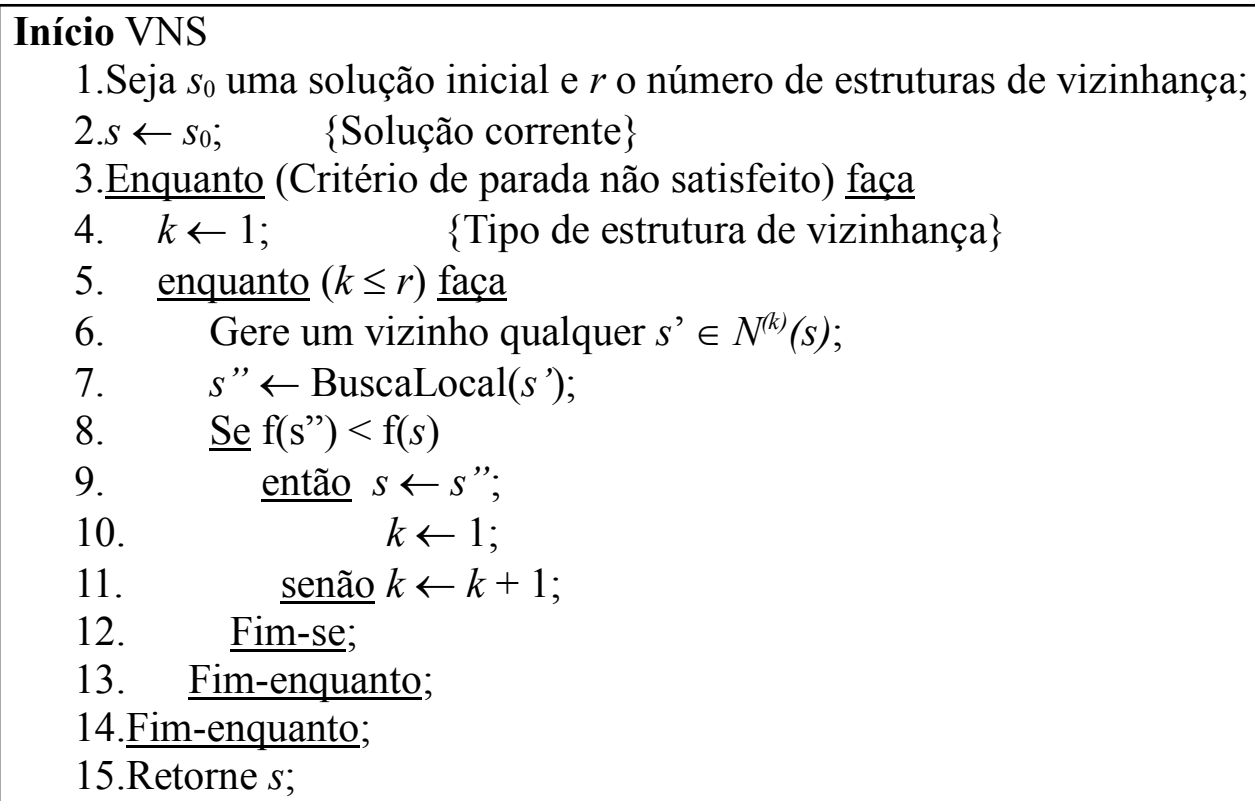

Figura 4.2 - Pseudocódigo VNS para Problema de Minimização.

Nessa metaheurística, parte-se de uma solução inicial qualquer e, a cada iteração, seleciona-se aleatoriamente um vizinho $s$ ' dentro da vizinhança $N^{(k)}(s)$ da solução corrente $s$. Esse vizinho é então submetido a um procedimento de busca local. Se a solução ótima local $s$ " for melhor que a solução $s$ corrente, a busca continua a partir de $s$ ” recomeçando da primeira estrutura de vizinhança $N^{(l)}(s)$. Caso contrário, continua-se a busca a partir da próxima estrutura de vizinhança $N^{(k+1)}(s)$.

Este procedimento é encerrado quando uma condição de parada for atingida, tal como o tempo máximo permitido de CPU, o número máximo de 
iterações ou número máximo de iterações consecutivas sem melhorias. A solução $s$ 'é gerada aleatoriamente no passo 6 da Figura 4.2, de forma a evitar ciclagem, situação que pode ocorrer se alguma regra determinística for usada. As estruturas de vizinhança utilizadas pela metaheurística VNS serão detalhadas no capítulo 5.

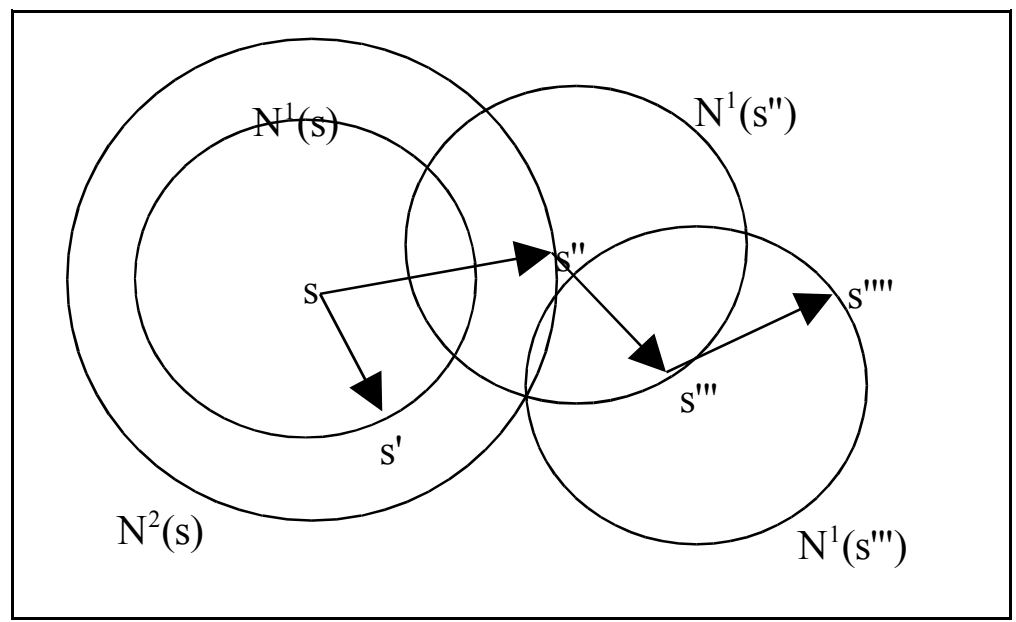

Figura 4.3 - Funcionamento do VNS.

Na Figura 4.3 pode-se observar como a metaheurística VNS explora o espaço de soluções em um problema de minimização. A partir de uma solução $s$ é realizado um movimento de exploração da vizinhança, e uma solução $s^{\prime}$ é escolhida dentro do raio de alcance da estrutura de vizinhança $N^{l}(s)$. Caso esta solução $s^{\prime}$ não resulte em melhoria, isto é, possua um valor na função de avaliação superior ao da solução $s$, retorna-se à solução $s$ e é realizado um novo movimento de exploração da vizinhança escolhendo-se uma solução $s^{\prime \prime}$ pertencente ao raio de alcance da estrutura de vizinhança $N^{2}(s)$.

Caso a nova solução $s^{\prime \prime}$ seja aceita como solução de melhora, a partir dessa solução é escolhida uma solução $s^{\prime \prime \prime}$ dentro do raio de alcance da estrutura $N^{l}\left(s^{\prime \prime}\right)$ após a realização de um movimento de exploração da vizinhança. Se a solução $s^{\prime \prime \prime}$ for aceita, uma nova solução $s^{\prime \prime \prime \prime}$, pertencente à vizinhança de $s^{\prime \prime \prime}$, é escolhida. Sempre que uma solução de melhora for encontrada, a solução corrente é movida para a nova solução e a busca é reiniciada considerando a primeira estrutura de vizinhança $\left(N^{I}\right)$. 


\subsection{Heurística Construtiva para a Solução Inicial}

Para a aplicação do VNS, é necessária a geração de uma solução inicial, a qual consiste de uma solução $s$ com todas as viagens diárias alocadas aos veículos da frota e as tripulações designadas aos veículos programados para realizar as viagens.

A solução inicial para o problema de programação integrado de veículos e tripulações (PPVT) é obtida através de uma heurística construtiva, cujo pseudocódigo é apresentado na Figura 4.4.

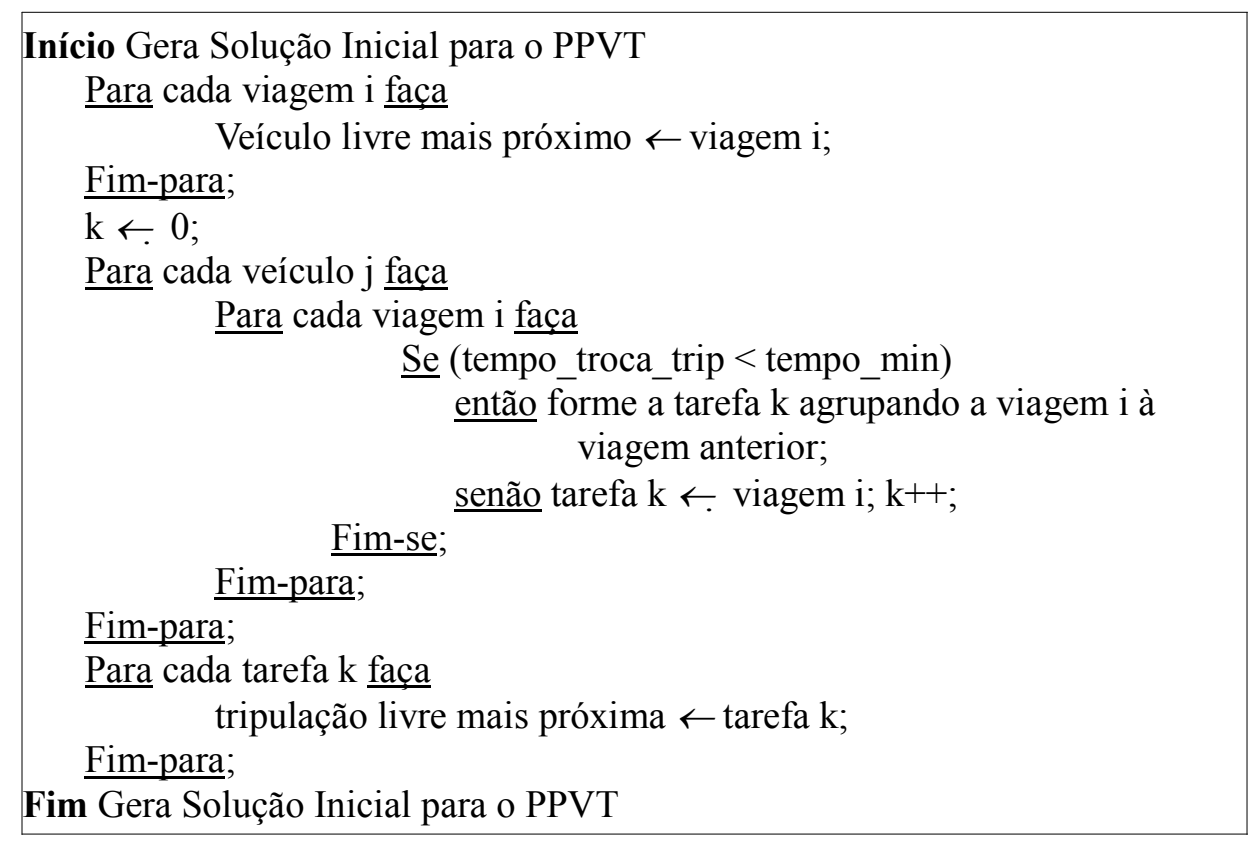

Figura 4.4 - Pseudocódigo da heurística construtiva.

A heurística construtiva para a geração da solução inicial atribui cada viagem ao veículo livre mais próximo do local de início dessa viagem. Após todas as viagens terem sido atribuídas a algum veículo, a heurística divide estas viagens em tarefas e atribui cada tarefa à tripulação livre mais próxima do local de realização desta tarefa.

O veículo livre mais próximo é definido como sendo o veículo que não esteja executando nenhuma viagem entre o horário de início e o horário de término da viagem a ser alocada e, encontra-se no mesmo ponto inicial (o ponto inicial da viagem pode ser a garagem ou um terminal) da viagem a ser alocada ou no ponto 
mais próximo, considerando-se para definir a distância o tempo de deslocamento do veículo (juntamente com uma tripulação) até o ponto inicial da viagem.

A tripulação livre mais próxima é definida como a tripulação que não esteja executando nenhuma tarefa entre o horário de início e o horário de término da tarefa a ser alocada e se encontra no mesmo ponto inicial da tarefa a ser alocada ou no ponto mais próximo. A distância é definida considerando-se o tempo de deslocamento da tripulação (juntamente com um veículo) até o ponto inicial da tarefa.

O número de veículos inicialmente disponíveis é um dado de entrada do problema. Desta forma pode ser definido conforme o tamanho da frota disponível para operar as linhas que serão programadas. No início da heurística todos os veículos estão disponíveis na garagem da empresa e as viagens estão ordenadas pelo horário de início de cada viagem.

Caso a frota disponível não seja suficientemente grande para atender todas as viagens programadas, são criados veículos extras para atender esta demanda. Uma solução que utilize veículos extras para executar as viagens programadas é considerada viável, apesar destes veículos extras não existirem a princípio. Caso a empresa deseje executar esta solução será necessário o deslocamento de veículos de outra garagem ou adquirir novos veículos.

No caso de o número de tripulações disponíveis não seja suficientemente grande para atender todas as tarefas programadas, são criadas jornadas de trabalho extras para atender esta demanda. Uma solução que utilize jornadas de trabalho extras para executar as tarefas programadas é considerada viável. Caso a empresa deseje executar esta solução será necessário o deslocamento de tripulantes de outras linhas ou contratar novos funcionários.

Após todas as viagens terem sido alocadas aos veículos, são identificados as oportunidades de troca (OT), isto é, oportunidades em que existe um tempo mínimo para a rendição de uma tripulação por outra e existe um fiscal da empresa naquele terminal onde a troca é realizada. As viagens consecutivas, de um mesmo veículo, entre duas OT são agrupadas em tarefas, e essas tarefas são alocadas às tripulações.

Após todas as viagens e tarefas serem atribuídas, respectivamente, aos 
veículos e tripulações, é verificada a existência dos intervalos de descansos regulamentados pela legislação trabalhista para cada tripulação. No caso de existir alguma tripulação sem o intervalo de descanso necessário, o mesmo é adicionado ao final da jornada de trabalho da tripulação, como um tempo adicional que a tripulação permanecerá parada no ponto final da viagem (garagem ou terminal). Desta forma, a heurística construtiva não gera soluções iniciais inviáveis, isto é, as soluções geradas inicialmente podem ser executadas em situações práticas embora não assegurem os menores custos operacionais.

\subsection{FunÇão de AvaliaÇão}

A função de avaliação tem o objetivo de avaliar a qualidade de uma solução. Além dos atributos clássicos da programação, medidos pelo número de veículos utilizados e pelo número de tripulantes alocados, a função de avaliação proposta visa a avaliar a qualidade de uma solução para o PPVT que leva em conta a penalização de cada uma das restrições essenciais e não-essenciais que forem infringidas. Para cada restrição infringida é atribuído um peso numérico, conforme a importância daquela restrição para a empresa de transporte coletivo, ou seja, a função de avaliação não representa um valor monetário para o custo operacional de uma determinada programação, mas determina um valor numérico representativo da qualidade de cada solução para o PPVT.

A qualidade de uma solução não é determinada somente pelo custo operacional, mas também depende de fatores inerentes a sua aplicabilidade como, por exemplo, a quantidade de vezes que um veículo ou um tripulante pode alternar entre duas linhas de ônibus distintas. Assim, a função de avaliação proposta é dada pela somatória dos produtos dos pesos pelas restrições essenciais e não essenciais.

A função de avaliação utilizada visa avaliar matematicamente uma solução $s$ para o PPVT através da penalização de cada uma das restrições essenciais e não-essenciais que forem infringidas. A mesma é dada pela expressão (1), onde $s$ é uma solução para o PPVT.

Conforme a expressão (1), a função de avaliação é dada pela soma das parcelas referentes ao PPV e ao PPT. A expressão (2) apresenta a função de avaliação 
do PPV, a qual é definida pela soma de duas parcelas definidas pelas restrições essenciais e pelas restrições não essenciais referentes aos veículos. A função de avaliação do PPT, apresentada na expressão (3), é análoga à referente ao PPV com a diferença de considerar apenas as restrições referentes aos tripulantes.

$$
F A(s)=F A_{P P V}(s)+F A_{P P T}(s)
$$

A parcela $\operatorname{FRE}(s)$, dada pela expressão (4) é composta pelas restrições essenciais descritas no capítulo 3. Já a expressão (5) computa as penalidades referentes ao não atendimento das restrições não essenciais consideradas, que também se encontram no capítulo 3.

$$
\begin{aligned}
& F A_{P P V}(s)=F R E_{P P V}(s)+F R N E_{P P V}(s) \\
& F A_{P P T}(s)=F R E_{P P T}(s)+F R N E_{P P T}(s)
\end{aligned}
$$

Os valores dos pesos são dados de entrada para o PPVT, definidos a partir das características desejáveis para a solução e ajustados empiricamente de acordo com a realidade local. Esse tipo de abordagem é fundamental para permitir gerar programações de veículos e tripulantes que sejam consideradas viáveis pelos operadores do transporte público.

Este ajuste empírico dos pesos é realizado observando-se as soluções obtidas e avaliando se essas refletem uma solução considerada como de boa qualidade pela empresa. Para tanto, é necessário definir o que é uma solução de boa qualidade para a empresa; para o caso estudado, uma solução com um número reduzido de veículos mas com pouco tempo de terminal e, um número reduzido de tripulações mas com poucas horas extras foi considerada como sendo de boa qualidade.

Basicamente o ajuste empírico dos pesos consiste em, por exemplo, aumentar o peso por minuto de viagem morta e observar como isto influencia na redução do número do tempo de viagem morta sem que ocorra um aumento 
significativo no número de veículos ou de tripulações da solução obtida.

O ajuste de um grande número de parâmetros é muito difícil, devido à existência de objetivos conflitantes no PPVT, por exemplo, minimizar o número de tripulações pode implicar em um aumento do número de horas extras. Parâmetros mal ajustados podem conduzir o método de busca em vizinhança variável (VNS) a uma direção errada durante a exploração do espaço de soluções viáveis. Deste modo o mesmo poderá retornar uma solução de baixa qualidade como se fosse a melhor possível.

Este ajuste empírico dos pesos implica em questionamentos como: quanto custa uma tripulação ou um veículo adicional; se é melhor reduzir o número de horas extras ou o número de tripulações; a partir de quanto tempo parado no terminal é preferível enviar o veículo para a garagem, entre outros. Essas perguntas são difíceis de serem respondidas (inclusive em alguns casos as empresas operadoras não sabem a resposta), entretanto o VNS e outros métodos de resolução necessitam de uma função matemática que indique através de um valor numérico o quanto que a solução $s$ é superior ou inferior a solução $s^{\prime}$. Não é possível garantir que os pesos utilizados são os melhores possíveis, mas os pesos utilizados é o melhor ajuste encontrado para o problema abordado.

Os pesos têm como objetivo estimar estes valores e, neste trabalho, um dos modos de ajuste foi o empírico, a partir do qual tentou-se calibrar os pesos para que a função de avaliação tenha a capacidade de avaliar as soluções obtidas e indicar para as heurísticas utilizadas qual a melhor solução dentro do espaço de soluções que foi explorado. O ajuste empírico dos pesos resultou nos valores da Tabela 4.1.

Uma tripulação ou um veículo serão considerados como dupla pegada sempre que a jornada diária for divisível em dois blocos de tarefas ou viagens (respectivamente tripulação e veículo) e existe um tempo mínimo ocioso entre estes dois blocos para que seja caracterizada a dupla pegada. Normalmente este tipo de jornada é utilizado para aumentar a oferta de transporte nos horários de pico (manhã e fim de tarde), onde ocorrem o aumento da demanda de passageiros.

Devido a jornada do tipo dupla pegada gerar insatisfação por parte dos tripulantes, os quais possuem preferência por jornadas corridas (executar a jornada de trabalho em um único bloco), este tipo de jornada é limitado a uma porcentagem 
máxima diária calculada em relação ao total de tripulações ou de veículos utilizados. Sempre que o número de tripulações ou de veículos com dupla pegada exceder o valor máximo diário, o número excedente será penalizado utilizando o valor do peso por excesso de tripulações ou veículos com dupla pegada. Esta porcentagem máxima de veículos com dupla pegada e de tripulações com dupla pegada foi determinada com base nas características das soluções atualmente em uso por uma empresa de transporte coletivo.

Tabela 4.1 - Valores limites de restrições e pesos determinados empiricamente.

\begin{tabular}{|l|c|}
\hline \multicolumn{1}{|c|}{ Parâmetro } & Peso \\
\hline Porcentagem Máxima de Veículos com Dupla Pegada & $60 \%$ \\
\hline Porcentagem Máxima de Tripulações com Dupla Pegada & $20 \%$ \\
\hline Tempo Mínimo de Permanência do Veículo na Garagem & $01: 00$ \\
\hline Tempo Normal de Trabalho da Tripulação & $07: 10$ \\
\hline Tempo Máximo de Horas Extras & $01: 00$ \\
\hline Tempo Máximo de Horas Super Extras & $01: 00$ \\
\hline Tempo Mínimo para Troca de Tripulações & $00: 05$ \\
\hline Tempo de Folga Corrida (tripulação) & $00: 10$ \\
\hline Tempo de Folga Acumulada (tripulação) & $00: 20$ \\
\hline Tempo Mínimo para uma Tripulação ser Dupla Pegada & $02: 00$ \\
\hline Tempo Mínimo para um Veículo ser Dupla Pegada & $02: 00$ \\
\hline Peso por Troca de Linha (veículo) & 0 \\
\hline Peso por Troca de Veículo (tripulação) & 0 \\
\hline Peso por Ausência do Tempo de Folga (tripulação) & 80 \\
\hline Peso por Minuto de Hora Extra (tripulação) & 2 \\
\hline Peso por Minuto de Hora Super Extra (tripulação) & 10 \\
\hline Peso por Minuto de Hora Ociosa (tripulação) & 1 \\
\hline Peso por Minuto de Sobreposição (veículo e tripulação) & 80 \\
\hline Peso por Utilizar um Veículo & 1.000 \\
\hline Peso por Utilizar uma Tripulação & 1.000 \\
\hline Peso por Excesso de Veículos com Dupla Pegada & 800 \\
\hline Peso por Excesso de Tripulações com Dupla Pegada & 800 \\
\hline Peso por Minuto de Viagem Morta (veículo) & 2 \\
\hline Peso por Minuto de Tempo de Terminal (veículo) & 1 \\
\hline
\end{tabular}

O tempo mínimo de permanência do veículo na garagem é o número de horas que cada um dos veículos deve permanecer na garagem para manutenção preventiva e/ou limpeza/higienização do veículo (este tempo pode ocorrer durante a 
jornada caso o veículo seja recolhido). Caso este tempo não seja respeitado pela solução $s$, as viagens executadas durante este tempo mínimo de permanência serão consideradas como sobreposição. O tempo mínimo para troca da tripulação é o tempo necessário para que uma tripulação seja rendida por outra tripulação, a qual continuará a operar o mesmo veículo. Para cada veículo utilizado na solução haverá um peso por utilizar o veículo e para cada tripulação utilizada também existirá um peso por utilizar a tripulação.

Os valores dos pesos por troca de linha (referente aos veículos) e por troca de veículo (referente aos tripulantes) foram considerados nulos, devido a não ser possível determinar o valor destes pesos com base no custo monetário. Estes pesos se referem a restrições não essenciais e caso não possuam o mesmo valor, quando utilizado os pesos determinados empiricamente e quando utilizado os pesos calculados com base no custo monetário, não seria possível comparar os resultados obtidos.

O tempo de folga corrida é o tempo que uma tripulação deve ter de intervalo de descanso ininterrupto. O tempo de folga acumulada é o tempo total que uma tripulação deve possuir para descanso durante um dia de trabalho para que esta jornada seja considerada viável. Por exemplo, uma jornada de trabalho será considerada viável se existir um intervalo de descanso de 10 minutos e mais dois intervalos de 5 minutos, totalizando os 20 minutos de folga acumulada, sendo pelo menos 10 minutos corridos conforme o acordo trabalhista em vigor na cidade na qual a empresa que forneceu os dados utilizados opera.

A ausência de folga é definido como o tempo (em minutos) que faltou para uma tripulação completar o tempo de folga corrida e/ou o tempo de folga acumulada. A hora super extra é definida como o tempo em que uma tripulação excede o tempo máximo total de trabalho considerando o tempo máximo de horaextra.

Será considerado sobreposição sempre que houver a ocorrência de duas ou mais viagens ou tarefas sendo executadas, respectivamente, por um mesmo veículo ou uma mesma tripulação. A sobreposição torna a solução inviável mas uma solução inviável, vizinha a uma solução viável, pode gerar uma solução de boa qualidade no movimento seguinte. 
Uma viagem será considerada como viagem morta sempre que ocorrer um percurso ocioso ou morto de um veículo, isto é, percurso no qual não são transportados passageiros (por exemplo, na viagem entre a garagem e um terminal de ônibus). O tempo de terminal é definido como o tempo que um veículo permanece ocioso em um terminal de ônibus.

Observe que alguns pesos são multiplicados por minutos (tempo de viagem morta) e outros por unidades (número de veículos utilizados). Quando a restrição associada a um peso for referente a tempo, o tempo sempre será medido em minutos. Por exemplo, considere uma solução $s$ com as seguintes características:

- 10 veículos;

- 25 tripulações;

- uma tripulação com um intervalo de descanso de apenas 5 minutos (faltam 15 minutos);

- 15 horas extras;

- 30 minutos de hora super extra;

- 5 minutos de sobreposição de um veículo;

- 10 tripulações que trocam de veículo durante a jornada de trabalho;

- 6 veículos com dupla pegada;

- 6 tripulações com dupla pegada;

- 2 horas e 30 minutos de viagem morta;

- 3 horas de tempo de terminal (veículo ocioso no terminal).

A função de avaliação seria calculada da seguinte forma:

$$
\begin{gathered}
F A(s)=F A_{P P V}(s)+F A_{P P T}(s) \\
F A_{P P V}(s)=F R E_{P P V}(s)+F R N E_{P P V}(s) \\
F A_{P P T}(s)=F R E_{P P T}(s)+F R N E_{P P T}(s)
\end{gathered}
$$

A parcela $F R N E_{P P V}(S)$ (expressão (2)) seria composta pelo número de veículos utilizados (10 veículos), o tempo de viagem morta (150 minutos) e o tempo de terminal (180 minutos). A parcela $F R N E_{P P T}(S)$ (expressão (3)) consideraria o 
número de tripulações utilizadas (25 tripulações), o tempo de hora-extra (900 minutos), o tempo de hora super extra (30 minutos) e o número de trocas de veículos (10 trocas). Ambas as parcelas correspondem às restrições não essenciais e, portanto, representam atributos de qualidade da solução.

A parcela $F R E_{P P V}(s)$ (expressão (2)) seria composta somente pelo tempo de sobreposição (5 minutos) e a $F R E_{P P T}(S)$ (expressão (3)) consideraria o tempo ausente de folga (15 minutos) e o excesso de duplas pegadas (1 dupla pegada além do permitido que é de $20 \%$ do total de 25 tripulações, ou seja, 5 duplas pegadas). Ambas as parcelas representam as restrições essenciais e representam inviabilidades, isto é, caso ambas as parcelas não tenham os seus valores iguais a zero a solução $s$ será considerada inviável. Substituindo os valores referentes à solução $s$ e os pesos da Tabela 4.1 na função de avaliação, obtemos:

$$
\begin{gathered}
F R E_{P P V}(s)=80 * 5=400 \\
F R E_{P P T}(s)=80 * 15+80 * 1=1.280 \\
F R N E_{P P V}(s)=1.000 * 10+2 * 150+1 * 180=10.480 \\
F R N E_{P P T}(s)=1.000 * 25+2 * 900+10 * 30+0 * 10=27.100 \\
F A_{P P V}(s)=400+10.480=10.880 \\
F A_{P P T}(s)=1.280+27.100=28.380 \\
F A(s)=10.880+28.380=39.260
\end{gathered}
$$

As parcelas (6) e (7), respectivamente, $F R E_{P P V}(s)$ e $F R E_{P P T}(s)$ representam as penalizações referentes às restrições essenciais não atendidas pela solução $s$. Desta forma, a solução $s$ é uma solução inviável pois as parcelas (6) e (7) possuem o valor diferente de zero e possui um custo de 39.260 unidades (expressão (12)), ou seja, as restrições essenciais não são atendidas pela solução $s$.

Devido à dificuldade de estabelecer-se os pesos empiricamente, é proposta uma alternativa para o calculo dos pesos utilizando custos monetários como referência. Os valores dos pesos apresentados na Tabela 4.2 foram calculados a partir de uma planilha tarifária de uma cidade brasileira (disponível na Figura A.1 do Anexo A). 
Os valores dos pesos referentes às restrições essenciais foram mantidos iguais aos valores da Tabela 4.1 devido ao fato que, se uma solução $s$ for considerada viável, as parcelas da função de avaliação para o $\operatorname{PPV}$ e $\operatorname{PPT}\left(F R E_{P P V}(s)\right.$ e $\left.F R E_{P P T}(s)\right)$ possuírão os seus coeficientes zerados e conseqüentemente os seus valores serão nulos. Deste modo os valores dos pesos referentes às restrições essenciais não influenciarão o valor da função de avaliação se a solução $s$ for viável.

Tabela 4.2 - Valores limites de restrições e pesos considerando custo monetário.

\begin{tabular}{|l|c|}
\hline \multicolumn{1}{|c|}{ Parâmetro } & Peso \\
\hline Porcentagem Máxima de Veículos com Dupla Pegada & $60 \%$ \\
\hline Porcentagem Máxima de Tripulações com Dupla Pegada & $20 \%$ \\
\hline Tempo Mínimo de Permanência do Veículo na Garagem & $01: 00$ \\
\hline Tempo Normal de Trabalho da Tripulação & $07: 10$ \\
\hline Tempo Máximo de Horas Extras & $01: 00$ \\
\hline Tempo Máximo de Horas Super Extras & $01: 00$ \\
\hline Tempo Mínimo para Troca de Tripulações & $00: 05$ \\
\hline Tempo de Folga Corrida (tripulação) & $00: 10$ \\
\hline Tempo de Folga Acumulada (tripulação) & $00: 20$ \\
\hline Tempo Mínimo para uma Tripulação ser Dupla Pegada & $02: 00$ \\
\hline Tempo Mínimo para um Veículo ser Dupla Pegada & $02: 00$ \\
\hline Peso por Troca de Linha (veículo) & 0 \\
\hline Peso por Troca de Veículo (tripulação) & 0 \\
\hline Peso por Ausência do Tempo de Folga (tripulação) & 80 \\
\hline Peso por Minuto de Hora Extra (tripulação) & 0,32 \\
\hline Peso por Minuto de Hora Super Extra (tripulação) & 0,64 \\
\hline Peso por Minuto de Hora Ociosa (tripulação) & 0,21 \\
\hline Peso por Minuto de Sobreposição (veículo e tripulação) & 80 \\
\hline Peso por Utilizar um Veículo & 447,19 \\
\hline Peso por Utilizar uma Tripulação & 92,09 \\
\hline Peso por Excesso de Veículos com Dupla Pegada & 800 \\
\hline Peso por Excesso de Tripulações com Dupla Pegada & 800 \\
\hline Peso por Minuto de Viagem Morta (veículo) & 0,88 \\
\hline Peso por Minuto de Tempo de Terminal (veículo) & 0,26 \\
\hline
\end{tabular}

A partir do salário base da tripulação foi calculado o custo por minuto de trabalho da tripulação. $\mathrm{O}$ valor do peso por minuto de hora-extra foi calculado como $50 \%$ acima do valor do custo por minuto de trabalho da tripulação e, o peso da hora super extra é o dobro do peso da hora-extra. O custo da hora ociosa é igual ao custo 
por minuto da tripulação.

O valor do peso por utilizar um veículo é calculado dividindo-se o custo fixo diário do veículo pelo número de dias do mês (30 dias). O peso por utilizar uma tripulação foi obtido dividindo a soma dos salários e encargos de uma tripulação pelo número de dias que uma tripulação trabalha por mês (24 dias).

O peso do minuto de viagem morta é igual ao custo total do veículo por quilômetro convertido para custo por minuto utilizando uma velocidade média adotada de 20 quilômetros por hora. $\mathrm{O}$ valor do peso por minuto do veículo ocioso no terminal ou tempo de terminal é calculado convertendo o custo variável do veículo por quilômetro para custo variável por minuto adotando uma velocidade média de 20 quilômetros por hora.

Tabela 4.3 - Dados utilizados no cálculo dos pesos.

\begin{tabular}{|l|r|}
\hline \multicolumn{1}{|c|}{ Descrição } & \multicolumn{1}{c|}{ Valor } \\
\hline Salário Motorista & $\mathrm{R} \$ 1.000,99$ \\
\hline Salário Cobrador & $\mathrm{R} \$ 600,59$ \\
\hline Salário Tripulação & $\mathrm{R} \$ 1.601,58$ \\
\hline Sal Tripulação + Encargos (38\%) & $\mathrm{R} \$ 2.210,18$ \\
\hline Dias trabalhados por mês & 24 \\
\hline Tempo de trabalho por dia (minutos) & 430 \\
\hline Custo por minuto de trabalho & $\mathrm{R} \$ 0,21$ \\
\hline Custo da hora extra & $\mathrm{R} \$ 0,32$ \\
\hline Custo da hora super extra & $\mathrm{R} \$ 0,64$ \\
\hline Custo por dia de trabalho & $\mathrm{R} \$ 92,09$ \\
\hline Custo fixo mensal do veículo & $\mathrm{R} \$ 13.415,58$ \\
\hline Dias por mês & 30 \\
\hline Custo do veículo & $\mathrm{R} \$ 447,19$ \\
\hline Velocidade média (km/h) & 20 \\
\hline Custo total por quilômetro & $\mathrm{R} \$ 2,64$ \\
\hline Custo por minuto de viagem morta & $\mathrm{R} \$ 0,88$ \\
\hline Custo variável por quilômetro & $\mathrm{R} \$ 0,78$ \\
\hline Custo por minuto de tempo de terminal & $\mathrm{R} \$ 0,26$ \\
\hline
\end{tabular}

Os dados necessários para o cálculo dos pesos que não estão disponíveis na Figura A.1 foram estimados. A Tabela 4.3 apresenta os dados utilizados para o cálculo dos pesos da Tabela 4.2. 


\subsection{Estruturas de Vizinhança}

Conforme observado no pseudocódigo da metaheurística Variable Neighborhood Search (Figura 4.2), dada uma solução, é necessário gerar uma solução vizinha cuja qualidade será avaliada pela função de avaliação.

Considere uma solução $s$. Uma solução vizinha $s$ 'pode ser obtida através de quatro tipos de movimentos diferentes: movimento de realocação de uma tarefa para o PPT, movimento de troca de duas tarefas para o PPT, movimento de realocação de uma viagem para o PPV e movimento de troca de duas viagens para o PPV. Qualquer um destes movimentos pode gerar uma solução inviável e esta característica é mantida para que o VNS implementado possua liberdade suficiente para explorar o espaço de soluções do PPVT.

O movimento de realocação de uma tarefa para o PPT consiste em realocar uma tarefa de uma tripulação a outra tripulação. Este movimento é apresentado na Figura 4.5.

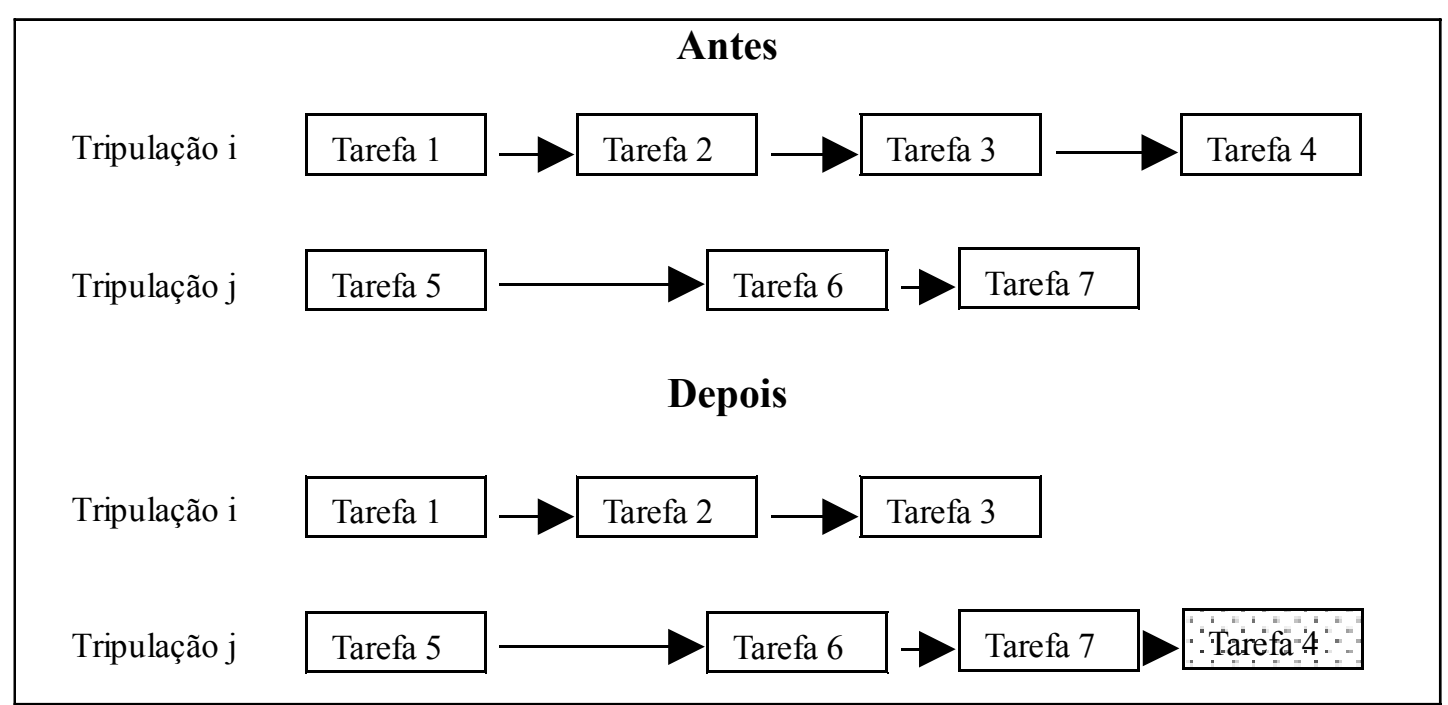

Figura 4.5 - Movimento de Realocação para o PPT.

O procedimento para a realização de um movimento de realocação para o PPT consiste em escolher aleatoriamente uma tripulação que cederá uma tarefa, em seguida escolhe-se aleatoriamente uma tripulação que receberá a tarefa da primeira tripulação. O passo seguinte é escolher aleatoriamente uma tarefa da primeira 
tripulação e atribuí-la à segunda tripulação.

O movimento de troca para o PPT é realizado trocando uma tarefa de uma tripulação com outra tarefa de outra tripulação. Esta estrutura de vizinhança é ilustrada na Figura 4.6.

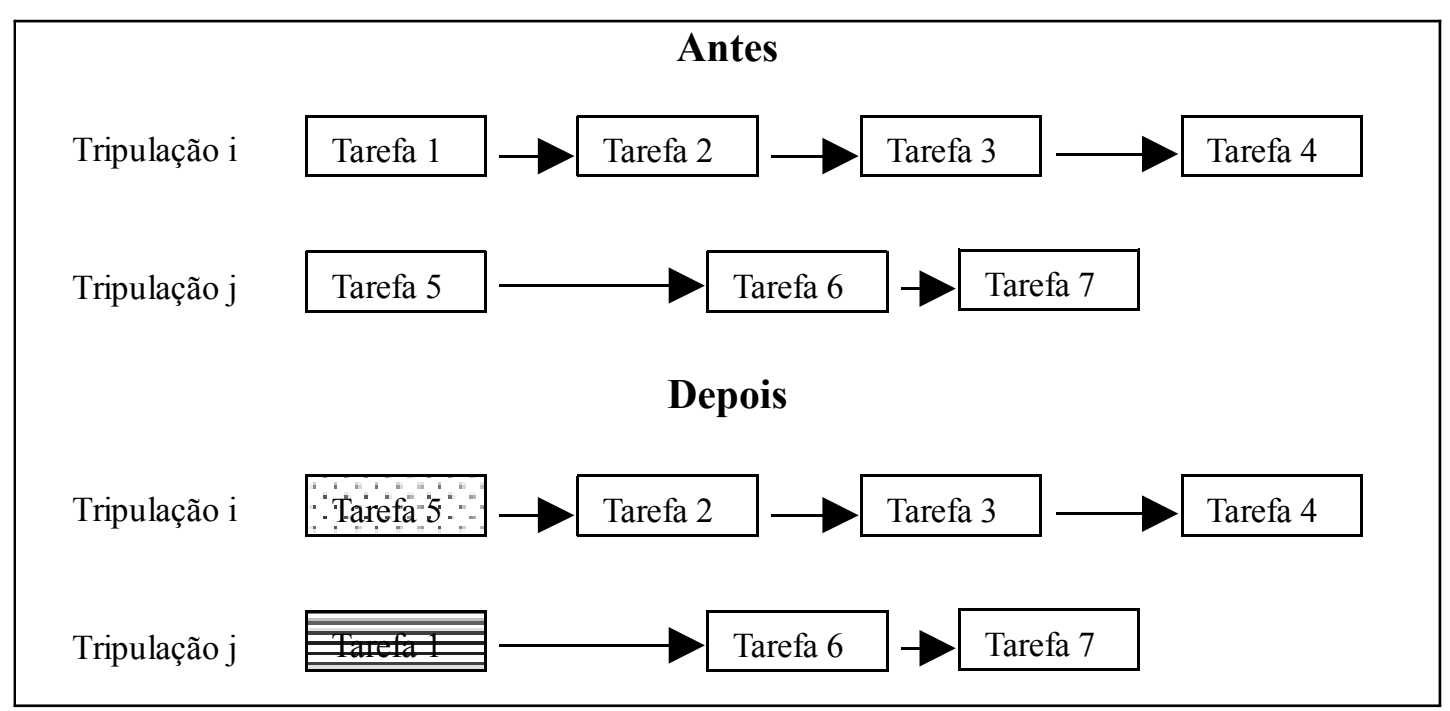

Figura 4.6 - Movimento de Troca para o PPT.

A seqüência de operações necessárias para se realizar um movimento de troca para o PPT é iniciada através da escolha aleatória de uma tripulação e, aleatoriamente escolhe-se uma tarefa desta tripulação. Em seguida, escolhe-se aleatoriamente uma segunda tripulação e seleciona-se aleatoriamente uma tarefa da segunda tripulação. O último passo do movimento de troca é a troca da tarefa selecionada da primeira tripulação com a tarefa da segunda tripulação.

O movimento de realocação para o PPV funciona de forma análoga ao movimento de realocação para o PPT. A diferença é que, ao invés de uma tripulação, é selecionado um veículo e, ao invés de realocar-se uma tarefa, uma viagem é realocada. A Figura 4.7 mostra este movimento. 


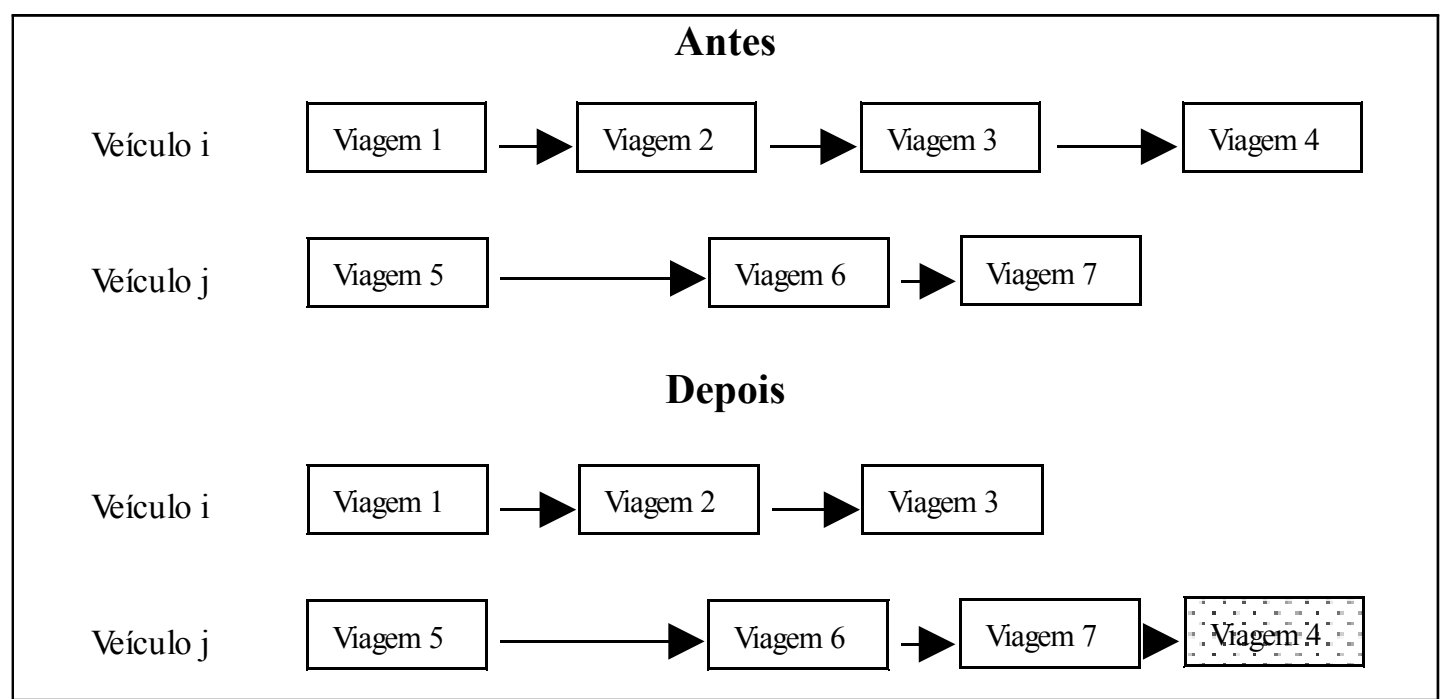

Figura 4.7 - Movimento de Realocação para o PPV.

O movimento de troca para o PPV consiste em trocar uma viagem de um veículo com uma viagem de outro veículo, de forma análoga ao movimento de troca para o PPT. Este movimento é exposto na Figura 4.8.

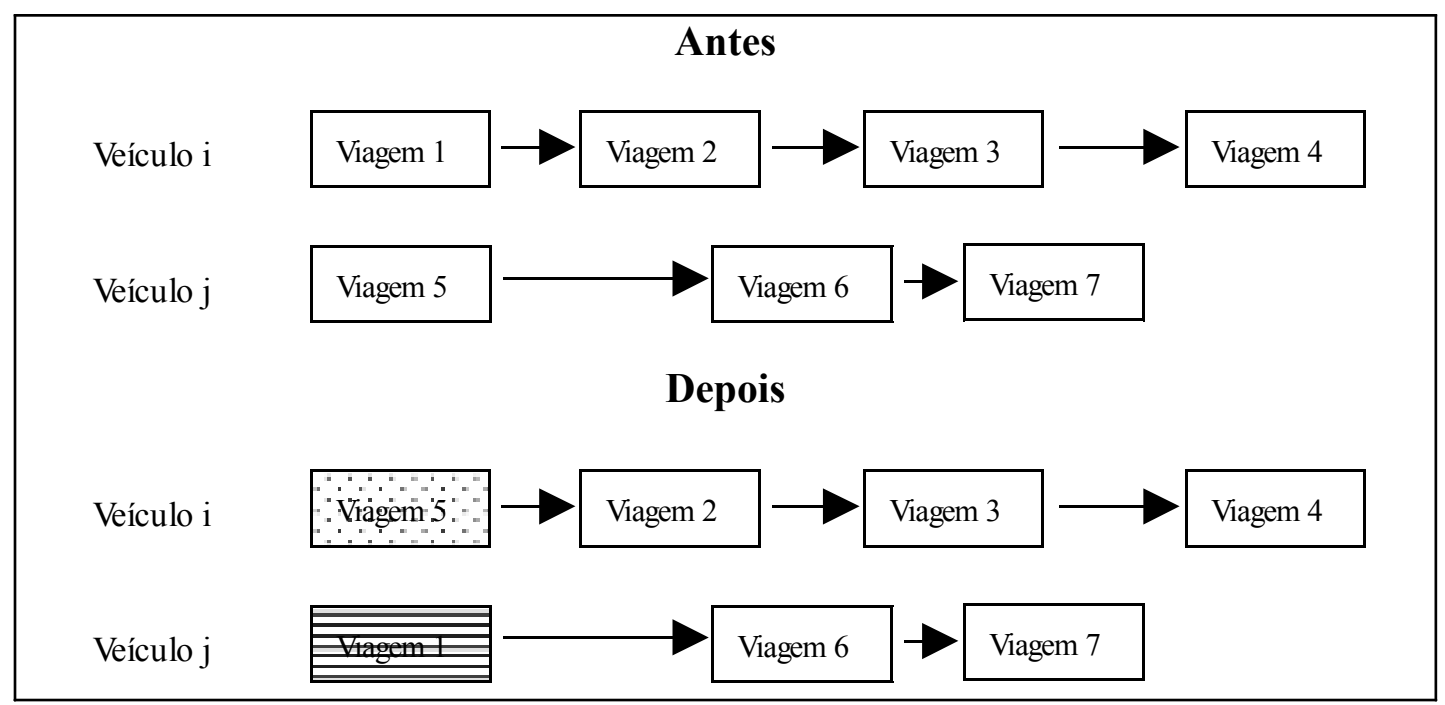

Figura 4.8-Movimento de Troca para o PPV.

Os movimento relacionados aos veículos são mais complexos do que os movimentos relacionados aos tripulante, devido ao fato de que, após uma mudança em uma ou mais viagens, pode ocorrer mudanças nas tarefas e conseqüentemente nos tripulantes que irão executá-las.

O próximo capítulo contém os detalhes relativos à implementação destes 
movimentos de exploração do espaço de soluções para cada uma das estruturas de vizinhanças nas diferentes abordagens implementadas. 


\section{ABORDAGENS IMPLEMENTADAS PARA O PPVT}

Durante o desenvolvimento deste trabalho foram implementadas cinco abordagens diferentes para o PPVT: Seqüencial Tradicional, Seqüencial Inversa, Independente, Integrada Nível 1 e Integrada Nível 2. A implementação computacional da metaheurística VNS para estas cinco abordagens serão detalhadas neste capítulo.

Uma grande parte das funções implementadas no código-fonte são compartilhadas entre as cinco abordagens; deste modo as diferenças de implementação entre elas são minimizadas e a comparação dos resultados obtidos por cada abordagem possui pouca interferência de diferenças relativas à implementação computacional. As implementações computacionais foram realizadas utilizando a linguagem $\mathrm{C}++$, devido a mesma possuir um bom gerenciamento de memória, além de ser bastante rápida.

Os dados de entrada são carregados a partir de um arquivo do tipo texto que contém as informações relativas às viagens a serem realizadas diariamente. Estas informações são armazenadas em objetos chamados viagens; cada objeto viagem possui os seguintes atributos: horário de início e de término da viagem, ponto inicial e final respectivos, tempo de terminal e número da linha.

\subsection{Abordagem Seqüencial Tradicional}

Na Abordagem Seqüencial Tradicional, inicialmente é gerada uma solução inicial para a programação dos veículos utilizando a heurística construtiva similar à descrita na seção 4.2. A principal diferença é que apenas as viagens são alocadas aos veículos e as tarefas não são criadas na solução inicial para o PPV (conforme ilustrado na Figura 5.1). 


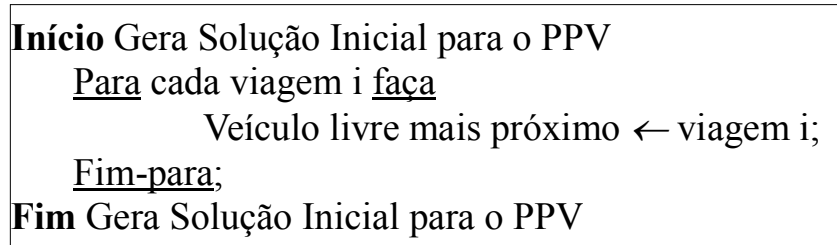

Figura 5.1 - Geração da solução inicial do PPV.

Após a solução inicial do PPV ser gerada, a metaheurística VNS, descrita anteriormente na seção 4.1, é inicializada a fim de resolver a programação dos veículos utilizando uma seqüência de movimentos exploratórios da vizinhança. Foram testadas cinco seqüências diferentes de movimentos de viagens para a vizinhança, e os resultados obtidos serão apresentados no capítulo 6 .

\section{Seqüência A:}

- Movimento de realocação de uma viagem para o PPV após um movimento inicial aleatório envolvendo o PPV;

- Movimento de troca de duas viagens para o PPV após um movimento inicial aleatório envolvendo o PPV.

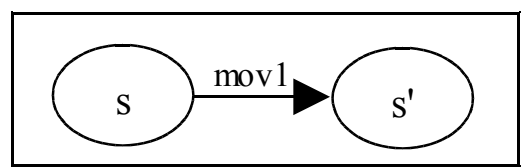

Figura 5.2 - Seqüência A.

Seqüência B:

- Movimento de realocação de uma viagem para o PPV após dois movimentos iniciais aleatórios envolvendo o PPV;

- Movimento de troca de duas viagens para o PPV após dois movimentos iniciais aleatórios envolvendo o PPV.

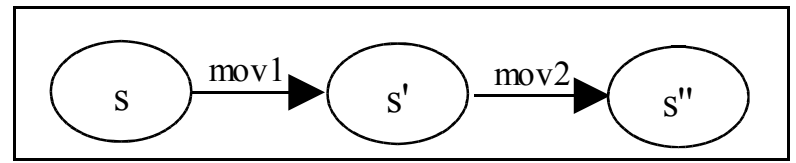

Figura 5.3 - Seqüência B. 
Seqüência $C$ :

- Movimento de realocação de uma viagem para o PPV após três movimentos iniciais aleatórios envolvendo o PPV;

- Movimento de troca de duas viagens para o PPV após três movimentos iniciais aleatórios envolvendo o PPV.

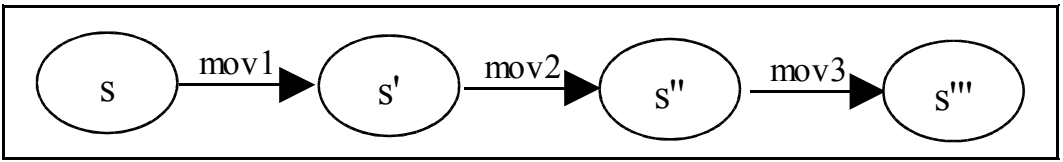

Figura 5.4-Seqüência $C$.

Seqüência $A B C$ :

- Movimento de realocação de uma viagem para o PPV após um movimento inicial aleatório envolvendo o PPV;

- Movimento de troca de duas viagens para o PPV após um movimento inicial aleatório envolvendo o PPV;

- Movimento de realocação de uma viagem para o PPV após dois movimentos iniciais aleatórios envolvendo o PPV;

- Movimento de troca de duas viagens para o PPV após dois movimentos iniciais aleatórios envolvendo o PPV;

- Movimento de realocação de uma viagem para o PPV após três movimentos iniciais aleatórios envolvendo o PPV;

- Movimento de troca de duas viagens para o PPV após três movimentos iniciais aleatórios envolvendo o PPV.

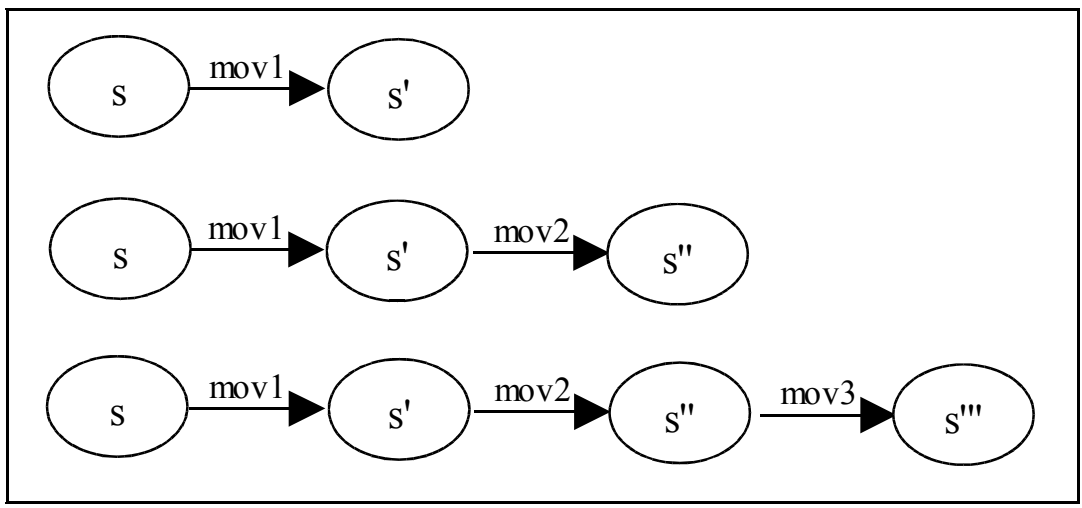

Figura 5.5 - Seqüência $A B C$. 
Seqüência NSLO:

- Movimento de realocação de uma viagem para o PPV após escolher o melhor vizinho entre quatro gerados aleatoriamente envolvendo o PPV;

- Movimento de troca de duas viagens para o PPV após escolher o melhor vizinho entre quatro gerados aleatoriamente envolvendo o PPV.

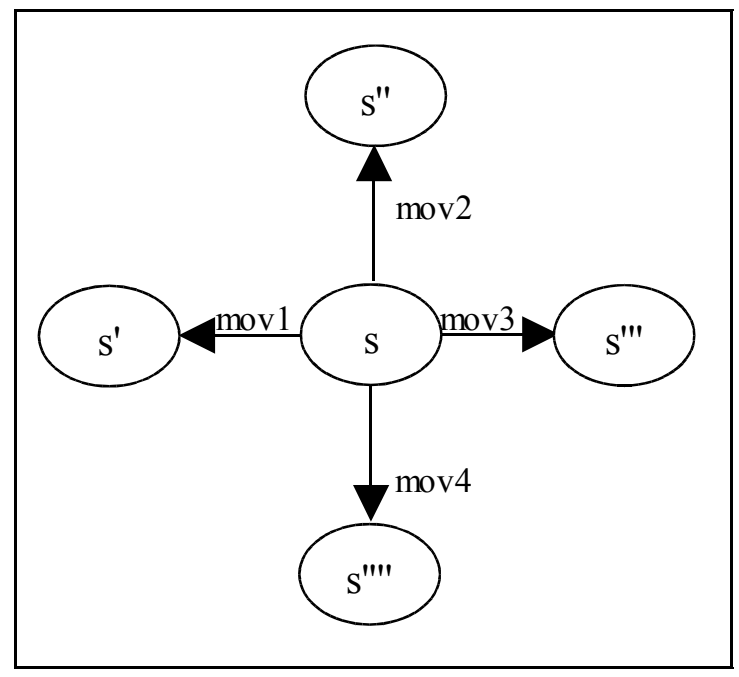

Figura 5.6-Seqüência NSLO.

Como apresentado anteriormente no pseudocódigo da Figura 4.2, para cada estrutura de vizinhança é realizada uma busca local, a qual é interrompida sempre que uma solução de melhora é encontrada ou após um número máximo de iterações sem melhora na solução. O número máximo de iterações foi definido como o número de viagens diárias para a programação dos veículos ou o número de tarefas diárias para a programação dos tripulantes.

A seqüência dos movimentos de vizinhança é repetida até que seja atingido um tempo mínimo computacional (admitido como sendo de 5 minutos; no capítulo 6 será explicado o motivo da escolha deste tempo de execução do VNS). Ao ser atingido este tempo a resolução do PPV é interrompida e as viagens são agrupadas em tarefas, considerando um tempo mínimo para troca de tripulantes de 5 minutos.

Em seguida é gerada uma solução inicial para a programação dos tripulantes (Figura 5.7) e, a metaheurística VNS é inicializada para resolver o PPT. 


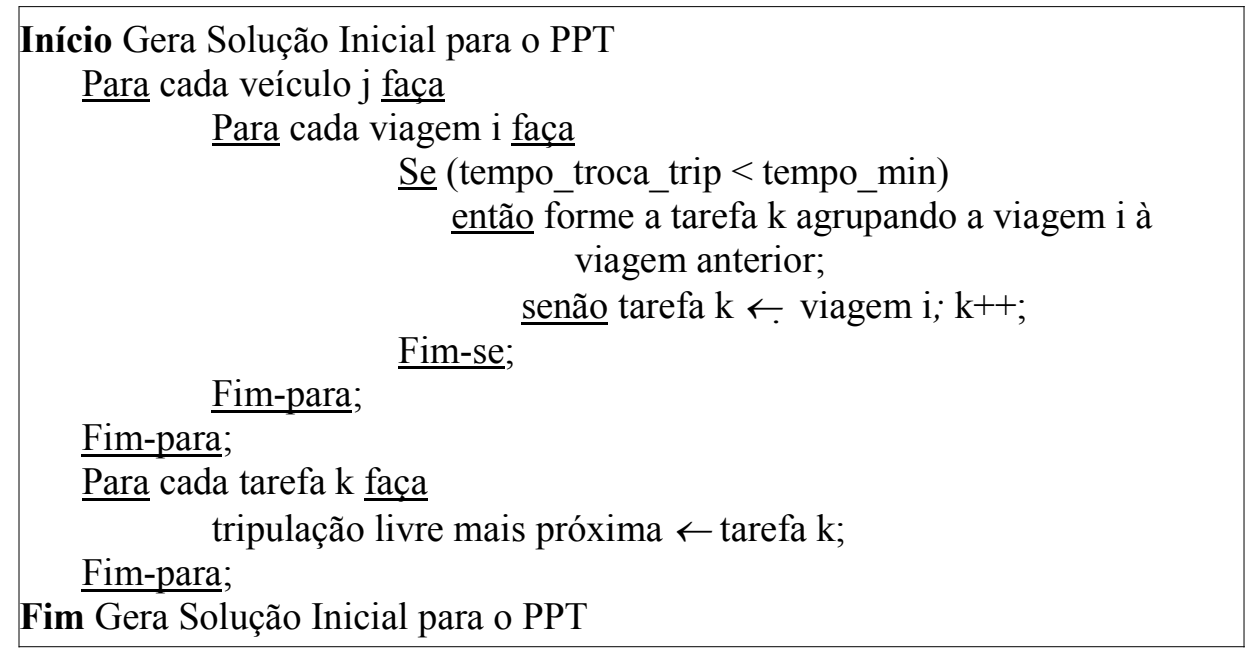

Figura 5.7 - Geração da solução inicial do PPT.

A metaheurística VNS é inicializada para resolver o PPT utilizando a mesma seqüência de movimentos de vizinhança utilizada para resolver o PPT. Por exemplo, se for utilizada a seqüência de movimentos NSLO para resolver o PPV, a mesma será utilizada para resolver o PPT considerando as seguintes modificações:

Seqüência A (Figura 5.2):

- Movimento de realocação de uma tarefa para o PPT após um movimento inicial aleatório envolvendo o PPT;

- Movimento de troca de duas tarefas para o PPT após um movimento inicial aleatório envolvendo o PPT.

Seqüência B (Figura 5.3):

- Movimento de realocação de uma tarefa para o PPT após dois movimentos iniciais aleatórios envolvendo o PPT;

- Movimento de troca de duas tarefas para o PPT após dois movimentos iniciais aleatórios envolvendo o PPT.

Seqüência C (Figura 5.4):

- Movimento de realocação de uma tarefa para o PPT após três movimentos iniciais aleatórios envolvendo o PPT;

- Movimento de troca de duas tarefas para o PPT após três movimentos 
iniciais aleatórios envolvendo o PPT.

Seqüência $A B C$ (Figura 5.5):

- Movimento de realocação de uma tarefa para o PPT após um movimento inicial aleatório envolvendo o PPT;

- Movimento de troca de duas tarefas para o PPT após um movimento inicial aleatório envolvendo o PPT;

- Movimento de realocação de uma tarefa para o PPT após dois movimentos iniciais aleatórios envolvendo o PPT;

- Movimento de troca de duas tarefas para o PPT após dois movimentos iniciais aleatórios envolvendo o PPT;

- Movimento de realocação de uma tarefa para o PPT após três movimentos iniciais aleatórios envolvendo o PPT;

- Movimento de troca de duas tarefas para o PPT após três movimentos iniciais aleatórios envolvendo o PPT.

Seqüência NSLO (Figura 5.6):

- Movimento de realocação de uma tarefa para o PPT após escolher o melhor vizinho entre quatro gerados aleatoriamente envolvendo o PPT;

- Movimento de troca de duas tarefas para o PPT após escolher o melhor vizinho entre quatro gerados aleatoriamente envolvendo o PPT.

Esta seqüência de movimentos é repetida até que seja atingido um tempo computacional mínimo (10 minutos). Desta forma, o tempo computacional total, adotado neste trabalho, para a resolução da programação dos veículos e das tripulações é de 15 minutos.

A vantagem de usar o tempo computacional como critério de parada deve-se ao fato que, para aplicações com motivação de problemas reais, muitas vezes não é necessário encontrar a solução ótima para um problema, mas é necessário encontrar a melhor solução dentro de um tempo máximo de processamento computacional. 


\subsection{Abordagem Seqüencial Inversa}

A principal diferença da abordagem seqüencial inversa para a seqüencial tradicional é a ordem de resolução da programação dos veículos e das tripulações. A abordagem seqüencial inversa resolve primeiramente a programação das tripulações e depois, utilizando os resultados obtidos, resolve a programação dos veículos.

Inicialmente os dados de entrada com as informações de cada viagem que será executada são carregados na estrutura de dados. Em seguida cada viagem é considerada como igual a uma tarefa e estas tarefas são atribuídas aos tripulantes gerando uma solução inicial (Figura 5.8).

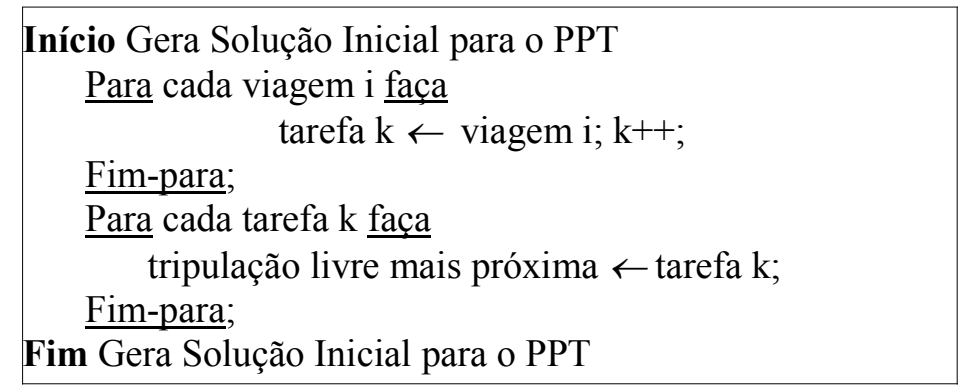

Figura 5.8 - Geração da solução inicial do PPT.

Quando a geração da solução inicial do PPT estiver concluída, a metaheurística VNS (Figura 4.2) é inicializada. Uma das seguintes seqüências de movimentos de vizinhança para as tarefas é selecionada:

Seqüência A (Figura 5.2):

- Movimento de realocação de uma tarefa para o PPT após um movimento inicial aleatório envolvendo o PPT;

- Movimento de troca de duas tarefas para o PPT após um movimento inicial aleatório envolvendo o PPT.

Seqüência B (Figura 5.3):

- Movimento de realocação de uma tarefa para o PPT após dois movimentos iniciais aleatórios envolvendo o PPT; 
- Movimento de troca de duas tarefas para o PPT após dois movimentos iniciais aleatórios envolvendo o PPT.

Seqüência C (Figura 5.4):

- Movimento de realocação de uma tarefa para o PPT após três movimentos iniciais aleatórios envolvendo o PPT;

- Movimento de troca de duas tarefas para o PPT após três movimentos iniciais aleatórios envolvendo o PPT.

Seqüência $A B C$ (Figura 5.5):

- Movimento de realocação de uma tarefa para o PPT após um movimento inicial aleatório envolvendo o PPT;

- Movimento de troca de duas tarefas para o PPT após um movimento inicial aleatório envolvendo o PPT;

- Movimento de realocação de uma tarefa para o PPT após dois movimentos iniciais aleatórios envolvendo o PPT;

- Movimento de troca de duas tarefas para o PPT após dois movimentos iniciais aleatórios envolvendo o PPT;

- Movimento de realocação de uma tarefa para o PPT após três movimentos iniciais aleatórios envolvendo o PPT;

- Movimento de troca de duas tarefas para o PPT após três movimentos iniciais aleatórios envolvendo o PPT.

Seqüência NSLO (Figura 5.6):

- Movimento de realocação de uma tarefa para o PPT após escolher o melhor vizinho entre quatro gerados aleatoriamente envolvendo o PPT;

- Movimento de troca de duas tarefas para o PPT após escolher o melhor vizinho entre quatro gerados aleatoriamente envolvendo o PPT.

Para ser possível comparar os resultados obtidos pelas diversas abordagens, é utilizada a mesma seqüência de movimentos para todas as abordagens.

A execução da metaheurística VNS é interrompida ao ser atingido o 
tempo de 10 minutos de processamento e a melhor solução encontrada para o PPT é retornada. A próxima etapa é gerar uma solução inicial para a programação dos veículos considerando a solução obtida para a programação dos tripulantes (Figura 5.9).

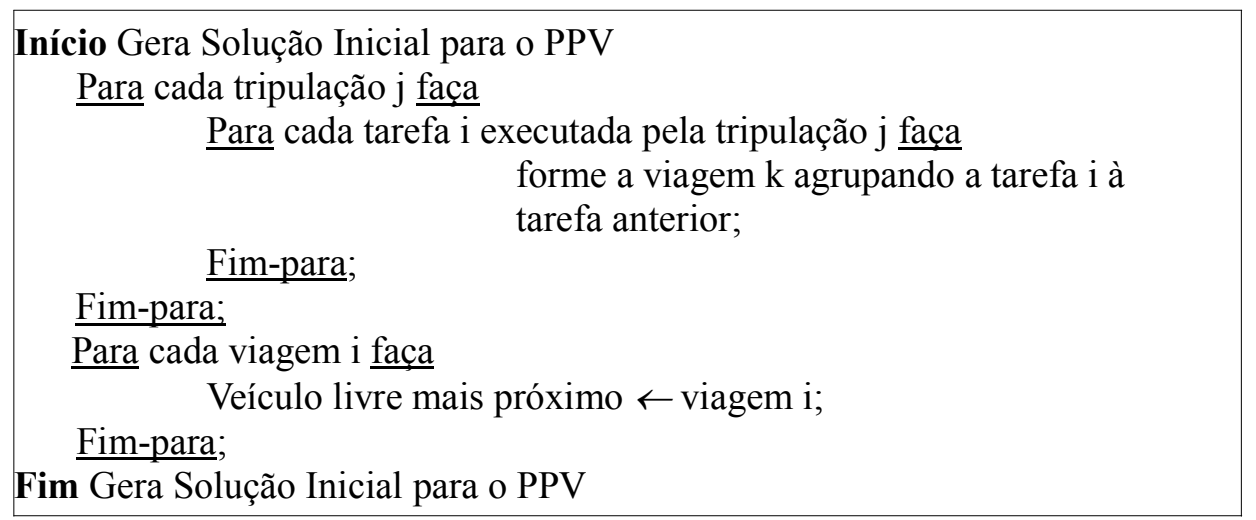

Figura 5.9 - Geração da solução inicial do PPV.

Cada jornada de trabalho de uma tripulação é considerado como uma única viagem, pois a programação dos veículos não pode alterar a programação obtida para as tripulações. Caso a tripulação execute uma jornada do tipo dupla pegada, cada pegada (bloco de tarefas consecutivas) será agrupada em uma viagem, ou seja, serão criadas duas viagens agrupando todas as tarefas desta tripulação.

A desvantagem de agrupar todas as tarefas de uma tripulação em uma única viagem é limitar o número de combinações possíveis de serem testadas durante a resolução do PPV (reduzir o espaço de soluções a ser explorado). A vantagem é eliminar a possibilidade de uma viagem ser trocada entre dois veículos, o que modificaria a solução obtida para o PPT (não permitido pela abordagem seqüencial inversa).

Em seguida à geração da solução inicial para o PPV, a metaheurística VNS é iniciada utilizando a mesma seqüência de movimentos de exploração da vizinhança utilizada durante a resolução do PPT.

Seqüência A (Figura 5.2):

- Movimento de realocação de uma viagem para o PPV após um movimento inicial aleatório envolvendo o PPV; 
- Movimento de troca de duas viagens para o PPV após um movimento inicial aleatório envolvendo o PPV.

Seqüência B (Figura 5.3):

- Movimento de realocação de uma viagem para o PPV após dois movimentos iniciais aleatórios envolvendo o PPV;

- Movimento de troca de duas viagens para o PPV após dois movimentos iniciais aleatórios envolvendo o PPV.

Seqüência C (Figura 5.4):

- Movimento de realocação de uma viagem para o PPV após três movimentos iniciais aleatórios envolvendo o PPV;

- Movimento de troca de duas viagens para o PPV após três movimentos iniciais aleatórios envolvendo o PPV.

Seqüência $A B C$ (Figura 5.5):

- Movimento de realocação de uma viagem para o PPV após um movimento inicial aleatório envolvendo o PPV;

- Movimento de troca de duas viagens para o PPV após um movimento inicial aleatório envolvendo o PPV;

- Movimento de realocação de uma viagem para o PPV após dois movimentos iniciais aleatórios envolvendo o PPV;

- Movimento de troca de duas viagens para o PPV após dois movimentos iniciais aleatórios envolvendo o PPV;

- Movimento de realocação de uma viagem para o PPV após três movimentos iniciais aleatórios envolvendo o PPV;

- Movimento de troca de duas viagens para o PPV após três movimentos iniciais aleatórios envolvendo o PPV.

Seqüência NSLO (Figura 5.6):

- Movimento de realocação de uma viagem para o PPV após escolher o melhor vizinho entre quatro gerados aleatoriamente envolvendo o PPV; 
- Movimento de troca de duas viagens para o PPV após escolher o melhor vizinho entre quatro gerados aleatoriamente envolvendo o PPV.

A metaheurística VNS é interrompida após 5 minutos e a melhor solução encontrada para o PPV é retornada pelo programa computacional.

Outro detalhe da implementação da abordagem seqüencial inversa é a alocação das viagens mortas dos veículos, as quais são criadas e atribuídas aos veículos durante a resolução do PPV; uma vez que as mesmas não haviam ainda sido atribuídas aos tripulantes, pois as viagens mortas ainda não existiam enquanto a programação das tripulações era resolvida.

Após a resolução do PPV, a tripulação que estiver operando o veículo na viagem anterior ou posterior a uma viagem morta recebe a tarefa de operar o veículo durante a viagem morta. Cada tripulação que recebe uma tarefa correspondente a uma viagem morta possui o seu custo recalculado, bem como a hora-extra, hora ociosa, tempo de trabalho, sobreposição e intervalos de folga.

\subsection{ABORDAGEM IndEPENDENTE}

$\mathrm{Na}$ abordagem independente resolve-se a programação dos veículos sem considerar a programação das tripulações e, em seguida, resolve-se a programação das tripulações sem considerar os resultados obtidos pela programação dos veículos.

Desta forma, a abordagem independente gera, na maioria dos casos, soluções inviáveis para o PPVT devido à solução obtida para a programação dos veículos e para a programação dos tripulantes não serem necessariamente compatíveis entre si. A principal finalidade da abordagem independente é a determinação da melhor programação para os veículos (independente das tripulações) e da melhor programação para as tripulações (independente dos veículos).

A solução inicial do PPV é gerada conforme a Figura 5.1 e, em seguida o PPV é resolvido utilizando a metaheurística VNS (Figura 4.2). O tempo computacional para a interrupção do VNS é de 5 minutos. A seguinte seqüência de movimentos é utilizada para o PPV: 
Seqüência A (Figura 5.2):

- Movimento de realocação de uma viagem para o PPV após um movimento inicial aleatório envolvendo o PPV;

- Movimento de troca de duas viagens para o PPV após um movimento inicial aleatório envolvendo o PPV.

Seqüência B (Figura 5.3):

- Movimento de realocação de uma viagem para o PPV após dois movimentos iniciais aleatórios envolvendo o PPV;

- Movimento de troca de duas viagens para o PPV após dois movimentos iniciais aleatórios envolvendo o PPV.

Seqüência C (Figura 5.4):

- Movimento de realocação de uma viagem para o PPV após três movimentos iniciais aleatórios envolvendo o PPV;

- Movimento de troca de duas viagens para o PPV após três movimentos iniciais aleatórios envolvendo o PPV.

\section{Seqüência $A B C$ (Figura 5.5):}

- Movimento de realocação de uma viagem para o PPV após um movimento inicial aleatório envolvendo o PPV;

- Movimento de troca de duas viagens para o PPV após um movimento inicial aleatório envolvendo o PPV;

- Movimento de realocação de uma viagem para o PPV após dois movimentos iniciais aleatórios envolvendo o PPV;

- Movimento de troca de duas viagens para o PPV após dois movimentos iniciais aleatórios envolvendo o PPV;

- Movimento de realocação de uma viagem para o PPV após três movimentos iniciais aleatórios envolvendo o PPV;

- Movimento de troca de duas viagens para o PPV após três movimentos iniciais aleatórios envolvendo o PPV. 
Seqüência NSLO (Figura 5.6):

- Movimento de realocação de uma viagem para o PPV após escolher o melhor vizinho entre quatro gerados aleatoriamente envolvendo o PPV;

- Movimento de troca de duas viagens para o PPV após escolher o melhor vizinho entre quatro gerados aleatoriamente envolvendo o PPV.

Em seguida é gerada a solução inicial para o PPT (conforme a Figura 5.8), ou seja, desconsiderando a solução obtida para a programação dos veículos. Observe que a mesma função utilizada para gerar a programação dos veículos na abordagem seqüencial tradicional e a mesma função utilizada para a gerar a solução inicial para a programação dos tripulantes utilizada na abordagem seqüencial inversa são utilizadas na abordagem independente.

A solução inicial obtida para o PPT é utilizada como dado de entrada para a metaheurística VNS, a qual é interrompida após 10 minutos de execução retornando a melhor solução obtida para o PPT. A seguinte seqüência de movimentos é utilizada para o PPT:

\section{Seqüência A (Figura 5.2):}

- Movimento de realocação de uma tarefa para o PPT após um movimento inicial aleatório envolvendo o PPT;

- Movimento de troca de duas tarefas para o PPT após um movimento inicial aleatório envolvendo o PPT.

Seqüência B (Figura 5.3):

- Movimento de realocação de uma tarefa para o PPT após dois movimentos iniciais aleatórios envolvendo o PPT;

- Movimento de troca de duas tarefas para o PPT após dois movimentos iniciais aleatórios envolvendo o PPT.

Seqüência C (Figura 5.4):

- Movimento de realocação de uma tarefa para o PPT após três movimentos iniciais aleatórios envolvendo o PPT; 
- Movimento de troca de duas tarefas para o PPT após três movimentos iniciais aleatórios envolvendo o PPT.

\section{Seqüência $A B C$ (Figura 5.5):}

- Movimento de realocação de uma tarefa para o PPT após um movimento inicial aleatório envolvendo o PPT;

- Movimento de troca de duas tarefas para o PPT após um movimento inicial aleatório envolvendo o PPT;

- Movimento de realocação de uma tarefa para o PPT após dois movimentos iniciais aleatórios envolvendo o PPT;

- Movimento de troca de duas tarefas para o PPT após dois movimentos iniciais aleatórios envolvendo o PPT;

- Movimento de realocação de uma tarefa para o PPT após três movimentos iniciais aleatórios envolvendo o PPT;

- Movimento de troca de duas tarefas para o PPT após três movimentos iniciais aleatórios envolvendo o PPT.

\section{Seqüência NSLO (Figura 5.6):}

- Movimento de realocação de uma tarefa para o PPT após escolher o melhor vizinho entre quatro gerados aleatoriamente envolvendo o PPT;

- Movimento de troca de duas tarefas para o PPT após escolher o melhor vizinho entre quatro gerados aleatoriamente envolvendo o PPT.

As soluções obtidas para a programação dos veículos e das tripulações são duas soluções normalmente incompatíveis entre si e portanto não podem ser utilizadas na prática. No entanto, a solução obtida pela abordagem independente do PPVT representa os limites inferiores que poderão ser alcançados pelas demais abordagens testadas para o PPVT. 


\subsection{Abordagem Integrada Nível 1}

A abordagem integrada nível 1 resolve a programação dos veículos considerando características da tripulação; desta forma é gerada uma programação dos veículos que facilita a programação das tripulações.

Inicialmente a solução inicial para a programação dos veículos é gerada usando o pseudocódigo da Figura 5.1. Em seguida a metaheurística VNS (Figura 4.2) é inicializada, entretanto a função de avaliação utilizada nesta abordagem é diferente da utilizada nas demais. Algumas restrições referentes aos tripulantes precisam ser atendidas pela programação dos veículos e o não atendimento destas restrições é penalizado utilizando os mesmos pesos utilizados para os tripulantes.

Por exemplo, a cada 07h10 (sete horas e dez minutos, tempo normal de trabalho da tripulação) do início do bloco de viagens do veículo, o veículo que não possuir um tempo mínimo necessário para a troca da tripulação é penalizado somando-se ao custo dele o valor do peso por minuto de hora-extra; ou seja, se o veículo trabalhar por um tempo superior ao tempo normal de trabalho, este veículo será considerado como incorrendo em hora-extra (a tripulação que for operar este veículo provavelmente terá que fazer hora-extra). Deste modo, em uma solução $s$ na qual há veículos sem um tempo para a rendição da tripulação, o custo será mais elevado e, conseqüentemente, as chances desta solução ser escolhida serão reduzidas.

Da mesma forma, a programação dos veículos também deve considerar, a cada $07 h 10$ (sete horas e dez minutos, tempo normal de trabalho da tripulação) do início do bloco de viagens do veículo, os intervalos de descanso (folga corrida e folga acumulada) necessários para cada tripulação. Caso o veículo não possua estes intervalos de descanso, o custo dele será acrescido do valor do peso por ausência de folga.

A seguinte seqüência de movimentos é utilizada para o PPV:

\section{Seqüência A (Figura 5.2):}

- Movimento de realocação de uma viagem para o PPV após um movimento inicial aleatório envolvendo o PPV;

- Movimento de troca de duas viagens para o PPV após um movimento 
inicial aleatório envolvendo o PPV.

Seqüência B (Figura 5.3):

- Movimento de realocação de uma viagem para o PPV após dois movimentos iniciais aleatórios envolvendo o PPV;

- Movimento de troca de duas viagens para o PPV após dois movimentos iniciais aleatórios envolvendo o PPV.

Seqüência C (Figura 5.4):

- Movimento de realocação de uma viagem para o PPV após três movimentos iniciais aleatórios envolvendo o PPV;

- Movimento de troca de duas viagens para o PPV após três movimentos iniciais aleatórios envolvendo o PPV.

Seqüência $A B C$ (Figura 5.5):

- Movimento de realocação de uma viagem para o PPV após um movimento inicial aleatório envolvendo o PPV;

- Movimento de troca de duas viagens para o PPV após um movimento inicial aleatório envolvendo o PPV;

- Movimento de realocação de uma viagem para o PPV após dois movimentos iniciais aleatórios envolvendo o PPV;

- Movimento de troca de duas viagens para o PPV após dois movimentos iniciais aleatórios envolvendo o PPV;

- Movimento de realocação de uma viagem para o PPV após três movimentos iniciais aleatórios envolvendo o PPV;

- Movimento de troca de duas viagens para o PPV após três movimentos iniciais aleatórios envolvendo o PPV.

Seqüência NSLO (Figura 5.6):

- Movimento de realocação de uma viagem para o PPV após escolher o melhor vizinho entre quatro gerados aleatoriamente envolvendo o PPV;

- Movimento de troca de duas viagens para o PPV após escolher o melhor 
vizinho entre quatro gerados aleatoriamente envolvendo o PPV.

Após 5 minutos de execução do VNS, a melhor solução encontrada para o PPV é retornada. Tendo em vista não existir nenhuma garantia de que todas as restrições referentes às tripulações sejam atendidas pelos veículos (e em alguns casos testados não foram atendidas), a solução encontrada para o PPV possui o seu custo recalculado (utilizando a mesma função de avaliação das demais abordagens) visando remover os valores correspondentes às restrições das tripulações impostas aos veículos que não foram atendidas.

Após o custo da solução encontrada para a programação dos veículos ter sido recalculado, caso todas as restrições referentes aos veículos tenham sido atendidas, é gerada a solução inicial do PPT (conforme a Figura 5.7). No caso de alguma restrição referente aos veículos não seja atendida, a solução obtida para o PPV será considerada inviável.

Em seguida, a metaheurística VNS (Figura 4.2) é inicializada para resolver o PPT, utilizando a mesma seqüência de movimentos de estrutura de vizinhança (com a diferença de executar movimentos de tarefas ao invés de viagens) usada durante a resolução do PPV e considerando somente as restrições referentes aos tripulantes. A seguinte seqüência de movimentos é utilizada para o PPT:

\section{Seqüência A (Figura 5.2):}

- Movimento de realocação de uma tarefa para o PPT após um movimento inicial aleatório envolvendo o PPT;

- Movimento de troca de duas tarefas para o PPT após um movimento inicial aleatório envolvendo o PPT.

Seqüência B (Figura 5.3):

- Movimento de realocação de uma tarefa para o PPT após dois movimentos iniciais aleatórios envolvendo o PPT;

- Movimento de troca de duas tarefas para o PPT após dois movimentos iniciais aleatórios envolvendo o PPT. 
Seqüência C (Figura 5.4):

- Movimento de realocação de uma tarefa para o PPT após três movimentos iniciais aleatórios envolvendo o PPT;

- Movimento de troca de duas tarefas para o PPT após três movimentos iniciais aleatórios envolvendo o PPT.

\section{Seqüência $A B C$ (Figura 5.5):}

- Movimento de realocação de uma tarefa para o PPT após um movimento inicial aleatório envolvendo o PPT;

- Movimento de troca de duas tarefas para o PPT após um movimento inicial aleatório envolvendo o PPT;

- Movimento de realocação de uma tarefa para o PPT após dois movimentos iniciais aleatórios envolvendo o PPT;

- Movimento de troca de duas tarefas para o PPT após dois movimentos iniciais aleatórios envolvendo o PPT;

- Movimento de realocação de uma tarefa para o PPT após três movimentos iniciais aleatórios envolvendo o PPT;

- Movimento de troca de duas tarefas para o PPT após três movimentos iniciais aleatórios envolvendo o PPT.

\section{Seqüência NSLO (Figura 5.6):}

- Movimento de realocação de uma tarefa para o PPT após escolher o melhor vizinho entre quatro gerados aleatoriamente envolvendo o PPT;

- Movimento de troca de duas tarefas para o PPT após escolher o melhor vizinho entre quatro gerados aleatoriamente envolvendo o PPT.

A melhor solução encontrada para o PPT é retornada após 10 minutos de execução do VNS. 


\subsection{Abordagem Integrada Nível 2}

A abordagem integrada nível 2 resolve simultaneamente a programação dos veículos e a dos tripulantes (ao contrário da abordagem integrada nível 1 que resolve o PPV com características das tripulações). Após os dados de entrada serem lidos e carregados na memória do computador, é gerada uma solução inicial para o PPVT utilizando o pseudocódigo da Figura 4.4. Em seguida a solução inicial gerada é submetida ao VNS, retornando a melhor solução encontrada após o tempo de 15 minutos.

Como as tarefas das tripulações são geradas após a programação dos veículos estar pronta, sempre que ocorrer uma alteração na programação dos veículos é necessário recalcular todas as tarefas afetadas e as tripulações que executavam estas tarefas. Deste modo é necessário realizar algumas adaptações nas seqüências de movimentos exploratórios da vizinhança (será escolhida somente uma única seqüência de movimentos em cada resolução do PPVT).

A seqüência proposta de movimentos para a busca em vizinhança variável (VNS) é a seguinte:

Seqüência A (Figura 5.2):

- Movimento de realocação de uma tarefa para o PPT após um movimento inicial aleatório envolvendo o PPT;

- Movimento de troca de duas tarefas para o PPT após um movimento inicial aleatório envolvendo o PPT;

- Movimento de realocação de uma viagem para o PPV após um movimento inicial aleatório envolvendo o PPV;

- Movimento de troca de duas viagens para o PPV após um movimento inicial aleatório envolvendo o PPV.

Seqüência B (Figura 5.3):

- Movimento de realocação de uma tarefa para o PPT após dois movimentos iniciais aleatórios envolvendo o PPT;

- Movimento de troca de duas tarefas para o PPT após dois movimentos 
iniciais aleatórios envolvendo o PPT;

- Movimento de realocação de uma viagem para o PPV após dois movimentos iniciais aleatórios envolvendo o PPV;

- Movimento de troca de duas viagens para o PPV após dois movimentos iniciais aleatórios envolvendo o PPV.

Seqüência C (Figura 5.4):

- Movimento de realocação de uma tarefa para o PPT após três movimentos iniciais aleatórios envolvendo o PPT;

- Movimento de troca de duas tarefas para o PPT após três movimentos iniciais aleatórios envolvendo o PPT;

- Movimento de realocação de uma viagem para o PPV após três movimentos iniciais aleatórios envolvendo o PPV;

- Movimento de troca de duas viagens para o PPV após três movimentos iniciais aleatórios envolvendo o PPV.

Seqüência $A B C$ (Figura 5.5):

- Movimento de realocação de uma tarefa para o PPT após um movimento inicial aleatório envolvendo o PPT;

- Movimento de troca de duas tarefas para o PPT após um movimento inicial aleatório envolvendo o PPT;

- Movimento de realocação de uma tarefa para o PPT após dois movimentos iniciais aleatórios envolvendo o PPT;

- Movimento de troca de duas tarefas para o PPT após dois movimentos iniciais aleatórios envolvendo o PPT;

- Movimento de realocação de uma tarefa para o PPT após três movimentos iniciais aleatórios envolvendo o PPT;

- Movimento de troca de duas tarefas para o PPT após três movimentos iniciais aleatórios envolvendo o PPT;

- Movimento de realocação de uma viagem para o PPV após um movimento inicial aleatório envolvendo o PPV;

- Movimento de troca de duas viagens para o PPV após um movimento inicial aleatório envolvendo o PPV; 
- Movimento de realocação de uma viagem para o PPV após dois movimentos iniciais aleatórios envolvendo o PPV;

- Movimento de troca de duas viagens para o PPV após dois movimentos iniciais aleatórios envolvendo o PPV;

- Movimento de realocação de uma viagem para o PPV após três movimentos iniciais aleatórios envolvendo o PPV;

- Movimento de troca de duas viagens para o PPV após três movimentos iniciais aleatórios envolvendo o PPV.

Seqüência NSLO (Figura 5.6):

- Movimento de realocação de uma tarefa para o PPT após escolher o melhor vizinho entre quatro gerados aleatoriamente envolvendo o PPT;

- Movimento de troca de duas tarefas para o PPT após escolher o melhor vizinho entre quatro gerados aleatoriamente envolvendo o PPT;

- Movimento de realocação de uma viagem para o PPV após escolher o melhor vizinho entre quatro gerados aleatoriamente envolvendo o PPV;

- Movimento de troca de duas viagens para o PPV após escolher o melhor vizinho entre quatro gerados aleatoriamente envolvendo o PPV.

Deve-se notar que primeiramente são realizados movimentos referentes aos tripulantes e posteriormente são realizados os movimentos referentes aos veículos. Isto ocorre porque cada modificação nas viagens atribuídas aos veículos implica em uma modificação no conjunto de tarefas que são atribuídas aos tripulantes. Entretanto, as modificações nas tarefas atribuídas aos tripulantes não alteram as viagens atribuídas aos veículos.

Sempre que um veículo possuir a sua programação de viagens alterada, é verificado se houve alterações nas tarefas (apenas não ocorrerão alterações nas tarefas quando a tarefa afetada for composta somente pela viagem realocada); no caso de haver alterações todas as tarefas referentes à viagem realocada são removidas da jornada de trabalho das tripulações e excluídas da estrutura de dados. Em seguida são geradas as novas tarefas, as quais são atribuídas conforme mostrado na Figura 5.10 . 
É válido ressaltar que serão modificadas apenas as tripulações que operam os veículos cujas viagens foram alteradas. Se o movimento realizado reduzir o valor da função de avaliação, o movimento é aceito e retorna-se à primeira estrutura de vizinhança. Caso contrário, o movimento é desfeito e é realizado um novo movimento exploratório da vizinhança. A melhor solução encontrada após 15 minutos é retornada como a solução do PPVT.

Início Gera Solução Inicial para o PPT

Para cada veículo envolvido $\mathrm{j}$ faça

Para cada viagem i faça

$\underline{\text { Se }}$ (tempo_troca_trip $<$ tempo_min)

então forme a tarefa $\mathrm{k}$ agrupando a viagem $\mathrm{i}$ à viagem anterior;

senão tarefa $\mathrm{k} \leftarrow$ viagem $\mathrm{i} ; \mathrm{k}++$;

Fim-se;

Fim-para;

Fim-para;

Para cada tarefa nova $\mathrm{k}$ faça

Fim-para;

tripulação livre mais próxima $\leftarrow$ tarefa nova k;

Fim Gera Solução Inicial para o PPT

Figura 5.10 - Geração da solução inicial do PPT.

Os resultados obtidos por cada uma das abordagens implementadas para o PPVT serão expostos e comparados no Capítulo 6. 


\section{EXPERIMENTOS COMPUTACIONAIS}

A abordagem integrada baseada em VNS para o PPVT proposta neste trabalho foi testada com dados reais de uma empresa de transporte coletivo de uma grande cidade brasileira e comparada com os resultados obtidos pelas abordagens convencionais descritas anteriormente. Os testes foram realizados em um total de 8 garagens, as quais contêm as programações de viagens a serem realizadas em três tipos de dias: úteis, sábados e domingos, remetendo a um total de 24 instâncias de testes. Cada garagem é programada separadamente resultando em oito problemas de programação com uma garagem em cada problema.

Neste trabalho a premissa adotada é que tanto o dimensionamento da frota quanto a programação são de responsabilidade do órgão de gestão do transporte coletivo. Entretanto, a abordagem proposta é aplicável tanto a casos em que essas tarefas são de atribuição do poder público, quanto em situações em que o poder público define apenas a programação horária de cada linha e a frota necessária para operá-la, cabendo à empresa operadora decidir todo o detalhamento da alocação/utilização dos veículos da frota, bem como a programação de pessoal, de acordo com os limites impostos pela legislação em vigor.

Foram considerados 8 problemas diferentes (cada um referente a uma garagem) para cada tipo de dia. O conjunto de problemas relativos aos dias úteis compreende um total de 3.654 viagens diárias, enquanto que os conjuntos relativos ao sábado e domingo correspondem a 2.613 e 1.914 viagens diárias, respectivamente.

Para cada instância do problema (uma garagem em um tipo de dia), o programa desenvolvido em $\mathrm{C}++$ foi rodado cinco vezes e as melhores soluções obtidas para cada instância estão apresentadas nas Tabelas 6.1, 6.2, 6.3 e 6.4. O computador utilizado para os testes apresentados a seguir foi um Core2Duo $1.8 \mathrm{GHz}$ com 2GB de RAM, entretanto é possível rodar o programa desenvolvido em computadores mais modestos. 
Tabela 6.1 - Resultados obtidos para o dia útil utilizando peso empírico.

\begin{tabular}{|c|c|c|c|c|c|c|}
\hline Instância & Problema & $\begin{array}{c}\text { Integrada } \\
\text { Nível } 2 \\
\end{array}$ & $\begin{array}{c}\text { Integrada } \\
\text { Nível } 1 \\
\end{array}$ & $\begin{array}{c}\text { Seqüencial } \\
\text { Tradicional }\end{array}$ & $\begin{array}{c}\text { Seqüencial } \\
\text { Inversa }\end{array}$ & Independente \\
\hline \multirow{6}{*}{1} & F. de Avaliação & 114.772 & 117.067 & 119.363 & 126.263 & 111.429 \\
\hline & $\%$ acima $\mathrm{MS} *$ & $0,00 \%$ & $2,00 \%$ & $4,00 \%$ & $10,01 \%$ & ----- \\
\hline & $\mathrm{N}^{0}$ veículos & 44 & 44 & 44 & 45 & 44 \\
\hline & $\mathrm{N}^{0}$ tripulantes & 60 & 61 & 61 & 58 & 58 \\
\hline & Viagem Morta & $43: 40$ & $42: 04$ & $42: 50$ & $45: 56$ & $42: 50$ \\
\hline & Horas Extras & $07: 52$ & 08:19 & $09: 17$ & $10: 01$ & $00: 25$ \\
\hline \multirow{6}{*}{2} & F. de Avaliação & 31.425 & 32.054 & 32.682 & 32.878 & 31.399 \\
\hline & $\%$ acima MS* & $0,00 \%$ & $2,00 \%$ & $4,00 \%$ & $4,62 \%$ & ----- \\
\hline & $\mathrm{N}^{0}$ veículos & 11 & 11 & 11 & 11 & 11 \\
\hline & $\mathbf{N}^{0}$ tripulantes & 16 & 16 & 16 & 16 & 16 \\
\hline & Viagem Morta & $12: 16$ & $13: 02$ & $12: 16$ & $14: 34$ & $12: 16$ \\
\hline & Horas Extras & $18: 19$ & 19:09 & $20: 20$ & 20:03 & $17: 41$ \\
\hline \multirow{6}{*}{3} & F. de Avaliação & 111.007 & 113.227 & 115.447 & 116.458 & 110.377 \\
\hline & $\%$ acima MS* & $0,00 \%$ & $2,00 \%$ & $4,00 \%$ & $4,91 \%$ & ----- \\
\hline & $\mathrm{N}^{0}$ veículos & 37 & 37 & 37 & 39 & 37 \\
\hline & $\mathrm{N}^{0}$ tripulantes & 65 & 65 & 66 & 62 & 62 \\
\hline & Viagem Morta & $20: 39$ & $22: 09$ & $19: 04$ & $24: 59$ & $19: 04$ \\
\hline & Horas Extras & $12: 58$ & $15: 03$ & 00:00 & 00:00 & 00:00 \\
\hline \multirow{6}{*}{4} & F. de Avaliação & 97.286 & 99.232 & 102.174 & 101.177 & 97.225 \\
\hline & \% acima MS* & $0,00 \%$ & $2,00 \%$ & $5,02 \%$ & $4,00 \%$ & ----- \\
\hline & $\mathrm{N}^{0}$ veículos & 30 & 30 & 30 & 30 & 30 \\
\hline & $N^{0}$ tripulantes & 59 & 59 & 60 & 58 & 58 \\
\hline & Viagem Morta & $21: 08$ & $21: 23$ & $18: 50$ & $23: 35$ & $19: 12$ \\
\hline & Horas Extras & 08:07 & 10:08 & 03:07 & $02: 18$ & 01:10 \\
\hline \multirow{6}{*}{5} & F. de Avaliação & 224.162 & 228.645 & 233.128 & 233.990 & 222.426 \\
\hline & $\%$ acima MS* & $0,00 \%$ & $2,00 \%$ & $4,00 \%$ & $4,38 \%$ & ----- \\
\hline & $\mathrm{N}^{0}$ veículos & 73 & 74 & 71 & 76 & 71 \\
\hline & $\mathrm{N}^{0}$ tripulantes & 131 & 133 & 135 & 128 & 128 \\
\hline & Viagem Morta & 53:09 & $50: 46$ & $52: 23$ & $65: 37$ & $48: 50$ \\
\hline & Horas Extras & $11: 56$ & $11: 13$ & $10: 23$ & $00: 32$ & 00:00 \\
\hline \multirow{6}{*}{6} & F. de Avaliação & 186.497 & 190.227 & 193.957 & 194.959 & 186.435 \\
\hline & $\%$ acima MS* & $0,00 \%$ & $2,00 \%$ & $4,00 \%$ & $4,54 \%$ & ----- \\
\hline & $\mathrm{N}^{\mathbf{0}}$ veículos & 61 & 62 & 61 & 64 & 61 \\
\hline & $\mathrm{N}^{0}$ tripulantes & 109 & 110 & 112 & 109 & 109 \\
\hline & Viagem Morta & $56: 53$ & $53: 54$ & $59: 08$ & $50: 44$ & $57: 05$ \\
\hline & Horas Extras & $25: 45$ & $27: 46$ & $25: 13$ & $25: 47$ & $22: 30$ \\
\hline \multirow{6}{*}{7} & F. de Avaliação & 88.669 & 89.937 & 91.701 & 92.286 & 88.174 \\
\hline & $\%$ acima $\mathrm{MS}^{*}$ & $0,00 \%$ & $1,43 \%$ & $3,42 \%$ & $4,08 \%$ & ----- \\
\hline & $\mathrm{N}^{0}$ veículos & 30 & 30 & 30 & 31 & 30 \\
\hline & $\mathrm{N}^{0}$ tripulantes & 51 & 52 & 52 & 51 & 51 \\
\hline & Viagem Morta & $19: 33$ & $12: 39$ & $16: 09$ & $12: 25$ & $14: 41$ \\
\hline & Horas Extras & $10: 18$ & $17: 07$ & $18: 47$ & $14: 30$ & $10: 45$ \\
\hline \multirow{6}{*}{8} & F. de Avaliação & 44.975 & 45.803 & 46.774 & 46.927 & 44.224 \\
\hline & $\%$ acima $\mathrm{MS} *$ & $0,00 \%$ & $1,84 \%$ & $4,00 \%$ & $4,34 \%$ & ----- \\
\hline & $\mathrm{N}^{0}$ veículos & 13 & 13 & 13 & 13 & 13 \\
\hline & $\mathrm{N}^{0}$ tripulantes & 19 & 19 & 19 & 19 & 19 \\
\hline & Viagem Morta & $33: 20$ & $32: 19$ & $39: 08$ & $38: 26$ & $32: 01$ \\
\hline & Horas Extras & $15: 12$ & $18: 37$ & $19: 42$ & 20:07 & $16: 09$ \\
\hline
\end{tabular}

* Desvio porcentual em relação à melhor solução obtida. 
A solução obtida pela abordagem independente possui o menor valor para a função de avaliação e também o menor número de veículos e o menor número de tripulações, para todos os tipos de dias (útil, sábado e domingo) programados. Entretanto, a solução obtida pela abordagem independente não pode ser utilizada na prática, pois a programação dos veículos não é compatível com a programação dos tripulantes e, portanto, serve apenas como limitante inferior em termos de necessidades de veículos e tripulações.

O tempo gasto para rodar cada instância de teste foi de 15 minutos e a seqüência de movimentos de exploração da vizinhança escolhida foi a $A B C$ conforme definido na Seção 5.1 do capítulo 5. A Tabela 6.1 apresenta os resultados correspondentes às oito instâncias para o dia útil, utilizando os valores dos pesos empíricos (Tabela 4.1). Pode-se observar que a solução obtida pela abordagem integrada nível 2 (PPV e PPT simultâneos) apresentou os melhores resultados para todas as instâncias, tendo em muitos resultados, valores muito próximos aos limitantes inferiores determinados pela abordagem independente. Em todas as instâncias testadas, a abordagem integrada nível 2 possui os melhores resultados, seguida pela abordagem integrada nível 1 (PPV com características do PPT).

Tabela 6.2 - Sumário de resultados obtidos utilizando peso empírico.

\begin{tabular}{|c|c|c|c|c|c|c|}
\hline Instância & Problema & $\begin{array}{c}\text { Integrada } \\
\text { Nível } 2\end{array}$ & $\begin{array}{c}\text { Integrada } \\
\text { Nível } 1\end{array}$ & $\begin{array}{l}\text { Seqüencial } \\
\text { Tradicional }\end{array}$ & $\begin{array}{l}\text { Seqüencial } \\
\text { Inversa }\end{array}$ & Independente \\
\hline \multirow{6}{*}{ Dia útil } & F. de Avaliação & 898.793 & 916.192 & 935.226 & 944.938 & 891.689 \\
\hline & $\%$ acima MS* & $0,00 \%$ & $1,94 \%$ & $4,05 \%$ & $5,13 \%$ & ----- \\
\hline & $\mathrm{N}^{0}$ veículos & 299 & 301 & 297 & 309 & 297 \\
\hline & $\mathrm{N}^{0}$ tripulantes & 510 & 515 & 521 & 501 & 501 \\
\hline & Viagem Morta & $260: 38$ & $248: 16$ & $259: 48$ & $276: 16$ & $245: 59$ \\
\hline & Horas Extras & $110: 27$ & $127: 22$ & $106: 49$ & $93: 18$ & $68: 40$ \\
\hline \multirow{6}{*}{ Sábado } & F. de Avaliação & 573.703 & 584.319 & 598.443 & 597.586 & 562.434 \\
\hline & $\%$ acima MS* & $0,00 \%$ & $1,85 \%$ & $4,31 \%$ & $4,16 \%$ & ----- \\
\hline & $\mathrm{N}^{\mathbf{0}}$ veículos & 177 & 179 & 174 & 189 & 174 \\
\hline & $N^{0}$ tripulantes & 341 & 347 & 350 & 338 & 338 \\
\hline & Viagem Morta & $129: 24$ & $117: 32$ & $141: 43$ & 113:05 & $86: 17$ \\
\hline & Horas Extras & $85: 05$ & $81: 26$ & $74: 15$ & $106: 22$ & $49: 47$ \\
\hline \multirow{6}{*}{ Domingo } & F. de Avaliação & 393.776 & 399.374 & 410.303 & 410.300 & 387.411 \\
\hline & $\%$ acima MS* & $0,00 \%$ & $1,42 \%$ & $4,20 \%$ & $4,20 \%$ & ----- \\
\hline & $\mathbf{N}^{0}$ veículos & 110 & 113 & 108 & 116 & 108 \\
\hline & $\mathrm{N}^{0}$ tripulantes & 242 & 243 & 248 & 242 & 242 \\
\hline & Viagem Morta & $90: 18$ & $89: 38$ & 96:07 & $111: 36$ & $79: 11$ \\
\hline & Horas Extras & $45: 02$ & $31: 14$ & $51: 45$ & $51: 13$ & $31: 56$ \\
\hline
\end{tabular}

* Desvio porcentual em relação à melhor solução obtida. 
Conforme mostrado na Tabela 6.2, que totaliza os resultados para todas as instâncias, o limitante inferior para o dia útil (dia com maior número de viagens), quanto ao número mínimo de veículos necessários é 297 e quanto ao número de tripulantes é 501, obtidos através da programação independente, ambos muito próximos dos resultados obtidos, embora essas programações não sejam factíveis na prática, tendo em vista que a programação dos veículos não é compatível com a programação dos tripulantes em nenhuma das instâncias.

Uma observação interessante quanto à Tabela 6.2 é que o número de veículos para a abordagem seqüencial tradicional (veículo primeiro, tripulação depois) é igual ao número de veículos obtidos pela abordagem independente (veículo e tripulação independentes) e que o número de tripulações da abordagem seqüencial inversa (tripulação primeiro, veículo depois) é igual ao número de tripulações obtido pela abordagem independente. Isto indica que a abordagem seqüencial tradicional e a abordagem independente possuem a melhor solução possível para a programação dos veículos e, que a abordagem seqüencial inversa e a abordagem independente possuem a melhor solução possível para a programação das tripulações.

Os resultados obtidos para a programação do sábado são apresentados na Tabela 6.3. Esses resultados mostram que a melhor solução para o PPVT é obtida pela abordagem integrada nível 2, cujo valor da F. de Avaliação é inferior aos valores obtidos pelas demais abordagens. A solução obtida pela abordagem integrada nível 2 utiliza 177 veículos e 341 tripulações para realizar 2.613 viagens diárias.

A Tabela 6.4 apresenta o sumário dos resultados obtidos para o domingo, o dia que corresponde ao menor número de viagens (1.914). É possível observar que nestes resultados, a diferença entre as soluções obtidas pelas diferentes abordagens é menor. No entanto, a abordagem integrada nível 2 ainda apresenta a melhor solução para a programação dos veículos e dos tripulantes. Observe que quanto maiores forem as dimensões do problema maior é a capacidade da abordagem integrada nível 2 reduzir os custos operacionais em relação às abordagens seqüenciais ou à abordagem integrada nível 1. Em todos os resultados obtidos para a programação dos veículos e das tripulações, a melhor solução foi obtida pela abordagem integrada nível 2, seguida pela abordagem integrada nível 1 e por último as abordagens seqüenciais (tradicional e inversa). 
Tabela 6.3 - Resultados obtidos para o sábado utilizando peso empírico.

\begin{tabular}{|c|c|c|c|c|c|c|}
\hline Instância & Problema & $\begin{array}{c}\text { Integrada } \\
\text { Nível } 2 \\
\end{array}$ & $\begin{array}{c}\text { Integrada } \\
\text { Nível } 1 \\
\end{array}$ & $\begin{array}{c}\text { Seqüencial } \\
\text { Tradicional }\end{array}$ & $\begin{array}{c}\text { Seqüencial } \\
\text { Inversa }\end{array}$ & Independente \\
\hline \multirow{6}{*}{1} & F. de Avaliação & 64.227 & 65.511 & 66.796 & 69.031 & 62.356 \\
\hline & $\%$ acima MS* & $0,00 \%$ & $2,00 \%$ & $4,00 \%$ & $7,48 \%$ & ---- \\
\hline & $\mathrm{N}^{0}$ veículos & 23 & 23 & 23 & 25 & 23 \\
\hline & $\mathrm{N}^{0}$ tripulantes & 34 & 34 & 35 & 34 & 34 \\
\hline & Viagem Morta & $16: 48$ & $17: 35$ & $16: 03$ & $14: 43$ & $16: 46$ \\
\hline & Horas Extras & $17: 46$ & 18:06 & 12:07 & $16: 26$ & 16:09 \\
\hline \multirow{6}{*}{2} & F. de Avaliação & 21.129 & 21.552 & 22.073 & 21.974 & 21.094 \\
\hline & $\%$ acima MS* & $0,00 \%$ & $2,00 \%$ & $4,47 \%$ & $4,00 \%$ & ----- \\
\hline & $\mathrm{N}^{\circ}$ veículos & 7 & 7 & 7 & 7 & 7 \\
\hline & $\mathrm{N}^{0}$ tripulantes & 11 & 11 & 11 & 11 & 11 \\
\hline & Viagem Morta & $06: 54$ & $07: 12$ & $07: 30$ & $06: 52$ & $02: 37$ \\
\hline & Horas Extras & 13:00 & $13: 46$ & 14:09 & $14: 18$ & $12: 49$ \\
\hline \multirow{6}{*}{3} & F. de Avaliação & 80.523 & 82.133 & 84.441 & 83.744 & 79.748 \\
\hline & $\%$ acima MS* & $0,00 \%$ & $2,00 \%$ & $4,87 \%$ & $4,00 \%$ & ----- \\
\hline & $\mathrm{N}^{\circ}$ veículos & 24 & 24 & 24 & 25 & 24 \\
\hline & $\mathrm{N}^{0}$ tripulantes & 51 & 52 & 52 & 51 & 51 \\
\hline & Viagem Morta & $11: 58$ & $08: 59$ & $14: 11$ & $13: 16$ & $10: 14$ \\
\hline & Horas Extras & $02: 53$ & $06: 50$ & 09:09 & $06: 26$ & 01:11 \\
\hline \multirow{6}{*}{4} & F. de Avaliação & 67.414 & 68.321 & 70.111 & 70.340 & 66.461 \\
\hline & $\%$ acima MS* & $0,00 \%$ & $1,35 \%$ & $4,00 \%$ & $4,34 \%$ & ---- \\
\hline & $\mathrm{N}^{0}$ veículos & 19 & 19 & 19 & 21 & 19 \\
\hline & $\mathrm{N}^{0}$ tripulantes & 42 & 43 & 43 & 42 & 42 \\
\hline & Viagem Morta & $13: 21$ & $23: 38$ & $26: 49$ & $18: 55$ & $05: 32$ \\
\hline & Horas Extras & $06: 11$ & 09:54 & 09:07 & $06: 54$ & 00:00 \\
\hline \multirow{6}{*}{5} & F. de Avaliação & 151.135 & 154.158 & 158.188 & 155.268 & 148.534 \\
\hline & $\%$ acima MS* & $0,00 \%$ & $2,00 \%$ & $4,67 \%$ & $2,73 \%$ & $\begin{array}{l}140.034 \\
----\end{array}$ \\
\hline & $\mathrm{N}^{0}$ veículos & 46 & 48 & 45 & 49 & 45 \\
\hline & $N^{0}$ tripulantes & 91 & 92 & 92 & 89 & 89 \\
\hline & Viagem Morta & $33: 29$ & $29: 07$ & $28: 33$ & $29: 30$ & $28: 03$ \\
\hline & Horas Extras & $01: 52$ & 09:29 & 04:07 & $10: 45$ & $08: 18$ \\
\hline \multirow{6}{*}{6} & F. de Avaliação & 117.459 & 119.573 & 122.594 & 122.181 & 114.038 \\
\hline & $\%$ acima MS* & $0,00 \%$ & $1,80 \%$ & $4,37 \%$ & $4,02 \%$ & - \\
\hline & $\mathrm{N}^{0}$ veículos & 35 & 35 & 33 & 37 & 33 \\
\hline & $\mathrm{N}^{\circ}$ tripulantes & 71 & 73 & 75 & 70 & 70 \\
\hline & Viagem Morta & $27: 10$ & $14: 11$ & $32: 06$ & $16: 08$ & $08: 35$ \\
\hline & Horas Extras & $22: 47$ & 07:07 & $07: 16$ & 09:51 & $02: 31$ \\
\hline \multirow{6}{*}{7} & F. de Avaliação & 54.305 & 55.391 & 56.477 & 56.837 & 52.979 \\
\hline & $\%$ acima MS* & $0,00 \%$ & $2,00 \%$ & $4,00 \%$ & $4,66 \%$ & ---- \\
\hline & $\mathrm{N}^{\circ}$ veículos & 18 & 18 & 18 & 20 & 18 \\
\hline & $\mathrm{N}^{\circ}$ tripulantes & 31 & 32 & 32 & 31 & 31 \\
\hline & Viagem Morta & $11: 24$ & 08:07 & $07: 22$ & 04:09 & 09:31 \\
\hline & Horas Extras & $13: 37$ & 09:06 & $10: 54$ & $33: 36$ & 04:20 \\
\hline \multirow{6}{*}{8} & F. de Avaliação & 17.511 & 17.680 & 17.763 & 18.211 & 17.224 \\
\hline & $\%$ acima MS* & $0,00 \%$ & $0,97 \%$ & $1,44 \%$ & $4,00 \%$ & ----- \\
\hline & $\mathrm{N}^{0}$ veículos & 5 & 5 & 5 & 5 & 5 \\
\hline & $\mathrm{N}^{0}$ tripulantes & 10 & 10 & 10 & 10 & 10 \\
\hline & Viagem Morta & 08:20 & $08: 43$ & 09:09 & 09:32 & 04:59 \\
\hline & Horas Extras & 06:59 & 07:08 & $07: 26$ & 08:06 & $04: 29$ \\
\hline
\end{tabular}

* Desvio porcentual em relação à melhor solução obtida. 
Tabela 6.4 - Resultados obtidos para o domingo utilizando peso empírico.

\begin{tabular}{|c|c|c|c|c|c|c|}
\hline Instância & Problema & \begin{tabular}{|c|} 
Integrada \\
Nível 2 \\
\end{tabular} & $\begin{array}{c}\text { Integrada } \\
\text { Nível } 1 \\
\end{array}$ & $\begin{array}{l}\text { Seqüencial } \\
\text { Tradicional }\end{array}$ & $\begin{array}{c}\text { Seqüencial } \\
\text { Inversa }\end{array}$ & Independente \\
\hline \multirow{6}{*}{1} & F. de Avaliação & 30.490 & 30.753 & 31.710 & 30.691 & 30.302 \\
\hline & $\%$ acima MS* & $0,00 \%$ & $0,86 \%$ & $4,00 \%$ & $0,66 \%$ & ----- \\
\hline & $\mathrm{N}^{0}$ veículos & 10 & 10 & 10 & 10 & 10 \\
\hline & $\mathrm{N}^{0}$ tripulantes & 17 & 17 & 17 & 17 & 17 \\
\hline & Viagem Morta & $08: 38$ & $09: 48$ & 09:12 & 09:16 & $08: 35$ \\
\hline & Horas Extras & $12: 16$ & $12: 00$ & $12: 32$ & $12: 00$ & $01: 47$ \\
\hline \multirow{6}{*}{2} & F. de Avaliação & 15.841 & 15.899 & 16.557 & 16.475 & 15.730 \\
\hline & $\%$ acima MS* & $0,00 \%$ & $0,37 \%$ & $4,52 \%$ & $4,00 \%$ & ----- \\
\hline & $\mathrm{N}^{\mathbf{0}}$ veículos & 5 & 5 & 5 & 5 & 5 \\
\hline & $\mathbf{N}^{0}$ tripulantes & 9 & 9 & 9 & 9 & 9 \\
\hline & Viagem Morta & $03: 50$ & $03: 50$ & $03: 50$ & $03: 50$ & $03: 26$ \\
\hline & Horas Extras & 06:08 & $06: 32$ & $06: 50$ & $06: 50$ & $05: 53$ \\
\hline \multirow{6}{*}{3} & F. de Avaliação & 57.131 & 58.274 & 59.416 & 60.364 & 55.467 \\
\hline & $\%$ acima MS* & $0,00 \%$ & $2,00 \%$ & $4,00 \%$ & $5,66 \%$ & ----- \\
\hline & $\mathrm{N}^{\mathbf{0}}$ veículos & 17 & 17 & 16 & 19 & 16 \\
\hline & $\mathrm{N}^{0}$ tripulantes & 36 & 37 & 37 & 36 & 36 \\
\hline & Viagem Morta & 09:48 & $10: 29$ & $09: 53$ & $16: 41$ & $09: 53$ \\
\hline & Horas Extras & $05: 58$ & 06:05 & $13: 46$ & 06:48 & $05: 34$ \\
\hline \multirow{6}{*}{4} & F. de Avaliação & 56.754 & 57.889 & 59.024 & 59.397 & 55.189 \\
\hline & \% acima MS* & $0,00 \%$ & $2,00 \%$ & $4,00 \%$ & $4,66 \%$ & ----- \\
\hline & $\mathrm{N}^{\mathbf{0}}$ veículos & 15 & 16 & 15 & 16 & 15 \\
\hline & $\mathbf{N}^{0}$ tripulantes & 36 & 36 & 37 & 36 & 36 \\
\hline & Viagem Morta & $10: 58$ & $11: 05$ & $12: 28$ & $12: 34$ & $10: 26$ \\
\hline & Horas Extras & 00:08 & 00:00 & $02: 10$ & $02: 28$ & 00:00 \\
\hline \multirow{6}{*}{5} & F. de Avaliação & 102.094 & 104.136 & 106.861 & 106.178 & 101.207 \\
\hline & $\%$ acima MS* & $0,00 \%$ & $2,00 \%$ & $4,67 \%$ & $4,00 \%$ & ----- \\
\hline & $\mathrm{N}^{\mathrm{o}}$ veículos & 25 & 26 & 24 & 26 & 24 \\
\hline & $\mathrm{N}^{0}$ tripulantes & 64 & 64 & 67 & 64 & 64 \\
\hline & Viagem Morta & 21:01 & $17: 56$ & $23: 49$ & 26:01 & $14: 39$ \\
\hline & Horas Extras & 00:00 & 00:00 & $07: 10$ & $02: 22$ & 00:18 \\
\hline \multirow{6}{*}{6} & F. de Avaliação & 87.498 & 88.298 & 90.998 & 91.468 & 85.748 \\
\hline & $\%$ acima MS* & $0,00 \%$ & $0,91 \%$ & $4,00 \%$ & $4,54 \%$ & ----- \\
\hline & $\mathrm{N}^{0}$ veículos & 25 & 26 & 25 & 27 & 25 \\
\hline & $\mathrm{N}^{0}$ tripulantes & 54 & 54 & 55 & 54 & 54 \\
\hline & Viagem Morta & $22: 30$ & $22: 26$ & $21: 17$ & $25: 46$ & $21: 17$ \\
\hline & Horas Extras & $14: 18$ & $00: 14$ & 01:09 & $12: 56$ & $12: 34$ \\
\hline \multirow{6}{*}{7} & F. de Avaliação & 27.596 & 27.747 & 28.802 & 28.700 & 27.456 \\
\hline & $\%$ acima MS* & $0,00 \%$ & $0,55 \%$ & $4,37 \%$ & $4,00 \%$ & ----- \\
\hline & $\mathrm{N}^{0}$ veículos & 8 & 8 & 8 & 8 & 8 \\
\hline & $\mathrm{N}^{0}$ tripulantes & 17 & 17 & 17 & 17 & 17 \\
\hline & Viagem Morta & $05: 13$ & $05: 34$ & $07: 18$ & $07: 08$ & $02: 35$ \\
\hline & Horas Extras & 00:10 & 00:00 & $00: 32$ & 00:00 & 00:00 \\
\hline \multirow{6}{*}{8} & F. de Avaliação & 16.372 & 16.378 & 16.935 & 17.027 & 16.312 \\
\hline & $\%$ acima MS* & $0,00 \%$ & $0,04 \%$ & $3,44 \%$ & $4,00 \%$ & ----- \\
\hline & $\mathrm{N}^{0}$ veículos & 5 & 5 & 5 & 5 & 5 \\
\hline & $\mathrm{N}^{0}$ tripulantes & 9 & 9 & 9 & 9 & 9 \\
\hline & Viagem Morta & 08:20 & $08: 30$ & 08:20 & $10: 20$ & 08:20 \\
\hline & Horas Extras & 06:04 & 06:23 & $07: 36$ & 07:49 & $05: 50$ \\
\hline
\end{tabular}

* Desvio porcentual em relação à melhor solução obtida. 


\subsection{Resultados Obtidos Utilizando Custo Monetário}

Os resultados expostos nas Tabelas $6.5,6.6,6.7$ e 6.8 foram obtidos utilizando-se os valores dos pesos da Tabela 4.2 correspondentes aos custos monetários na função de avaliação conforme explicado na seção 4.3 e a seqüência de movimentos de exploração da vizinhança $A B C$.

Tabela 6.5 - Resultados obtidos utilizando custo monetário.

\begin{tabular}{|c|c|c|c|c|c|c|}
\hline Instância & Problema & $\begin{array}{c}\text { Integrada } \\
\text { Nível } 2 \\
\end{array}$ & \begin{tabular}{|c|} 
Integrada \\
Nível 1
\end{tabular} & $\begin{array}{l}\text { Seqüencial } \\
\text { Tradicional }\end{array}$ & $\begin{array}{c}\text { Seqüencial } \\
\text { Inversa }\end{array}$ & Independente \\
\hline \multirow{3}{*}{ Dia útil } & $\begin{array}{l}\text { F. de Avaliação } \\
\text { \% acima MS* }\end{array}$ & $\begin{array}{c}255.294 \\
0,00 \% \\
\end{array}$ & $\begin{array}{c}258.512 \\
1,26 \% \\
\end{array}$ & $\begin{array}{c}262.689 \\
2,90 \% \\
\end{array}$ & $\begin{array}{c}263.287 \\
3,13 \% \\
\end{array}$ & $\begin{array}{c}250.754 \\
----- \\
\end{array}$ \\
\hline & \begin{tabular}{|l|}
$N^{0}$ veículos \\
$\mathbf{N}^{0}$ tripulantes
\end{tabular} & $\begin{array}{l}301 \\
532\end{array}$ & $\begin{array}{l}300 \\
567\end{array}$ & $\begin{array}{l}300 \\
575\end{array}$ & $\begin{array}{l}315 \\
522\end{array}$ & $\begin{array}{l}300 \\
522\end{array}$ \\
\hline & $\begin{array}{l}\text { Viagem Morta } \\
\text { Horas Extras }\end{array}$ & $\begin{array}{c}247: 36 \\
88: 02 \\
\end{array}$ & $\begin{array}{c}247: 57 \\
96: 06 \\
\end{array}$ & $\begin{array}{l}284: 59 \\
122: 18 \\
\end{array}$ & $\begin{array}{l}258: 48 \\
133: 52 \\
\end{array}$ & $\begin{array}{c}205: 34 \\
85: 03 \\
\end{array}$ \\
\hline \multirow{3}{*}{ Sábado } & $\begin{array}{l}\text { F. de Avaliação } \\
\text { \% acima MS* }\end{array}$ & $\begin{array}{c}132.365 \\
0,00 \% \\
\end{array}$ & $\begin{array}{c}134.637 \\
1,72 \% \\
\end{array}$ & $\begin{array}{c}136.876 \\
3,41 \% \\
\end{array}$ & $\begin{array}{c}137.049 \\
3,54 \% \\
\end{array}$ & $\begin{array}{c}130.234 \\
----- \\
\end{array}$ \\
\hline & $\begin{array}{l}\mathrm{N}^{0} \text { veículos } \\
\mathrm{N}^{\mathrm{o}} \text { tripulantes } \\
\end{array}$ & $\begin{array}{l}177 \\
357 \\
\end{array}$ & $\begin{array}{l}177 \\
383 \\
\end{array}$ & $\begin{array}{l}176 \\
390 \\
\end{array}$ & $\begin{array}{l}187 \\
353 \\
\end{array}$ & $\begin{array}{l}175 \\
353 \\
\end{array}$ \\
\hline & $\begin{array}{l}\text { Viagem Morta } \\
\text { Horas Extras }\end{array}$ & $\begin{array}{c}119: 11 \\
42: 47 \\
\end{array}$ & $\begin{array}{c}115: 28 \\
37: 00 \\
\end{array}$ & $\begin{array}{c}147: 19 \\
43: 49 \\
\end{array}$ & $\begin{array}{c}123: 48 \\
37: 48 \\
\end{array}$ & $\begin{array}{c}107: 26 \\
40: 47 \\
\end{array}$ \\
\hline \multirow{3}{*}{ Domingo } & $\begin{array}{l}\text { F. de Avaliação } \\
\text { \% acima MS* }\end{array}$ & $\begin{array}{l}84.634 \\
0,00 \% \\
\end{array}$ & $\begin{array}{l}86.966 \\
2,76 \% \\
\end{array}$ & $\begin{array}{l}88.597 \\
4,68 \% \\
\end{array}$ & $\begin{array}{l}89.172 \\
5,36 \% \\
\end{array}$ & $\begin{array}{c}83.386 \\
----- \\
\end{array}$ \\
\hline & $\begin{array}{l}\mathrm{N}^{0} \text { veículos } \\
\mathrm{N}^{\mathrm{o}} \text { tripulantes }\end{array}$ & $\begin{array}{l}110 \\
252 \\
\end{array}$ & $\begin{array}{l}110 \\
267 \\
\end{array}$ & $\begin{array}{l}109 \\
268 \\
\end{array}$ & $\begin{array}{l}117 \\
251 \\
\end{array}$ & $\begin{array}{l}109 \\
251\end{array}$ \\
\hline & $\begin{array}{l}\text { Viagem Morta } \\
\text { Horas Extras }\end{array}$ & $\begin{array}{l}79: 16 \\
23: 41 \\
\end{array}$ & $\begin{array}{l}79: 38 \\
22: 47 \\
\end{array}$ & $\begin{array}{c}108: 10 \\
32: 56 \\
\end{array}$ & $\begin{array}{l}98: 57 \\
33: 00\end{array}$ & $\begin{array}{l}72: 35 \\
19: 38 \\
\end{array}$ \\
\hline
\end{tabular}

* Desvio porcentual em relação à melhor solução obtida.

O resultado obtido pela abordagem independente (veículo e tripulações independentes) mostra que os limitantes inferiores do PPVT são 300 veículos e 522 tripulações (resultado para o dia útil). A solução integrada nível 2 (PPV e PPT simultâneos) apresenta os melhores resultados para o PPVT e está em média entre $1,50 \%$ e $1,81 \%$ acima dos limitantes inferiores.

$\mathrm{Na}$ Tabela 6.6 observa-se os resultados obtidos para o dia útil. A abordagem integrada nível 2 apresenta os melhores resultados para todas as instâncias testadas, utilizando 301 veículos e 532 tripulações. Isto representa um veículo a mais e 35 tripulações a menos que a abordagem integrada nível 1 (PPV com características das tripulações), a qual apresenta o segundo melhor resultado. 
Tabela 6.6-Resultados obtidos para o dia útil utilizando custo monetário.

\begin{tabular}{|c|c|c|c|c|c|c|}
\hline Instância & Problema & \begin{tabular}{|c|} 
Integrada \\
Nível 2 \\
\end{tabular} & \begin{tabular}{|c|} 
Integrada \\
Nível 1 1 \\
\end{tabular} & $\begin{array}{c}\text { Seqüencial } \\
\text { Tradicional } \\
\end{array}$ & $\begin{array}{c}\text { Seqüencial } \\
\text { Inversa }\end{array}$ & Independente \\
\hline \multirow{4}{*}{1} & $\begin{array}{l}\text { F. de Avaliação } \\
\text { \% acima MS* }\end{array}$ & $\begin{array}{c}71.311,50 \\
0,00 \%\end{array}$ & $\begin{array}{c}71.363,77 \\
0,07 \%\end{array}$ & $\begin{array}{c}72.677,76 \\
1,92 \%\end{array}$ & $\begin{array}{c}72.440,01 \\
1,58 \%\end{array}$ & $\begin{array}{c}70.221,33 \\
-----\end{array}$ \\
\hline & \begin{tabular}{|l|}
$\mathbf{N}^{0}$ veículos \\
$\mathrm{N}^{0}$ trinulante
\end{tabular} & $\begin{array}{l}44 \\
50\end{array}$ & 44 & 44 & $\begin{array}{l}45 \\
58\end{array}$ & $\begin{array}{l}44 \\
58\end{array}$ \\
\hline & \begin{tabular}{|l|} 
Notripulantes \\
Viagem Morta \\
\end{tabular} & $\begin{array}{c}59 \\
43: 04\end{array}$ & $\frac{60}{43: 18}$ & $\frac{60}{50: 23}$ & $\begin{array}{c}58 \\
44: 28\end{array}$ & $\begin{array}{c}58 \\
39: 07\end{array}$ \\
\hline & Horas Extras & $35: 15$ & $30: 53$ & $38: 20$ & $36: 02$ & $28: 34$ \\
\hline \multirow{5}{*}{2} & $\begin{array}{l}\text { F. de Avaliação } \\
\% \text { acima MS* }\end{array}$ & $\begin{array}{c}7.534,37 \\
0,00 \%\end{array}$ & $\begin{array}{c}7.576,74 \\
0,56 \%\end{array}$ & $\begin{array}{c}7.698,09 \\
2,17 \%\end{array}$ & $\begin{array}{c}7.681,10 \\
1,95 \%\end{array}$ & $\begin{array}{c}7.414,00 \\
----\end{array}$ \\
\hline & $\mathrm{N}^{\mathbf{o}}$ veículos & 11 & 11 & 11 & 11 & 11 \\
\hline & $\mathrm{N}^{0}$ tripulantes & 18 & 18 & 18 & 18 & 18 \\
\hline & \begin{tabular}{|l|} 
Viagem Morta \\
\end{tabular} & $12: 16$ & $12: 16$ & $14: 02$ & $13: 41$ & $09: 22$ \\
\hline & Horas Extras & 06:04 & $08: 13$ & 09:31 & 09:37 & 07:56 \\
\hline \multirow{6}{*}{3} & F. de Avaliação & $25.496,39$ & $26.027,21$ & $26.631,10$ & $26.480,42$ & $25.227,36$ \\
\hline & $\%$ acima $M S^{*}$ & $0,00 \%$ & $2,08 \%$ & $4,45 \%$ & $3,86 \%$ & ----- \\
\hline & $\mathrm{N}^{0}$ veículos & 37 & 37 & 37 & 39 & 37 \\
\hline & $\mathrm{N}^{0}$ tripulantes & 68 & 73 & 74 & 67 & 67 \\
\hline & \begin{tabular}{|l|} 
Viagem Morta \\
\end{tabular} & $18: 24$ & $18: 56$ & $26: 53$ & 19:01 & $16: 11$ \\
\hline & Horas Extras & 03:50 & $04: 15$ & 07:01 & $08: 18$ & $01: 37$ \\
\hline \multirow{6}{*}{4} & F. de Avaliação & $22.331,54$ & $22.356,99$ & $23.004,17$ & $22.725,19$ & $21.369,76$ \\
\hline & $\%$ acima MS* & $0,00 \%$ & $0,11 \%$ & $3,01 \%$ & $1,76 \%$ & ---- \\
\hline & $\mathrm{N}^{0}$ veículos & 31 & 30 & 30 & 31 & 30 \\
\hline & $\mathrm{N}^{0}$ tripulantes & 63 & 69 & 70 & 61 & 61 \\
\hline & Viagem Morta & $18: 20$ & 18:02 & $25: 27$ & $27: 13$ & $14: 19$ \\
\hline & Horas Extras & $03: 26$ & 00:00 & $06: 03$ & $07: 36$ & $00: 56$ \\
\hline \multirow{6}{*}{5} & F. de Avaliação & $51.630,08$ & $53.089,10$ & $53.595,66$ & $54.887,75$ & $50.627,07$ \\
\hline & $\%$ acima MS* & $0,00 \%$ & $2,83 \%$ & $3,81 \%$ & $6,31 \%$ & ----- \\
\hline & $\mathrm{N}^{0}$ veículos & 73 & 73 & 73 & 79 & 73 \\
\hline & $\mathrm{N}^{0}$ tripulantes & 137 & 150 & 153 & 134 & 134 \\
\hline & \begin{tabular}{|l|} 
Viagem Morta \\
\end{tabular} & $48: 33$ & $50: 36$ & $49: 06$ & $56: 23$ & $35: 05$ \\
\hline & Horas Extras & 07:41 & $10: 18$ & $24: 33$ & $18: 26$ & $10: 34$ \\
\hline \multirow{6}{*}{6} & F. de Avaliação & \begin{tabular}{|l|}
$43.185,74$ \\
\end{tabular} & $43.798,47$ & $44.420,66$ & $44.508,30$ & $42.643,28$ \\
\hline & $\%$ acima MS* & $0,00 \%$ & $1,42 \%$ & $2,86 \%$ & $3,06 \%$ & ----- \\
\hline & $\mathrm{N}^{0}$ veículos & 61 & 61 & 61 & 65 & 61 \\
\hline & $\mathbf{N}^{0}$ tripulantes & 116 & 123 & 125 & 114 & 114 \\
\hline & Viagem Morta & $55: 22$ & $53: 38$ & $61: 06$ & $48: 13$ & $49: 26$ \\
\hline & Horas Extras & $10: 14$ & $11: 47$ & $12: 29$ & $11: 51$ & $09: 16$ \\
\hline \multirow{6}{*}{7} & F. de Avaliação & $20.755,76$ & $21.054,21$ & $21.356,98$ & $21.195,06$ & $20.294,05$ \\
\hline & $\%$ acima MS* & $0,00 \%$ & $1,44 \%$ & $2,90 \%$ & $2,12 \%$ & --- \\
\hline & $\mathrm{N}^{\circ}$ veículos & 31 & 31 & 31 & 32 & 31 \\
\hline & $\mathrm{N}^{0}$ tripulantes & 53 & 57 & 57 & 53 & 53 \\
\hline & \begin{tabular}{|l|} 
Viagem Morta \\
\end{tabular} & $18: 17$ & $17: 51$ & $22: 13$ & $17: 33$ & 09:10 \\
\hline & Horas Extras & $04: 38$ & $01: 28$ & $04: 30$ & $05: 11$ & $06: 46$ \\
\hline \multirow{6}{*}{8} & F. de Avaliação & $13.048,45$ & $13.245,18$ & $13.304,84$ & $13.368,84$ & $12.957,00$ \\
\hline & $\%$ acima MS* & $0,00 \%$ & $1,51 \%$ & $1,96 \%$ & $2,46 \%$ & ---- \\
\hline & $\mathrm{N}^{0}$ veículos & 13 & 13 & 13 & 13 & 13 \\
\hline & $\mathrm{N}^{0}$ tripulantes & 18 & 17 & 18 & 17 & 17 \\
\hline & Viagem Morta & $33: 20$ & $33: 20$ & $35: 49$ & $32: 16$ & $32: 54$ \\
\hline & Horas Extras & $16: 54$ & $29: 12$ & $19: 51$ & $36: 51$ & $19: 24$ \\
\hline
\end{tabular}

* Desvio porcentual em relação à melhor solução obtida. 
Na Tabela 6.7 são apresentados os resultados obtidos para o sábado. A melhor solução é obtida pela abordagem integrada nível 2 e utiliza 177 veículos e 357 tripulações. A segunda melhor solução é a obtida pela abordagem integrada nível 1, a qual utiliza 177 veículos e 383 tripulações (mesmo número de veículos mas com 26 tripulações a mais). A abordagem seqüencial tradicional vem em seguida com 176 veículos (1 a menos) e 390 tripulações (33 tripulações a mais) e, por último está a abordagem seqüencial inversa 187 veículos (10 a mais) e 353 tripulações (4 a menos).

Nos resultados expostos na Tabela 6.8, a abordagem integrada nível 2 apresenta os melhores resultados para o domingo em todas as instâncias testadas (110 veículos e 252 tripulações). Na seqüência está a abordagem integrada nível 1, a seqüencial tradicional e a seqüencial inversa, entretanto em algumas instâncias as abordagens seqüenciais (tradicional e inversa) invertem as suas posições. 
Tabela 6.7 - Resultados obtidos para o sábado utilizando custo monetário.

\begin{tabular}{|c|c|c|c|c|c|c|}
\hline Instância & Problema & \begin{tabular}{|c|} 
Integrada \\
Nível 2
\end{tabular} & \begin{tabular}{|c|} 
Integrada \\
Nível 1
\end{tabular} & $\begin{array}{c}\text { Seqüencial } \\
\text { Tradicional }\end{array}$ & $\begin{array}{c}\text { Seqüencial } \\
\text { Inversa }\end{array}$ & Independente \\
\hline \multirow{4}{*}{1} & $\begin{array}{l}\text { F. de Avaliação } \\
\text { \% acima MS* }\end{array}$ & $\begin{array}{c}19.719,52 \\
0,00 \%\end{array}$ & $\begin{array}{c}19.762,86 \\
0,22 \%\end{array}$ & $\begin{array}{c}20.120,61 \\
2,03 \%\end{array}$ & $\begin{array}{c}20.188,32 \\
2,38 \%\end{array}$ & $\begin{array}{c}19.430,69 \\
-----\end{array}$ \\
\hline & $\mathbf{N}^{0}$ veículos & 23 & 23 & 23 & 24 & 23 \\
\hline & \begin{tabular}{|l} 
Viagem Morta \\
\end{tabular} & $\frac{55}{20 \cdot 28}$ & $\begin{array}{c}38 \\
16: 12\end{array}$ & $\frac{58}{22: 05}$ & $\frac{55}{20: 42}$ & $\begin{array}{c}53 \\
19: 28\end{array}$ \\
\hline & Horas Extras & $16: 12$ & $15: 15$ & 13:09 & $10: 43$ & $07: 35$ \\
\hline \multirow{5}{*}{2} & $\begin{array}{l}\text { F. de Avaliação } \\
\text { \% acima MS* }\end{array}$ & $\begin{array}{c}4.886,63 \\
0,00 \%\end{array}$ & $\begin{array}{c}4.931,66 \\
0.92 \%\end{array}$ & $\begin{array}{c}5.025,63 \\
2,84 \%\end{array}$ & $\begin{array}{c}5.021,13 \\
2,75 \%\end{array}$ & $\begin{array}{c}4.804,08 \\
-----\end{array}$ \\
\hline & \begin{tabular}{|l|}
$N^{0}$ veículos \\
\end{tabular} & 7 & 7 & 7 & 7 & 7 \\
\hline & $\mathrm{N}^{0}$ tripulantes & 12 & 12 & 12 & 12 & 12 \\
\hline & Viagem Morta & $06: 54$ & $06: 54$ & 09:03 & $08: 45$ & $04: 56$ \\
\hline & Horas Extras & $04: 37$ & $06: 52$ & 05:39 & $06: 15$ & 05:54 \\
\hline \multirow{5}{*}{3} & $\begin{array}{l}\text { F. de Avaliação } \\
\% \text { acima MS* }\end{array}$ & $\begin{array}{c}17.149,65 \\
0,00 \%\end{array}$ & $\begin{array}{c}17.535,11 \\
2,25 \%\end{array}$ & $\begin{array}{c}17.930,95 \\
4,56 \%\end{array}$ & $\begin{array}{c}18.017,64 \\
5,06 \%\end{array}$ & $\begin{array}{c}17.006,38 \\
----\end{array}$ \\
\hline & $\mathrm{N}^{0}$ veículos & 24 & 24 & 24 & 26 & 24 \\
\hline & $\mathrm{N}^{\circ}$ tripulantes & 52 & 56 & 56 & 52 & 52 \\
\hline & \begin{tabular}{|l|} 
Viagem Morta \\
\end{tabular} & $10: 05$ & $09: 59$ & $16: 15$ & $08: 39$ & $07: 35$ \\
\hline & Horas Extras & $00: 46$ & $00: 40$ & $02: 45$ & $00: 29$ & $00: 39$ \\
\hline \multirow{6}{*}{4} & F. de Avaliação & $14.346,23$ & $14.450,47$ & $14.822,39$ & $15.099,80$ & $14.125,98$ \\
\hline & $\%$ acima MS* & $0,00 \%$ & $0,73 \%$ & $3,32 \%$ & $5,25 \%$ & $---{ }_{-}$ \\
\hline & $\mathrm{N}^{0}$ veículos & 19 & 19 & 19 & 20 & 19 \\
\hline & $\mathrm{N}^{\circ}$ tripulantes & 44 & 45 & 46 & 43 & 43 \\
\hline & Viagem Morta & $11: 33$ & $11: 37$ & $16: 20$ & $17: 44$ & 09:19 \\
\hline & Horas Extras & $00: 00$ & 00:00 & $00: 00$ & $00: 30$ & $00: 25$ \\
\hline \multirow{6}{*}{5} & F. de Avaliação & $33.775,42$ & $34.866,61$ & $35.492,87$ & $35.134,68$ & $33.058,36$ \\
\hline & \% acima MS* & $0,00 \%$ & $3,23 \%$ & $5,08 \%$ & $4,02 \%$ & ---- \\
\hline & $\mathrm{N}^{0}$ veículos & 46 & 45 & 45 & 49 & 45 \\
\hline & $\mathbf{N}^{0}$ tripulantes & 95 & 111 & 115 & 93 & 93 \\
\hline & Viagem Morta & $27: 37$ & $27: 40$ & $30: 34$ & $29: 10$ & $26: 55$ \\
\hline & Horas Extras & $02: 03$ & $00: 19$ & $02: 55$ & 02:06 & $02: 47$ \\
\hline \multirow{6}{*}{6} & F. de Avaliação & $26.109,13$ & $26.583,02$ & $26.768,57$ & $26.748,94$ & $25.752,83$ \\
\hline & $\%$ acima MS* & $0,00 \%$ & $1,82 \%$ & $2,53 \%$ & $2,45 \%$ & ---- \\
\hline & $\mathrm{N}^{\circ}$ veículos & 35 & 36 & 35 & 37 & 34 \\
\hline & $\mathrm{N}^{0}$ tripulantes & 74 & 74 & 76 & 73 & 73 \\
\hline & Viagem Morta & $25: 29$ & $26: 27$ & $33: 17$ & $21: 58$ & $27: 38$ \\
\hline & Horas Extras & $15: 56$ & $12: 47$ & $16: 37$ & $14: 36$ & $20: 58$ \\
\hline \multirow{6}{*}{7} & F. de Avaliação & $12.513,06$ & $12.632,87$ & $12.790,48$ & $12.858,90$ & $12.299,49$ \\
\hline & $\%$ acima $\mathrm{MS} *$ & $0,00 \%$ & $0,96 \%$ & $2,22 \%$ & $2,76 \%$ & ---- \\
\hline & $\mathrm{N}^{0}$ veículos & 18 & 18 & 18 & 19 & 18 \\
\hline & $\mathrm{N}^{0}$ tripulantes & 34 & 36 & 36 & 34 & 34 \\
\hline & Viagem Morta & $08: 45$ & $08: 19$ & $10: 21$ & $06: 41$ & $05: 21$ \\
\hline & Horas Extras & $02: 58$ & $00: 24$ & $02: 29$ & $02: 12$ & $01: 55$ \\
\hline \multirow{6}{*}{8} & F. de Avaliação & $3.865,39$ & $3.874,77$ & $3.924,33$ & $3.979,83$ & $3.755,72$ \\
\hline & $\%$ acima MS* & $0,00 \%$ & $0,24 \%$ & $1,52 \%$ & $2,96 \%$ & - \\
\hline & $\mathrm{N}^{0}$ veículos & 5 & 5 & 5 & 5 & 5 \\
\hline & $\mathrm{N}^{\circ}$ tripulantes & 11 & 11 & 11 & 11 & 11 \\
\hline & Viagem Morta & $08: 20$ & $08: 20$ & 09:24 & $10: 09$ & $06: 14$ \\
\hline & Horas Extras & $00: 15$ & $00: 43$ & $00: 15$ & $00: 57$ & $00: 34$ \\
\hline
\end{tabular}

* Desvio porcentual em relação à melhor solução obtida. 
Tabela 6.8 - Resultados obtidos para o domingo utilizando custo monetário.

\begin{tabular}{|c|c|c|c|c|c|c|}
\hline Instância & Problema & $\begin{array}{c}\text { Integrada } \\
\text { Nível } 2 \\
\end{array}$ & $\begin{array}{c}\text { Integrada } \\
\text { Nível } 1 \\
\end{array}$ & $\begin{array}{l}\text { Seqüencial } \\
\text { Tradicional }\end{array}$ & $\begin{array}{l}\text { Seqüencial } \\
\text { Inversa }\end{array}$ & Independente \\
\hline \multirow{5}{*}{1} & $\begin{array}{l}\text { F. de Avaliação } \\
\text { \% acima MS* }\end{array}$ & $\begin{array}{c}6.949,53 \\
0,00 \%\end{array}$ & $\begin{array}{c}6.951,43 \\
0,03 \%\end{array}$ & $\begin{array}{c}7.180,71 \\
3,33 \%\end{array}$ & $\begin{array}{c}7.306,40 \\
5,14 \%\end{array}$ & $\begin{array}{c}.902,63 \\
-----\end{array}$ \\
\hline & $\mathrm{N}^{\circ}$ veí́culos & 10 & 10 & 10 & 10 & 10 \\
\hline & $\mathrm{N}^{0}$ tripulantes & 18 & 18 & 18 & 18 & 18 \\
\hline & Viagem Morta & 08:02 & 08:02 & $11: 36$ & $14: 22$ & 07:48 \\
\hline & Horas Extras & $05: 37$ & 05:39 & $07: 21$ & 06:01 & $03: 55$ \\
\hline \multirow{5}{*}{2} & F. de Avaliação & $3.563,92$ & $3.587,05$ & $3.699,60$ & $3.716,13$ & $3.538,26$ \\
\hline & $\begin{array}{l}\text { \% acima MS* } \\
\text { o vá́culos }\end{array}$ & $\frac{0,00 \%}{5}$ & $\frac{0,65 \%}{5}$ & $\frac{3,81 \%}{5}$ & $\frac{4,27 \%}{5}$ & ----- \\
\hline & $N^{0}$ tripulantes & 9 & 9 & 9 & $\begin{array}{l}5 \\
9\end{array}$ & $\begin{array}{l}5 \\
9\end{array}$ \\
\hline & Viagem Morta & $03: 50$ & $03: 50$ & $06: 25$ & $06: 39$ & $04: 12$ \\
\hline & Horas Extras & 06:01 & $06: 49$ & 07:26 & $07: 37$ & $05: 28$ \\
\hline \multirow{6}{*}{3} & F. de Avaliação & $12.402,59$ & $12.698,35$ & $12.993,27$ & $12.938,86$ & $12.065,09$ \\
\hline & $\%$ acima MS* & $0,00 \%$ & $2,38 \%$ & $4,76 \%$ & $4,32 \%$ & ----- \\
\hline & $\mathbf{N}^{0}$ veículos & 17 & 17 & 16 & 18 & 16 \\
\hline & $\mathrm{N}^{0}$ tripulantes & 37 & 39 & 39 & 37 & 37 \\
\hline & Viagem Morta & $07: 10$ & 07:09 & $13: 17$ & $06: 32$ & $09: 36$ \\
\hline & Horas Extras & $01: 55$ & 00:00 & $03: 47$ & $03: 35$ & $02: 32$ \\
\hline \multirow{6}{*}{4} & F. de Avaliação & $12.054,05$ & $12.553,75$ & $12.778,27$ & $12.631,78$ & $11.788,65$ \\
\hline & $\%$ acima MS* & $0,00 \%$ & $4,15 \%$ & $6,01 \%$ & $4,79 \%$ & ----- \\
\hline & $\mathbf{N}^{0}$ veículos & 15 & 15 & 15 & 16 & 15 \\
\hline & $\mathrm{N}^{0}$ tripulantes & 38 & 41 & 41 & 38 & 38 \\
\hline & Viagem Morta & 09:08 & 10:00 & $14: 57$ & $10: 11$ & $04: 53$ \\
\hline & Horas Extras & $00: 35$ & 00:00 & $03: 41$ & 01:07 & 00:00 \\
\hline \multirow{6}{*}{5} & F. de Avaliação & $21.182,21$ & $22.555,47$ & $22.828,88$ & $22.913,61$ & $20.986,51$ \\
\hline & $\%$ acima MS* & $0,00 \%$ & $6,48 \%$ & $7,77 \%$ & $8,17 \%$ & ----- \\
\hline & $\mathrm{N}^{0}$ veículos & 25 & 25 & 25 & 28 & 25 \\
\hline & $\mathrm{N}^{0}$ tripulantes & 67 & 76 & 76 & 67 & 67 \\
\hline & Viagem Morta & $19: 28$ & $18: 38$ & $22: 41$ & $25: 40$ & $18: 56$ \\
\hline & Horas Extras & $00: 32$ & $00: 32$ & $01: 34$ & $00: 56$ & 00:00 \\
\hline \multirow{6}{*}{6} & F. de Avaliação & $18.815,50$ & $18.816,26$ & $19.237,82$ & $19.800,75$ & $18.595,32$ \\
\hline & $\%$ acima MS* & $0,00 \%$ & $0,00 \%$ & $2,24 \%$ & $5,24 \%$ & ----- \\
\hline & $\mathbf{N}^{0}$ veículos & 25 & 25 & 25 & 27 & 25 \\
\hline & $\mathrm{N}^{0}$ tripulantes & 56 & 56 & 57 & 55 & 55 \\
\hline & Viagem Morta & $19: 58$ & $19: 33$ & $25: 33$ & $21: 15$ & $18: 02$ \\
\hline & Horas Extras & 08:18 & 09:29 & 08:40 & $10: 51$ & $07: 43$ \\
\hline \multirow{6}{*}{7} & F. de Avaliação & $5.896,67$ & $6.034,43$ & $6.069,82$ & $6.060,52$ & $5.861,10$ \\
\hline & $\%$ acima MS* & $0,00 \%$ & $2,34 \%$ & $2,94 \%$ & $2,78 \%$ & ----- \\
\hline & $\mathbf{N}^{0}$ veículos & 8 & 8 & 8 & 8 & 8 \\
\hline & $\mathrm{N}^{0}$ tripulantes & 17 & 18 & 18 & 17 & 17 \\
\hline & Viagem Morta & $03: 20$ & $04: 06$ & $04: 38$ & $05: 20$ & $02: 58$ \\
\hline & Horas Extras & $00: 40$ & $00: 15$ & $00: 27$ & $02: 53$ & 00:00 \\
\hline \multirow{6}{*}{8} & F. de Avaliação & $3.769,54$ & $3.769,54$ & $3.808,18$ & $3.803,57$ & $3.648,67$ \\
\hline & $\%$ acima MS* & $0,00 \%$ & $0,00 \%$ & $1,03 \%$ & $0,90 \%$ & ----- \\
\hline & $\mathrm{N}^{0}$ veículos & 5 & 5 & 5 & 5 & 5 \\
\hline & $\mathrm{N}^{0}$ tripulantes & 10 & 10 & 10 & 10 & 10 \\
\hline & Viagem Morta & 08:20 & 08:20 & 09:03 & $08: 58$ & $06: 10$ \\
\hline & Horas Extras & 00:03 & 00:03 & 00:00 & 00:00 & 00:00 \\
\hline
\end{tabular}

* Desvio porcentual em relação à melhor solução obtida. 


\subsection{Comparativo entre Pesos Empíricos e Monetários}

Os resultados anteriores da Tabela 6.5 mostram que os limitantes inferiores para o PPVT são 300 veículos e 522 tripulações (obtidos pela abordagem independente no dia útil). Estes valores são superiores aos limitantes inferiores obtidos na Tabela 6.2 (297 veículos e 501 tripulações), ou seja, a solução obtida utilizando os custos empíricos (Tabela 4.1) utiliza menos veículos e menos tripulações que a solução obtida utilizando os custos monetários (Tabela 4.2).

Este resultado pode significar duas coisas: (i) o uso dos pesos determinados empiricamente resulta em soluções melhores que o uso dos pesos baseados nos custos monetários monetários; (ii) os custos determinados empiricamente não representam a realidade existente na empresa de transporte coletivo estudada. Para responder a este questionamento, o custo da solução obtida utilizando os pesos determinados empiricamente (Tabela 4.1) foi recalculado considerando os pesos determinados na Tabela 4.2 (custo monetário).

A Tabela 6.9 apresenta a totalização, por tipo de dia, do valor obtido pela função de avaliação para as oito garagens obtida pela heurística VNS para cada uma das abordagens. O valor da função de avaliação obtida utilizando pesos determinados empiricamente foi recalculado usando os pesos determinados com base no custo monetário.

Tabela 6.9 - Peso empírico versus peso monetário.

\begin{tabular}{|c|c|c|c|c|c|c|}
\hline Instância & Peso & \begin{tabular}{|c|} 
Integrada \\
Nível 2 \\
\end{tabular} & $\begin{array}{c}\text { Integrada } \\
\text { Nível } 1 \\
\end{array}$ & \begin{tabular}{|c|} 
Seqüencial \\
Tradicional \\
\end{tabular} & $\begin{array}{c}\text { Seqüencial } \\
\text { Inversa }\end{array}$ & Independente \\
\hline \multirow{2}{*}{ DOM } & Empírico & $84.407,51$ & $85.669,29$ & $84.522,27$ & $88.719,76$ & 96 \\
\hline & Monetário & 84.6 & $86.966,28$ & 88.59 & $89.171,62$ & 23 \\
\hline \multirow{2}{*}{ DU } & Em & 252 & & 253 & 257 & 248 \\
\hline & & 25 & 258 & 262 & 26 & 85 \\
\hline \multirow{2}{*}{ SAB } & & 13 & $13 ?$ & 132 & 13 & 12 \\
\hline & Mone & $132.365,03$ & $134.637,37$ & $136.875,83$ & $137.049,24$ & $130.233,53$ \\
\hline
\end{tabular}

A Tabela 6.9 apresenta a comparação das soluções, por tipo de dia, entre o peso empírico e o peso com base no custo monetário. Observe que as soluções obtidas utilizando os valores dos pesos calculados empiricamente possuem os menores valores para o custo operacional. 
Deste modo, pode-se concluir que o uso dos custos determinados empiricamente apresenta soluções melhores que o uso dos custo monetários ou que o cálculo dos custos monetários não foi realizado de modo a refletir a realidade. A Tabela B.1 do Anexo B apresenta os valores da função de avaliação calculados para cada instância do problema.

\subsection{Testes dos Métodos de Exploração da Vizinhança}

A Figura 6.1 apresenta a evolução da função de avaliação durante a resolução da instância de maior porte do problema (referente ao dia útil) utilizando a abordagem integrada nível 1 , tendo sido testadas as seqüenciais de movimentos da exploração da vizinhança: $A$ (Figura 5.2), $B$ (Figura 5.3), $C$ (Figura 5.4), $A B C$ (Figura 5.5) e NSLO (Figura 5.6). Os resultados completos estão no Anexo C nas Tabelas C.1 a C. 15

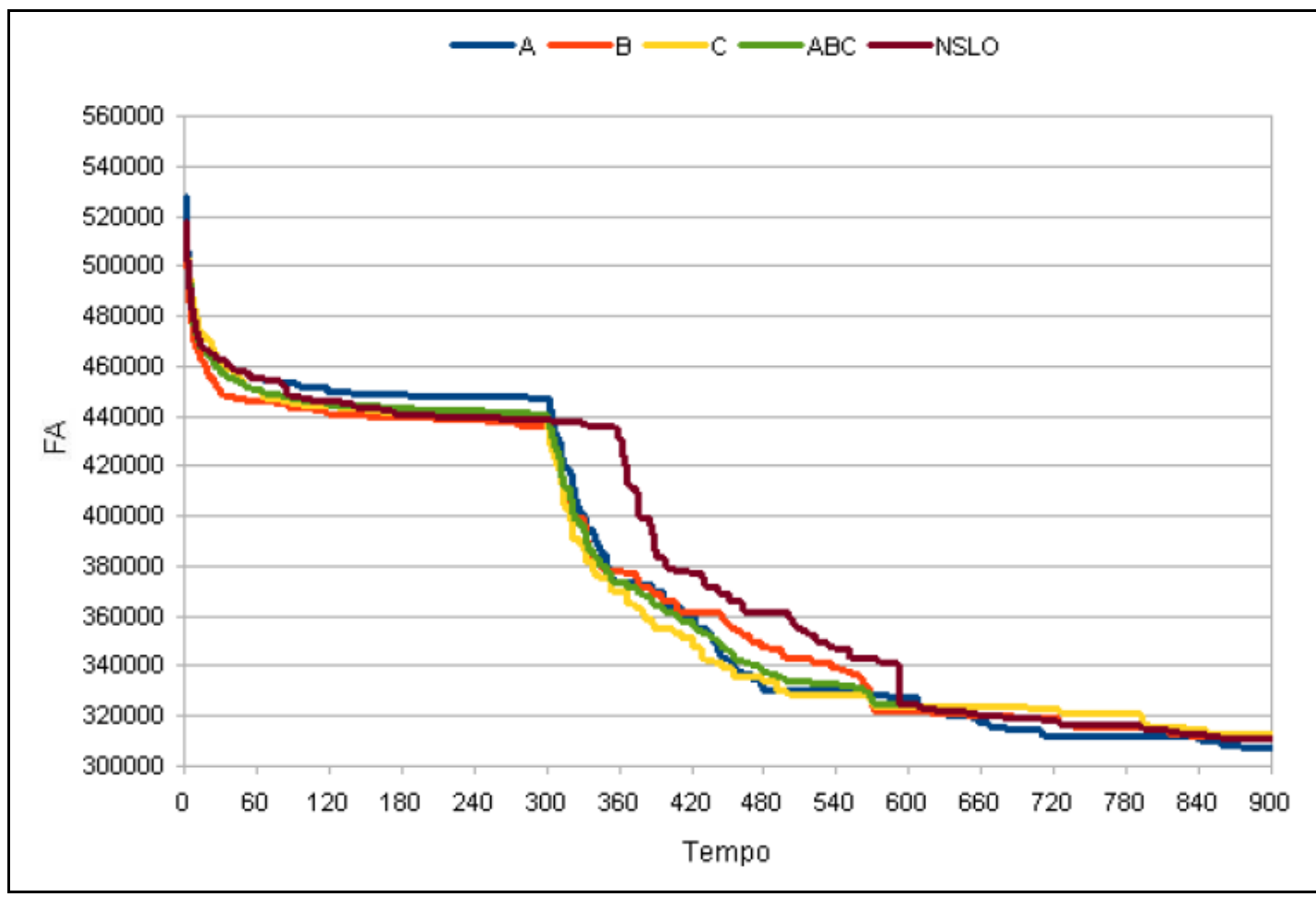

Figura 6.1 - Influência da seqüência de movimentos sobre a FA.

O gráfico na Figura 6.1 mostra que independentemente da seqüência de 
movimentos utilizadas, as soluções obtidas são muito próximas e não foram encontradas diferenças significativas entre os resultados obtidos com cada um das seqüências de exploração de movimentos da vizinhança. Deste modo, é possível concluir que a utilização de qualquer uma das cinco seqüências de movimentos de exploração da vizinhança testadas não influenciam na qualidade do resultado obtido.

\subsection{Evolução da Função de Avaliação}

Nesta seção são apresentados os resultados de alguns testes computacionais realizados considerando o tempo computacional. O gráfico da Figura 6.2 mostra a evolução da função de avaliação durante a resolução do PPVT utilizando a abordagem integrada nível 1 (PPV com características do PPT).

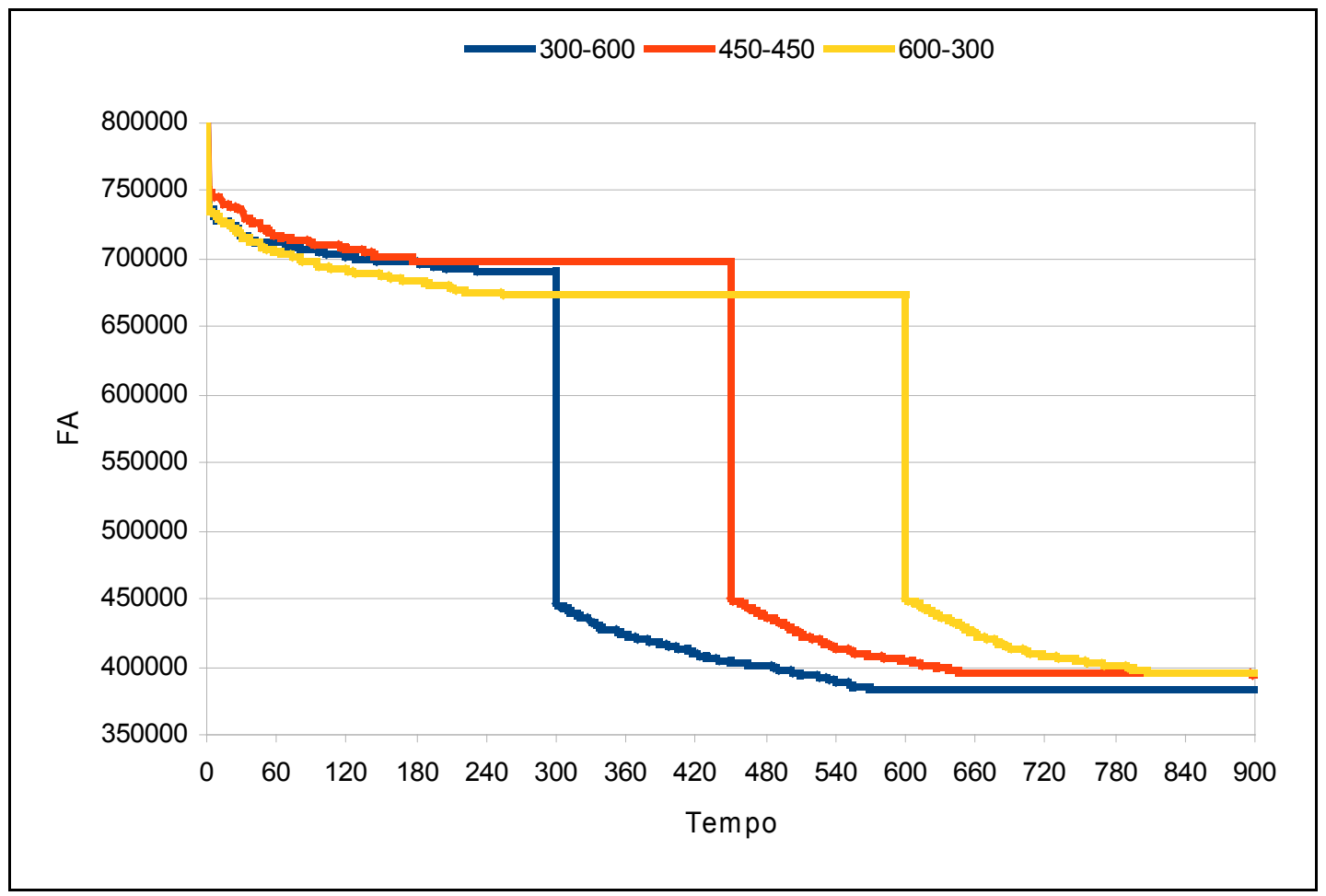

Figura 6.2 - Divisão do tempo entre o PPV е o PPT.

O tempo de execução da heurística VNS foi fixado em 15 minutos. Entretanto este tempo deve ser dividido entre a resolução da programação dos veículos e a programação das tripulações quando utilizadas as abordagens 
seqüenciais, independente ou integrada nível 1 (nestas abordagens o PPV e o PPT são resolvidos separadamente ao contrário do que ocorre na abordagem integrada nível 2). Visando determinar qual deveria ser a melhor divisão de tempo entre o PPV e o PPT, foram executados testes com as seguintes divisões: (i) 300-600, 5 minutos (300 segundos) para o PPV e 10 minutos (600 segundos) para o PPT; (ii) 450-450, 7.5 minutos (450 segundos) para o PPV e 7.5 minutos (450 segundos) para o PPT; (iii) 600-300, 10 minutos (600 segundos) para o PPV e 5 minutos (300 segundos) para o PPT.

Através do gráfico da Figura 6.2 pode-se observar que o menor valor da função de avaliação é obtido quando o tempo dedicado à resolução da programação das tripulações é superior ao tempo dedicado à programação dos veículos.

A Figura 6.3 mostra a evolução do melhor valor da função de avaliação durante a resolução do PPVT utilizando a abordagem integrada nível 2 (PPV e PPT simultâneos) até o tempo máximo de uma hora. Observe que, conforme maior o tempo computacional permitido, melhor será a qualidade da solução encontrada.

No entanto, a redução no valor da função de avaliação possui uma velocidade menor conforme cresce o tempo computacional. Isto demonstra que, dependendo da qualidade esperada da solução, é interessante retornar à melhor solução encontrada após um determinado tempo, não permitindo que o VNS seja executado por um tempo computacional muito elevado. É válido ressaltar que depois de 15 minutos de execução da metaheurística VNS a melhoria no valor da função de avaliação é pequena. 


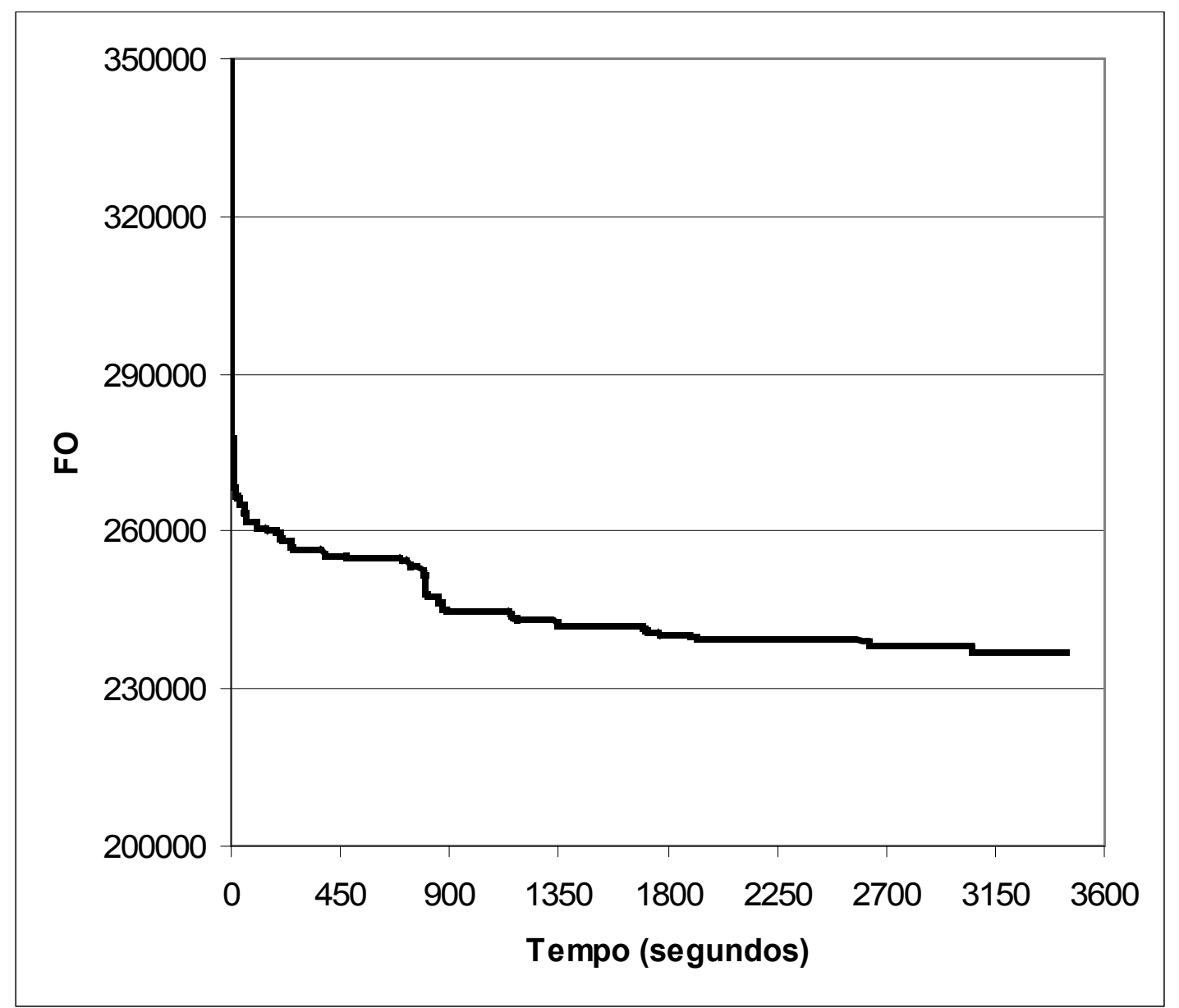

Figura 6.3 - Evolução do valor da melhor solução na abordagem integrada nível 2.

\subsection{Variação nos Resultados Obtidos}

Cada instância de testes foi submetida cinco vezes a cada abordagem implementada para o PPVT e o menor resultado obtido foi adotado como sendo a solução da programação dos veículos e dos tripulantes. 
Tabela 6.10 - Variação nos resultados obtidos para o dia útil.

\begin{tabular}{|c|c|c|c|c|c|c|}
\hline Instância & FA & \begin{tabular}{|c|} 
Integrada \\
Nível 2 \\
\end{tabular} & $\begin{array}{c}\text { Integrada } \\
\text { Nível } 1 \\
\end{array}$ & $\begin{array}{c}\text { Seqüencial } \\
\text { Tradicional }\end{array}$ & $\begin{array}{c}\text { Seqüencial } \\
\text { Inversa } \\
\end{array}$ & Independente \\
\hline \multirow{3}{*}{1} & Menor & 114.772 & 117.067 & 119.363 & 126.263 & 111.429 \\
\hline & Média & 116.374 & 118.701 & 121.029 & 128.006 & 112.984 \\
\hline & Maior & 119.311 & 121.697 & 124.084 & 130.768 & 115.836 \\
\hline \multirow{3}{*}{2} & Menor & 31.425 & 32.054 & 32.682 & 32.878 & 31.399 \\
\hline & Média & 32.109 & 32.133 & 33.393 & 34.089 & 31.639 \\
\hline & Maior & 32.890 & 32.191 & 34.206 & 36.838 & 31.932 \\
\hline \multirow{3}{*}{3} & Menor & 111.007 & 113.227 & 115.447 & 116.458 & 110.377 \\
\hline & Média & 113.675 & 115.948 & 118.222 & 119.290 & 111.395 \\
\hline & Maior & 114.975 & 117.275 & 119.574 & 120.621 & 111.968 \\
\hline \multirow{3}{*}{4} & Menor & 97.286 & 99.232 & 102.174 & 101.177 & 97.225 \\
\hline & Média & 99.605 & 101.597 & 104.610 & 103.827 & 97.827 \\
\hline & Maior & 101.652 & 103.685 & 106.760 & 105.718 & 98.787 \\
\hline \multirow{3}{*}{5} & Menor & 224.162 & 228.645 & 233.128 & 233.990 & 222.426 \\
\hline & Média & 228.478 & 233.048 & 237.617 & 238.496 & 226.581 \\
\hline & Maior & 232.710 & 237.364 & 242.018 & 242.913 & 229.772 \\
\hline \multirow{3}{*}{6} & Menor & 186.497 & 190.227 & 193.957 & 194.959 & 186.435 \\
\hline & Média & 190.104 & 193.906 & 197.708 & 198.729 & 190.730 \\
\hline & Maior & 192.987 & 196.847 & 200.706 & 201.743 & 199.178 \\
\hline \multirow{3}{*}{7} & Menor & 88.669 & 89.937 & 91.701 & 92.286 & 88.174 \\
\hline & Média & 89.484 & 90.952 & 92.918 & 93.511 & 89.658 \\
\hline & Maior & 91.022 & 92.842 & 94.663 & 95.267 & 91.453 \\
\hline \multirow{3}{*}{8} & Menor & 44.975 & 45.803 & 46.774 & 46.927 & 44.224 \\
\hline & Média & 45.355 & 46.093 & 47.169 & 48.333 & 44.228 \\
\hline & Maior & 45.556 & 46.467 & 47.378 & 50.114 & 44.229 \\
\hline \multirow{3}{*}{ Total } & Menor & 787.786 & 802.965 & 819.779 & 828.480 & 781.312 \\
\hline & Média & 801.508 & 816.429 & 834.445 & 844.993 & 793.646 \\
\hline & Maior & 816.128 & 831.093 & 849.815 & 863.361 & 811.187 \\
\hline
\end{tabular}

As Tabelas 6.10 (referente ao dia útil), 6.11 (referente ao sábado) e 6.12 (referente ao domingo) apresentam o menor, o maior e a média dos valores obtidos para cada uma das instâncias testadas. Observe que não existem grandes variações entre a média e os menores valores obtidos para cada instância, mostrando que as abordagens implementadas possuem uma boa robustez. 
Tabela 6.11 - Variação nos resultados obtidos para o sábado.

\begin{tabular}{|c|c|c|c|c|c|c|}
\hline Instância & FA & \begin{tabular}{|c|} 
Integrada \\
Nível 2 \\
\end{tabular} & $\begin{array}{c}\text { Integrada } \\
\text { Nível } 1 \\
\end{array}$ & $\begin{array}{l}\text { Seqüencial } \\
\text { Tradicional }\end{array}$ & $\begin{array}{c}\text { Seqüencial } \\
\text { Inversa }\end{array}$ & Independente \\
\hline \multirow{3}{*}{1} & Menor & 64.227 & 65.511 & 66.796 & 69.031 & 62.356 \\
\hline & Média & 64.548 & 65.839 & 67.130 & 74.336 & 62.668 \\
\hline & Maior & 65.750 & 67.065 & 68.380 & 81.579 & 63.835 \\
\hline \multirow{3}{*}{2} & Menor & 21.129 & 21.552 & 22.073 & 21.974 & 21.094 \\
\hline & Média & 21.412 & 21.840 & 22.369 & 22.268 & 21.820 \\
\hline & Maior & 21.512 & 21.942 & 22.473 & 22.372 & 23.059 \\
\hline \multirow{3}{*}{3} & Menor & 80.523 & 82.133 & 84.441 & 83.744 & 79.748 \\
\hline & Média & 82.540 & 83.843 & 86.555 & 85.841 & 82.599 \\
\hline & Maior & 84.512 & 86.202 & 88.623 & 87.892 & 84.089 \\
\hline \multirow{3}{*}{4} & Menor & 67.414 & 68.321 & 70.111 & 70.340 & 66.461 \\
\hline & Média & 68.029 & 69.174 & 70.750 & 71.045 & 66.911 \\
\hline & Maior & 68.693 & 70.067 & 71.440 & 71.996 & 68.052 \\
\hline \multirow{3}{*}{5} & Menor & 151.135 & 154.158 & 158.188 & 155.268 & 148.534 \\
\hline & Média & 152.490 & 155.539 & 159.606 & 159.426 & 150.447 \\
\hline & Maior & 154.501 & 157.591 & 161.712 & 164.444 & 151.341 \\
\hline \multirow{3}{*}{6} & Menor & 117.459 & 119.573 & 122.594 & 122.181 & 114.038 \\
\hline & Média & 118.272 & 120.075 & 123.442 & 123.711 & 116.099 \\
\hline & Maior & 118.950 & 120.900 & 124.149 & 124.863 & 118.498 \\
\hline \multirow{3}{*}{7} & Menor & 54.305 & 55.391 & 56.477 & 56.837 & 52.979 \\
\hline & Média & 54.735 & 55.830 & 56.924 & 57.423 & 54.071 \\
\hline & Maior & 55.587 & 56.699 & 57.810 & 58.392 & 55.883 \\
\hline \multirow{3}{*}{8} & Menor & 17.511 & 17.680 & 17.763 & 18.211 & 17.224 \\
\hline & Média & 17.669 & 17.720 & 17.794 & 18.377 & 17.226 \\
\hline & Maior & 17.741 & 17.761 & 17.810 & 18.458 & 17.232 \\
\hline \multirow{3}{*}{ Total } & Menor & 573.703 & 584.319 & 598.443 & 597.586 & 562.434 \\
\hline & Média & 579.694 & 589.860 & 604.571 & 612.429 & 571.841 \\
\hline & Maior & 587.246 & 598.227 & 612.397 & 629.996 & 581.989 \\
\hline
\end{tabular}

Entretanto, existe uma diferença de valores pouco significativa entre o menor e o maior valor encontrado para cada instância. Possivelmente, um aumento no tempo computacional de execução do VNS irá reduzir estas variações tornando as abordagens implementadas mais robustas. 
Tabela 6.12 - Variação nos resultados obtidos para o domingo.

\begin{tabular}{|c|c|c|c|c|c|c|}
\hline Instância & FA & \begin{tabular}{|c|} 
Integrada \\
Nível 2 \\
\end{tabular} & \begin{tabular}{c|} 
Integrada \\
Nível 1 \\
\end{tabular} & $\begin{array}{c}\text { Seqüencial } \\
\text { Tradicional }\end{array}$ & $\begin{array}{c}\text { Seqüencial } \\
\text { Inversa } \\
\end{array}$ & Independente \\
\hline \multirow{3}{*}{1} & Menor & 30.490 & 30.753 & 31.710 & 30.691 & 30.302 \\
\hline & Média & 30.525 & 30.826 & 31.746 & 31.448 & 30.348 \\
\hline & Maior & 30.582 & 30.949 & 31.805 & 31.805 & 30.390 \\
\hline \multirow{3}{*}{2} & Menor & 15.841 & 15.899 & 16.557 & 16.475 & 15.730 \\
\hline & Média & 15.870 & 15.939 & 16.587 & 16.505 & 15.944 \\
\hline & Maior & 15.898 & 15.986 & 16.616 & 16.534 & 16.243 \\
\hline \multirow{3}{*}{3} & Menor & 57.131 & 58.274 & 59.416 & 60.364 & 55.467 \\
\hline & Média & 57.511 & 58.662 & 59.812 & 61.931 & 55.839 \\
\hline & Maior & 58.726 & 59.901 & 61.075 & 65.070 & 57.032 \\
\hline \multirow{3}{*}{4} & Menor & 56.754 & 57.889 & 59.024 & 59.397 & 55.189 \\
\hline & Média & 57.761 & 58.917 & 60.071 & 63.495 & 56.695 \\
\hline & Maior & 60.027 & 61.228 & 62.428 & 72.282 & 58.279 \\
\hline \multirow{3}{*}{5} & Menor & 102.094 & 104.136 & 106.861 & 106.178 & 101.207 \\
\hline & Média & 104.037 & 106.118 & 108.755 & 108.536 & 104.871 \\
\hline & Maior & 105.607 & 107.719 & 110.538 & 110.101 & 107.439 \\
\hline \multirow{3}{*}{6} & Menor & 87.498 & 88.298 & 90.998 & 91.468 & 85.748 \\
\hline & Média & 88.599 & 88.457 & 92.142 & 92.645 & 86.687 \\
\hline & Maior & 90.226 & 88.642 & 93.835 & 94.320 & 88.497 \\
\hline \multirow{3}{*}{7} & Menor & 27.596 & 27.747 & 28.802 & 28.700 & 27.456 \\
\hline & Média & 27.926 & 28.102 & 29.147 & 29.043 & 28.209 \\
\hline & Maior & 28.958 & 28.261 & 30.223 & 30.116 & 28.873 \\
\hline \multirow{3}{*}{8} & Menor & 16.372 & 16.378 & 16.935 & 17.027 & 16.312 \\
\hline & Média & 16.565 & 16.577 & 17.228 & 17.227 & 16.312 \\
\hline & Maior & 16.699 & 16.708 & 17.407 & 17.367 & 16.312 \\
\hline \multirow{3}{*}{ Total } & Menor & 290.437 & 295.177 & 302.748 & 302.357 & 285.933 \\
\hline & Média & 294.325 & 299.201 & 306.759 & 311.681 & 292.274 \\
\hline & Maior & 300.599 & 304.766 & 313.476 & 326.741 & 298.325 \\
\hline
\end{tabular}




\section{CONCLUSÕES}

Este trabalho abordou o Problema de Programação Integrada de Veículos e Tripulações (PPVT) no contexto do transporte coletivo urbano por ônibus. Trata-se de um problema relevante, tendo em vista não só a perspectiva de redução de custos para as empresas operadoras, como também a possibilidade de redução das tarifas pagas pelos usuários, buscando, assim, contribuir para evitar ou favorecer a utilização do sistema de transporte coletivo urbano por ônibus.

Uma das dificuldades desse problema é a interação e interdependência entre a programação dos veículos e dos tripulantes, ou seja, qualquer mudança na programação dos veículos afeta a programação dos tripulantes e vice-versa. Tendo em vista que ambos são problemas complexos, de natureza combinatória, em que o número de possíveis soluções é muito elevado, os mesmos são normalmente resolvidos de maneira seqüencial, não integrada.

Buscou-se, neste trabalho, uma abordagem integrada, em que ambos os problemas são resolvidos simultaneamente, permitindo incorporar diversas restrições, que são consideradas pelas empresas para avaliar a viabilidade das programações. Dentre estas restrições pode-se citar, por exemplo, trocas de linhas por um veículo, trocas de veículo por uma tripulação, duplas pegadas, entre outras.

Para tanto, foi proposta uma estratégia de solução baseada na metaheurística Busca em Vizinhança Variável (VNS), a qual foi aplicada a instâncias de problemas reais. Os resultados obtidos indicam que essa abordagem se mostrou adequada e comprovou ser eficiente para a utilização em problemas de grandes dimensões, os quais podem ser aplicados na prática à realidade das cidades brasileiras, permitindo reduzir os custos operacionais do sistema de transporte público. Também ficou evidente que quanto maior a dimensão do problema em termos do número de viagens diárias a serem realizadas, maior será a interação entre a programação dos veículos e a programação dos tripulantes e, conseqüentemente, maior será a possibilidade de redução dos custos operacionais.

Os resultados obtidos indicam também:

- A abordagem integrada de nível 2 (PPV e PPT simultaneamente) 
possibilita obter soluções de melhor qualidade para o PPVT. Basicamente, os resultados obtidos pela abordagem integrada de nível 2 são melhores que os obtidos pela abordagem integrada de nível 1 (PPV com características das tripulações), os quais por sua vez são melhores que as soluções obtidas pelas abordagens seqüenciais, tanto a tradicional (veículo primeiro, tripulação depois) quanto a inversa (tripulação primeiro, veículo depois);

- Não existem diferenças significativas entre as solução obtidas utilizando as diferentes seqüências de movimentos de exploração do espaço de soluções testadas;

- Os pesos ajustados empiricamente levam a soluções de qualidade superior às dos pesos determinados com base nos custos monetários, ou os pesos determinados com base nos custos monetários não foram calculados de forma apropriada;

- A programação das tripulações necessita de um tempo de processamento computacional superior ao tempo de processamento computacional da programação dos veículos;

- Quanto maior o tempo de execução, melhor será a qualidade da solução obtida; entretanto, a diferença entre uma solução obtida em 15 minutos e uma obtida após 60 minutos é relativamente pequena.

Entre as propostas para a continuidade do presente trabalho, pode-se sugerir a implementação da programação mensal integrada de veículos e tripulantes, a qual compreende a escala das tripulações considerando as folgas e/ou descansos semanais.

Outra sugestão para a continuidade da pesquisa é a integração entre a definição da tabela de horários, a programação dos veículos e a programação dos tripulantes. Desta forma, alterações na tabela de horários das viagens podem reduzir o custo operacional da programação de veículos e tripulações. Entretanto, a demanda de passageiros deverá ser atendida.

A programação integrada de veículos e tripulantes de ônibus para instâncias com múltiplas garagens também é uma proposta a ser considerada para a 
continuidade da pesquisa. Neste tipo de problema, existem múltiplas garagens e os veículos não necessitam iniciar e terminar a sua jornada diária em uma mesma garagem. 


\section{REFERÊNCIAS}

AGUIAR, M. R. Avaliação dos objetivos de política tarifária sob o enfoque da elasticidadetarifa e elasticidade-renda da demanda: o caso da RMSP. Trabalhos Técnicos em Eventos da ANTP. 2001. Disponível na internet via www. URL: http://portal.antp.org.br/Eventos/ Congressos/13 ANTP/Trabalhos/012/html/012.html. Acessado em 01/07/2007.

ANTP. Disponível na internet via www. URL: http://www.antp.org.br/. Acessado em 10/06/2007.

ARABEYRE, J. P. et al. The airline crew scheduling problem: a survey. Transportation Science, n. 3, p. 140-163. 1969.

BALL, M.; BODIN, L.; DIAL, R. Experimentation with a computerized system for scheduling mass transit vehicles and crews. Computer Scheduling of Public Transport, Urban Passenger Vehicle and Crew Scheduling, p. 313-334. 1981.

BALL, M.; BODIN, L.; DIAL, R. A matching based heuristic for scheduling mass transit crews and vehicles. Transportation Science, n. 17, v. 1, p. 4-31. 1983.

BALL, M.; ROBERTS, A. A graph partitioning approach to airline crew scheduling. Transportation Science, n. 19, v. 2, p. 107-126. 1985

BARNHART, C. et al. Branch-and-price: column generation for solving huge integer programs. Operations Research, v. 46, p. 316-329. 1998.

BLAIS, J.; LAMONT, J.; ROUSSEAU, J. The HASTUS vehicle and manpower scheduling systems at society de transport de la communate urbane de montreal. Interfaces, n. 20, v. 1, p. 26-42. 1990.

BODIN, L. et al. Routing and scheduling of vehicles and crews - the state of the art. Computers and Operations Research, n. 10, v. 2, p. 63-211. 1983.

CEDER, A.; FJORNES, B.; STERN, H. OPTIBUS: a scheduling package. Computer-aided Transit Scheduling, Lecture Notes in Economics and Mathematical Systems, v. 308, p. 212-225. 1988.

CUNHA, C. B. Contribuição à Modelagem de Problemas em Logística e Transportes. Tese (livre docência), Escola Politécnica 1. ed. São Paulo: Universidade de São Paulo, 2006. $315 \mathrm{p}$.

DESROCHERS, M.; SOUMIS, F. A column generation approach to the urban transit crew scheduling problem. Transportation Science, v. 23, p. 1-13. 1989.

DESROCHERS, M. et al. CREW-OPT: subproblem modeling in a column generation approach to urban crew scheduling. Computer-aided Transit Scheduling, Lecture Notes in Economics and Mathematical Systems, Desrochers e Rousseau (eds.), Springer-Verlag, Berlim, v. 386, p. 395-406. 1992.

ERNST, A. T. et al. An annotated bibliography of personnel scheduling and rostering. Annals of Operations Research, v. 127, p. 21-144. 2004. 
ETSCHMAIER, M. M.; MATHAISEL, D. F. X. Airline scheduling: an overview. Transportation Science, n. 19, v. 2, p. 127-138. 1985.

FISCHETTI, M. et al. A polyhedral approach to simplified crew scheduling and vehicle scheduling problems. Management Science, n. 47, v. 6, p. 833-850. 2001.

FORES, S.; PROLL, L.; WREN, A. An improved ILP system for driver scheduling. Computer-aided Transit Scheduling, Wilson, N. H. M. (ed.), Springer-Verlag, Berlim , p. 43-61. 1999.

FREITAS, S. L. O.; CARDOSO, G.; FERNANDES Jr., J. L. Análise das características geométricas de corredores de ônibus: estudo na cidade de Porto Alegre, RS. Trabalhos Técnicos em Eventos da ANTP. 2001. Disponível na internet via www. URL: http://portal.antp.org.br/Eventos/Congressos/13 ANTP/Trabalhos/186/html/168.html . Acessado em 01/07/2007.

FRELING, R.; WAGELMANS, P.; PAIXÃO, M. An overview of models and techniques for integrating vehicle and crew scheduling. Computer-Aided Transit Scheduling, Lecture Notes in Economics and Mathematical Systems, Wilson, N. H. M. (ed.), Springer-Verlag, Berlim, v. 471, p. 441-460. 1999.

FRELING, R.; HUISMAN, D.; WAGELMANS, A. Applying an integrated approach to vehicle and crew scheduling in practice. Computer-Aided Transit Scheduling of Public transport, Lecture Notes in Economics and Mathematical Systems, S. Vo $\beta$, J. R. Daduna (eds), Springer, Berlim, v. 505, p. 73-90. 2001.

FRELING, R.; HUISMAN, D.; WAGELMANS, A. Models and algorithms for integration of vehicle and crew scheduling. Journal of Scheduling, v. 6, n. 1, p. 63-85. 2003.

FRIBERG, C.; HAASE, K. An exact branch and cut algorithm for the vehicle and crew scheduling problem. Computer-Aided Transit Scheduling, Wilson, N. H. M. (ed.), Springer-Verlag, Berlim, p. 63-80. 1999.

GAFFI, A.; NONATO, M. An integrated approach to ex-urban crew and vehicle scheduling. Computer-aided Transit Scheduling, Lecture Notes in Economics and Mathematical Systems, Wilson, N. H. M. (ed.), Springer, v. 471, p. 103-128. 1999.

GLOVER, F. Future paths for Integer Programming and links to Artificial Intelligence. Computers and Operations Research, v. 5, p.533-549. 1986.

GOPALAKRISHNAN, B.; JOHNSON, E. L. Airline crew scheduling: state-of-the-art. Annals of Operations Research, n. 140, v. 1, p. 305-337. 2005.

HAASE, K.; FRIBERG, C. An exact algorithm for the vehicle and crew scheduling problem. Computer-aided Transit Scheduling, Lecture Notes in Economics and Mathematical Systems, Wilson, N. H. M. (ed.), Springer, v. 471, p. 63-80. 1999.

HAASE, K.; DESAULNIERS, G.; DESROSRIERS, J. Simultaneous vehicle and crew scheduling in urban mass transit systems. Transportation Science, v. 35, n. 3, p. 286-303. 2001.

HUISMAN, D.; FRELING, R.; WAGELMANS, A. P. M. A dynamic approach to vehicle 
scheduling. Econometric Institute Report, Econometric Institute, Erasmus University Rotterdam, n. 225, v. 2. 2001.

HUISMAN, D.; FRELING, R.; WAGELMANS, A. P. M. Multiple-depot integrated vehicle and crew scheduling. Econometric Institute Report, Econometric Institute, Erasmus University Rotterdam, n. 2001-17. 2003.

HUISMAN, D.; WAGELMANS, A. P. M. A solution approach for dynamic vehicle and crew scheduling. Econometric Institute Report, v. 2. 2004.

HUISMAN, D.; WAGELMANS, A. P. M. A solution approach for dynamic vehicle and crew scheduling. European Journal of Operational Research, v. 172, ed. 2, p. 453-471. 2006.

IBGE (2007). Disponível na internet via www. URL: http://www.ibge.gov.br/home/. Acessado em 12/06/2007.

KLABJAN, D. et al. Airline crew scheduling with time windows and plane count constraints. Transportation Science, n. 3, v. 36, p. 337-348. 2002.

MARINHO, E. H. et al. Busca Tabu Aplicada ao Problema de Programação de Tripulações de Ônibus Urbano. In: SIMPÓSIO BRASILEIRO DE PESQUISA OPERACIONAL, XXXVI, 2004, São João Del Rei. Anais do XXXVI SBPO. São João Del Rei, SOBRAPO, 2004. p. 1471-1482.

MLADENOVIC, N. \& HANSEN, P. Variable neighborhood Search. Computers and Operations Research, v. 24, n. 11, p. 1097-1100. 1997.

MOURA, A. V.; YUNES, T. H.; SOUZA, C. C. A hybrid approach for solving large scale crew scheduling problems with constraint programming and integer programming. Second Workshop on Practical Aspects of Declarative Languages, Lecture Notes in Computer Science. Heidelebrg: Springer. 2000.

NTU. Disponível na internet via www. URL: http://www.ntu.org.br/novosite/arquivos/anuario2006 2007.pdf. Acessado em $13 / 05 / 2008$.

PEDROSA, D.; CONSTANTINO, M. Days-off scheduling in public transport companies. Computer-aided Scheduling of Public Transport, Lecture Notes in Economics and Mathematical Systems, Springer, v. 505, p. 215-232. 2001.

Planilha Tarifária 2007. Disponível na internet via www. URL: http://www.natal.rn.gov.br/ sttu/paginas/arquivos/PLANILHATARIF\%C3\%81RIA\%20-\%20resumo.pdf.

Acessado em 18/02/2008.

REIS, J. A. Técnicas de otimização aplicadas à programação diária de veículos e de tripulações de ônibus. Monografia (curso de Engenharia de Produção), 1. ed. Ouro Preto: Universidade Federal de Ouro Preto, 2006. 70 p.

REIS, J. A.; SILVA, G. P.; SOUZA, M. J. F. Otimização integrada no sistema de transporte público. In: CONGRESSO DE PESQUISA E ENSINO EM TRANSPORTES, XX, 2006, Brasília. Anais do XX ANPET. Brasília, ANPET, 2006. v. II, p. 717-728. 
SILVA, G. P.; GUALDA, N. D. F. Um Algoritmo de Geração de Arcos para o Problema de Programação de Veículos. Transportes, Rio de Janeiro, v. 8, n. 1, p. 35-55. 2000.

SILVA, G. P.; GUALDA, N. D. F. O Método Arcgen para Programação de Veículos: Um Estudo de Caso da Cidade de Belo Horizonte. In: Congresso de Pesquisa e Ensino em Transportes, 15., Campinas, 2001. Anais: Panorama Nacional da Pesquisa em Transportes 2001 - v.1, Campinas, ANPET, p. 129-137. 2001.

SILVA, G. P. Uma metodologia baseada na técnica da geração de arcos para o problema de programação de veículos, Tese (doutorado em Enegnharia de Transportes), 1. ed. Escola Politécnica, Universidade de São Paulo, 2001. 146 p.

SILVA, G. P.; SOUZA, M. J. F.; ATZINGEN J. Um método híbrido de geração de colunas para otimizar a mão de obra do sistema de transporte público. SIMPÓSIO BRASILEIRO DE PESQUISA OPERACIONAL, XXXVI, 2004, São João Del Rei. Anais do XXXVI SBPO. São João Del Rei, SOBRAPO, p. 1989-1995. 2004.

SILVER, E.A. An overview of heuristic solution methods. Journal of the Operational Research Society, n. 55, v. 9, p. 936-956. 2004.

SMITH, B. M.; WREN, A. VAMPIRES and TASC: two successfully applied bus scheduling programs. Computer Scheduling of Public Transport, Wren A., Amsterdam. 1981

SMITH, B. M.; WREN, A. A bus crew scheduling system using a set covering formulation. Transportation Research, v. 22A, p. 97-108. 1988

SOUZA, M.J.F. et al. Metaheurísticas aplicadas ao problema de programação de tripulações no sistema de transporte público, Tendências em Matemática Aplicada e Computacional, v. 5, n. 12 , p. 357-368. 2004.

SPTRANS Expresso Tiradentes: transformar e urbanizar o meio ambiente. São Paulo, 2006, p. 23-54.

VALOUXIS, C.; HOUSOS, E. Combined bus and driver scheduling. Computers and Operations Research, Elsevier, v. 29, n. 3, p. 243-259. 2002.

VANCE, P.H. et al. Airline crew scheduling: a new formulation and decomposition algorithm. Operations Research, n. 45, v. 2, p. 188-200. 1995.

WREN, A.; GUALDA, N. D. F. Integrated Scheduling of Buses and Drivers. Computeraided Scheduling of Public Transport, Lecture Notes in Economics and Mathematical Systems, Wilson, N.H.M. (ed.), Cambridge MA. Springer-Verlag, v. 471, p.155-176. 1999. 


\section{Anexo A}

PLANILHA TARIFÁRIA - RESUMO (com Renovação \& Melhorias) Cálculo setembro/2007

\begin{tabular}{|c|c|c|c|c|c|}
\hline SISTEMA & $\underline{1.74206988}$ & & & & \\
\hline INSUMOS & & & FROTA & & \\
\hline Combustivel................ & 1,7213 & & $\begin{array}{l}\text { Frota Total......... } \\
\text { Frota Efetiva...... }\end{array}$ & $\begin{array}{l}704 \\
639\end{array}$ & \\
\hline Pneu Novo.................. & 1050,681 & & & & \\
\hline $\begin{array}{l}\text { Recapagem............ } \\
\text { Câmara de ar............ }\end{array}$ & $\begin{array}{r}275,000 \\
75,000\end{array}$ & & $\frac{\text { Faixa etária }}{\text { de } 0 \text { a } 1 \text { ano.... }}$ & $\frac{\text { Qtd. veículos }}{111}$ & \\
\hline Protetor........................... & 25,000 & & $\begin{array}{l}\text { de } 1 \text { a } 2 \text { anos.. } \\
\text { de } 2 \text { a } 3 \text { anos.. }\end{array}$ & $\begin{array}{r}140 \\
44\end{array}$ & \\
\hline $\begin{array}{l}\text { Veiculo Novo............. } \\
\text { Seguro/beneficios }\end{array}$ & $\begin{array}{r}200.525,57 \\
7.185,78\end{array}$ & & $\begin{array}{l}\text { de } 3 \text { a } 4 \text { anos.. } \\
\text { de } 4 \text { a } 5 \text { anos.. }\end{array}$ & $\begin{array}{l}29 \\
71\end{array}$ & \\
\hline seguro obrigatorio & 480,17 & & de 5 a 6 anos.. & 62 & \\
\hline Seg. Resp.Clvil & 1335,84 & & de 6 a 7 anos.. & Idade & \\
\hline Vale refelçăo & 4476,08 & & acima 7 anos.. & medla- & 4,18 \\
\hline fardamento & 893,39 & & & & \\
\hline Sal. Motorista (R\$).... & 1000,99 & & Pass. Equival. .. & $7.637 .344,1 \mathrm{~s} /$ desconto & 5.997 .653 \\
\hline Sal. Cobrador (R\$).... & 800,59 & & Km Percorridos. & $4.605 .691,25 \mathrm{~d} /$ desconto & 3.279 .383 \\
\hline Sal. Despach. (R\$).... & 920,91 & & $\begin{array}{l}\text { Pass. p/Veículo } \\
\text { P.M.M. ............ }\end{array}$ & $\begin{array}{l}11.952,03 \% \text { estud } \\
7.207,65\end{array}$ & $35,35 \%$ \\
\hline CUSTOS & $\mathrm{R} \$ / \mathrm{Km}$ & R\$/Veiculo & R\$/Mês & $\%$ Custo Total & \\
\hline Combustivel............... & 0,6133 & $4.420,53$ & $2.824 .720,77$ & 23,241 & \\
\hline Lubrificantes............... & 0,0689 & 496,26 & $317.111,05$ & 2,609 & \\
\hline 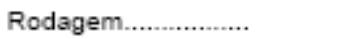 & 0,0954 & 687,85 & $439.533,43$ & 3,616 & \\
\hline Deprec. Frota & 0,2125 & 1.531 .44 & $978.591,15$ & 8,052 & \\
\hline Deprec. Máq/Equip.... & 0,0028 & 20,05 & $12.813,58$ & 0,105 & \\
\hline Remuner. Frota ......... & 0,1373 & 989,71 & $632.427,25$ & 5,203 & \\
\hline Remun. Almoxarifado & 0,0083 & 60,16 & $38.440,75$ & 0,316 & \\
\hline Remun. Inst./Equip.... & $\begin{array}{l}0,0111 \\
0.1585\end{array}$ & $\begin{array}{r}80,21 \\
1.142,67\end{array}$ & $\begin{array}{r}51.254,34 \\
730.168 .00\end{array}$ & $\begin{array}{l}0.422 \\
6.008\end{array}$ & pe55031(\%) \\
\hline Desp. Operacionais... & 0,8998 & $6.485,77$ & $4.144 .406,41$ & 34,099 & 41,431 \\
\hline Desp. Administrativas & 0,3831 & 2.761 .41 & $1.764 .538,61$ & 14,518 & 6,627 \\
\hline Segibenef. e outras desp. & & $1.260,55$ & $805.491,23$ & 6,627 & \\
\hline Pessoal adm./manutençăo & & $1.394,44$ & $891.047,38$ & 7,331 & \\
\hline Custo Fixo p/ Km...... & 1,8613 & $13.415,58$ & $8.572 .557,80$ & 70,533 & \\
\hline Custo Variável p/ Km. & 0,7776 & $5.604,64$ & $3.581 .365,25$ & 29,467 & \\
\hline Custo Total & 2,6389 & $19.020,22$ & $12.153 .923,06$ & 100,000 & \\
\hline I.P.K. liquido................ & 1,6582 & & & & \\
\hline Custo Tot/km sem Tributos & 2,6389 & & & & \\
\hline Custo Tot/km com Tributos & 2,8888 & & 0,7776 & & \\
\hline PMM & 7207,6545 & & & & \\
\hline TARIFA & ..... & -sem TRIB. : & 1,5914 & & \\
\hline & & - com TRIB.: & 1,7421 & & \\
\hline
\end{tabular}

Figura A.1 - Planilha Tarifária 2007 de Natal-RN. 


\section{Anexo B}

Tabela B.1 - Peso empírico versus custo monetário.

\begin{tabular}{|c|c|c|c|c|c|c|}
\hline Instância & Peso & $\begin{array}{c}\text { Integrada } \\
\text { Nível } 2 \\
\end{array}$ & $\begin{array}{c}\text { Integrada } \\
\text { Nível } 1 \\
\end{array}$ & $\begin{array}{c}\text { Seqüencial } \\
\text { Tradicional }\end{array}$ & $\begin{array}{c}\text { Seqüencial } \\
\text { Inversa }\end{array}$ & Independente \\
\hline \multirow{2}{*}{ 1-DOM } & Empírico & & & $7.056,26$ & & \\
\hline & Monetário & & & & & \\
\hline \multirow{2}{*}{ 1-DU } & Empírico & $70.289,90$ & $70.331,20$ & $70.481,24$ & $71.367,36$ & $69.346,50$ \\
\hline & Monetário & $71.311,50$ & 71.3 & $72.677,76$ & $72.440,01$ & $70.221,33$ \\
\hline \multirow{2}{*}{ 1-SAB } & Empírico & 19.3 & 19.4 & $19.307,14$ & $20.385,44$ & $19.337,83$ \\
\hline & Monetário & $19.719,52$ & $19.762,86$ & $20.120,61$ & $20.188,32$ & $19.430,69$ \\
\hline \multirow{2}{*}{ 2-DOM } & Empírico & $3.566,28$ & $3.574,37$ & $3.580,44$ & $3.580,44$ & $3.538,97$ \\
\hline & Monetário & 3.56 & 3.58 & $3.699,60$ & $3.716,13$ & $3.538,26$ \\
\hline \multirow{2}{*}{ 2-DU } & Empírico & $7.586,73$ & $7.644,70$ & & $7.745,53$ & $7.574,25$ \\
\hline & Monetário & 7.53 & 7.5 & 7.6 & $7.681,10$ & $7.414,00$ \\
\hline \multirow{2}{*}{ 2-SAB } & Empírico & 4.9 & 4.9 & & 4.98 & \\
\hline & Monetário & 4.8 & 4.9 & 5.0 & $5.021,13$ & 08 \\
\hline \multirow{2}{*}{ 3-DOM } & Empírico & 12.5 & $12.679,55$ & $12.319,84$ & $13.920,82$ & $12.048,95$ \\
\hline & Monetário & 12.4 & & & 86 & \\
\hline \multirow{2}{*}{ 3-DU } & Empírico & $25.515,51$ & 25.6 & $25.258,48$ & $26.154,65$ & 4,74 \\
\hline & Mon & 25.4 & 26.0 & & 42 & 36 \\
\hline \multirow{2}{*}{ 3-SAB } & Empírico & 17.2 & & & 16 & \\
\hline & Mone & 17.1 & 17 & 17 & 64 & 38 \\
\hline \multirow{2}{*}{ 4-DOM } & Empírico & 11.9 & & & & \\
\hline & Monetário & 12.0 & 12. & 27 & 78 & 65 \\
\hline \multirow{2}{*}{ 4-DU } & Empírico & $21.708,16$ & 21.7 & $21.572,92$ & 7,88 & 71 \\
\hline & Monetário & $22.331,54$ & $22.356,99$ & $23.004,17$ & $22.725,19$ & $21.369,76$ \\
\hline \multirow{2}{*}{ 4-SAB } & Empírico & $14.378,48$ & 15.1 & 5,51 & $15.689,05$ & $13.799,07$ \\
\hline & Monetário & $14.346,23$ & $14.450,47$ & $14.822,39$ & $15.099,80$ & $14.125,98$ \\
\hline \multirow{2}{*}{ 5-DOM } & Empírico & $20.946,44$ & $21.274,04$ & $21.078,36$ & $21.818,05$ & $20.050,68$ \\
\hline & Monetário & 21.1 & & & & \\
\hline \multirow{2}{*}{ 5-DU } & Empírico & 51.3 & 51.9 & 50. &, 02 & 49. \\
\hline & Monetário & 51.6 & & & 75 &, 07 \\
\hline \multirow{2}{*}{ 5-SAB } & Empírico & 33.7 & 34.6 &, 00 & 2,27 & 6,31 \\
\hline & Monetário & 33.7 & & & & 058,36 \\
\hline \multirow{2}{*}{ 6-DOM } & Empírico & $18.884,95$ & $19.071,05$ & $18.644,13$ & $20.000,58$ & $18.780,40$ \\
\hline & Monetário & $18.815,50$ & $18.816,26$ & & $19.800,75$ & $18.595,32$ \\
\hline \multirow{2}{*}{ 6-DU } & Empírico & $42.905,45$ & 43.3 & $43.310,00$ & $43.975,07$ & 0,95 \\
\hline & Monetário & $43.185,74$ & & $44.420,66$ & $44.508,30$ & $42.643,28$ \\
\hline \multirow{2}{*}{ 6-SAB } & Empírico & $26.048,65$ & $25.180,27$ & $25.438,66$ & $26.017,70$ & $23.497,26$ \\
\hline & Monetário & $26.109,13$ & $26.583,02$ & $26.768,57$ & $26.748,94$ & $25.752,83$ \\
\hline \multirow{2}{*}{ 7-DOM } & Empírico & $5.712,18$ & $5.728,28$ & $5.835,49$ & $5.815,43$ & $5.562,32$ \\
\hline & Monetário & $5.896,67$ & $6.034,43$ & $6.069,82$ & $6.060,52$ & $5.861,10$ \\
\hline \multirow{2}{*}{ 7-DU } & Empírico & $20.278,02$ & $20.129,84$ & $20.357,12$ & $20.436,53$ & $20.017,69$ \\
\hline & Monetário & $20.755,76$ & & $21.356,98$ & $21.195,06$ & $20.294,05$ \\
\hline \multirow{2}{*}{ 7-SAB } & Empírico & $12.585,93$ & $12.406,26$ & $12.400,86$ & $13.543,45$ & $12.288,94$ \\
\hline & Monetário & $12.513,06$ & $12.632,87$ & $12.790,48$ & $12.858,90$ & $12.299,49$ \\
\hline $8 \mathrm{DOM}$ & Empírico & $3.794,09$ & $3.809,68$ & $3.824,93$ & $3.939,93$ & $3.789,39$ \\
\hline 8-DOM & Monetário & $3.769,54$ & $3.769,54$ & $3.808,18$ & $3.803,57$ & $3.648,67$ \\
\hline 8 & Empírico & $13.129,63$ & $13.145,91$ & $13.665,79$ & $13.626,25$ & $13.059,61$ \\
\hline 8 & Monetário & $13.048,45$ & $13.245,18$ & $13.304,84$ & $13.368,84$ & $12.957,00$ \\
\hline & Empírico & $3.904,31$ & $3.928,50$ & $3.958,47$ & $3.993,05$ & $3.668,98$ \\
\hline & Monetário & $3.865,39$ & $3.874,77$ & $3.924,33$ & $3.979,83$ & $3.755,72$ \\
\hline
\end{tabular}




\section{Anexo C}

Tabela C.1 - Resultados para o dia útil utilizando a abordagem seqüencial tradicional.

\begin{tabular}{|c|c|c|c|c|c|c|}
\hline Instância & Movimentos & $\mathbf{A}$ & B & $\mathbf{C}$ & $\mathbf{A B C}$ & NSLO \\
\hline \multirow{5}{*}{1} & F. de Avaliação & 150.111 & 145.089 & 147.010 & 145.913 & 138.760 \\
\hline & $\%$ acima MS* & $8,18 \%$ & $4,56 \%$ & $5,95 \%$ & $5,15 \%$ & $0,00 \%$ \\
\hline & $\mathrm{N}^{0}$ Viagens & 269 & 269 & 269 & 269 & 269 \\
\hline & $\mathbf{N}^{0}$ Veículos & 44 & 44 & 44 & 44 & 44 \\
\hline & $\mathbf{N}^{0}$ Tripulantes & 58 & 59 & 57 & 57 & 57 \\
\hline \multirow{5}{*}{2} & F. de Avaliação & 36.261 & 36.473 & 36.600 & 37.601 & 36.221 \\
\hline & $\%$ acima MS* & $0,11 \%$ & $0,70 \%$ & $1,05 \%$ & $3,81 \%$ & $0,00 \%$ \\
\hline & \begin{tabular}{|l|}
$N^{\circ}$ Viagens \\
\end{tabular} & 98 & 98 & 98 & 98 & 98 \\
\hline & $\mathbf{N}^{0}$ Veículos & 11 & 11 & 11 & 11 & 11 \\
\hline & $\mathrm{N}^{\circ}$ Tripulantes & 19 & 19 & 19 & 19 & 19 \\
\hline \multirow{5}{*}{3} & F. de Avaliação & 130.331 & 136.467 & 130.988 & 130.457 & 129.272 \\
\hline & $\%$ acima $\mathrm{MS} *$ & $0,82 \%$ & $5,57 \%$ & $1,33 \%$ & $0,92 \%$ & $0,00 \%$ \\
\hline & $\mathrm{N}^{0}$ Viagens & 507 & 507 & 507 & 507 & 507 \\
\hline & $\mathbf{N}^{\circ}$ Veículos & 37 & 38 & 37 & 38 & 36 \\
\hline & $\mathbf{N}^{0}$ Tripulantes & 67 & 67 & 66 & 64 & 67 \\
\hline \multirow{5}{*}{4} & F. de Avaliação & 126.850 & 129.190 & 124.899 & 122.138 & 127.764 \\
\hline & $\%$ acima MS* & $3,86 \%$ & $5,77 \%$ & $2,26 \%$ & $0,00 \%$ & $4,61 \%$ \\
\hline & \begin{tabular}{|l|}
$N^{0}$ Viagens \\
\end{tabular} & 468 & 468 & 468 & 468 & 468 \\
\hline & $\mathbf{N}^{\circ}$ Veículos & 31 & 31 & 31 & 31 & 31 \\
\hline & $\mathbf{N}^{0}$ Tripulantes & 63 & 63 & 61 & 63 & 63 \\
\hline \multirow{5}{*}{5} & F. de Avaliação & 256.854 & 260.540 & 268.141 & 247.219 & 270.007 \\
\hline & $\%$ acima MS* & $3,90 \%$ & $5,39 \%$ & $8,46 \%$ & $0,00 \%$ & $9,22 \%$ \\
\hline & $\mathrm{N}^{0}$ Viagens & 1.038 & 1.038 & 1.038 & 1.038 & 1.038 \\
\hline & $N^{0}$ Veículos & 74 & 75 & 74 & 73 & 74 \\
\hline & $\mathrm{N}^{\mathbf{0}}$ Tripulantes & 125 & 125 & 121 & 122 & 128 \\
\hline \multirow{5}{*}{6} & F. de Avaliação & 210.626 & 225.073 & 219.457 & 225.502 & 215.175 \\
\hline & $\%$ acima MS* & $0,00 \%$ & $6,86 \%$ & $4,19 \%$ & $7,06 \%$ & $2,16 \%$ \\
\hline & \begin{tabular}{|l|}
$N^{0}$ Viagens \\
\end{tabular} & 706 & 706 & 706 & 706 & 706 \\
\hline & $\mathrm{N}^{0}$ Veículos & 61 & 61 & 61 & 62 & 61 \\
\hline & $\mathbf{N}^{0}$ Tripulantes & 114 & 117 & 113 & 117 & 116 \\
\hline \multirow{5}{*}{7} & F. de Avaliação & 103.301 & 109.423 & 108.173 & 100.549 & 109.663 \\
\hline & $\%$ acima MS* & $2,74 \%$ & $8,83 \%$ & $7,58 \%$ & $0,00 \%$ & $9,06 \%$ \\
\hline & \begin{tabular}{|l|}
$N^{0}$ Viagens \\
\end{tabular} & 361 & 361 & 361 & 361 & 361 \\
\hline & $\mathbf{N}^{\circ}$ Veículos & 31 & 30 & 30 & 30 & 30 \\
\hline & $\mathbf{N}^{0}$ Tripulantes & 54 & 55 & 53 & 54 & 56 \\
\hline \multirow{5}{*}{8} & F. de Avaliação & 48.737 & 49.335 & 49.327 & 50.772 & 48.359 \\
\hline & $\%$ acima MS* & $0,78 \%$ & $2,02 \%$ & $2,00 \%$ & $4,99 \%$ & $0,00 \%$ \\
\hline & $\mathrm{N}^{0}$ Viagens & 207 & 207 & 207 & 207 & 207 \\
\hline & $\mathbf{N}^{0}$ Veículos & 13 & 13 & 13 & 13 & 13 \\
\hline & $\mathrm{N}^{0}$ Tripulantes & 18 & 19 & 19 & 18 & 18 \\
\hline \multirow{5}{*}{ Somatório } & F. de Avaliação & 1.063 .071 & 1.091 .590 & 1.084 .595 & 1.060 .151 & 1.075 .221 \\
\hline & $\%$ acima MS* & $0,28 \%$ & $2,97 \%$ & $2,31 \%$ & $\mathbf{0 , 0 0 \%}$ & $1,42 \%$ \\
\hline & \begin{tabular}{|l}
$N^{0}$ Viagens \\
\end{tabular} & 3.654 & 3.654 & 3.654 & 3.654 & 3.654 \\
\hline & $\mathbf{N}^{0}$ Veículos & 302 & 303 & 301 & 302 & 300 \\
\hline & $\mathbf{N}^{0}$ Tripulantes & 518 & 524 & 509 & 514 & 524 \\
\hline
\end{tabular}

* Desvio porcentual em relação à melhor solução obtida. 
Tabela C.2 - Resultados para o domingo utilizando a abordagem seqüencial tradicional

\begin{tabular}{|c|c|c|c|c|c|c|}
\hline Instância & Movimentos & $\mathbf{A}$ & B & $\mathbf{C}$ & $\mathbf{A B C}$ & NSLO \\
\hline \multirow{5}{*}{1} & F. de Avaliação & 35.889 & 36.387 & 35.859 & 35.792 & 36.066 \\
\hline & $\%$ acima MS* & $0,27 \%$ & $1,66 \%$ & $0,19 \%$ & $0,00 \%$ & $0,77 \%$ \\
\hline & $N^{0}$ Viagens & 90 & 90 & 90 & 90 & 90 \\
\hline & $\mathbf{N}^{0}$ Veículos & 10 & 10 & 10 & 10 & 10 \\
\hline & $\mathrm{N}^{0}$ Tripulantes & 20 & 20 & 20 & 20 & 20 \\
\hline \multirow{5}{*}{2} & F. de Avaliação & 20.424 & 20.424 & 20.632 & 20.424 & 19.878 \\
\hline & $\%$ acima MS* & $2,75 \%$ & $2,75 \%$ & $3,79 \%$ & $2,75 \%$ & $0,00 \%$ \\
\hline & $\mathrm{N}^{0}$ Viagens & 53 & 53 & 53 & 53 & 53 \\
\hline & $\mathrm{N}^{0}$ Veículos & 5 & 5 & 5 & 5 & 5 \\
\hline & $\mathrm{N}^{\circ}$ Tripulantes & 10 & 10 & 10 & 10 & 10 \\
\hline \multirow{5}{*}{3} & F. de Avaliação & 73.569 & 75.224 & 76.010 & 69.540 & 78.300 \\
\hline & $\%$ acima MS* & $5,79 \%$ & $8,17 \%$ & $9,30 \%$ & $0,00 \%$ & $12,60 \%$ \\
\hline & $\mathrm{N}^{0}$ Viagens & 287 & 287 & 287 & 287 & 287 \\
\hline & $\mathbf{N}^{0}$ Veículos & 17 & 17 & 17 & 17 & 17 \\
\hline & $\mathbf{N}^{0}$ Tripulantes & 39 & 40 & 38 & 38 & 41 \\
\hline \multirow{5}{*}{4} & F. de Avaliação & 82.190 & 79.861 & 79.902 & 80.128 & 80.857 \\
\hline & $\%$ acima MS* & $2,92 \%$ & $0,00 \%$ & $0,05 \%$ & $0,33 \%$ & $1,25 \%$ \\
\hline & $\mathbf{N}^{0}$ Viagens & 299 & 299 & 299 & 299 & 299 \\
\hline & $\mathbf{N}^{0}$ Veículos & 16 & 16 & 17 & 17 & 15 \\
\hline & $\mathrm{N}^{0}$ Tripulantes & 38 & 38 & 37 & 37 & 39 \\
\hline \multirow{5}{*}{5} & F. de Avaliação & 126.879 & 121.434 & 130.705 & 119.913 & 141.020 \\
\hline & $\%$ acima MS* & $5,81 \%$ & $1,27 \%$ & $9,00 \%$ & $0,00 \%$ & $17,60 \%$ \\
\hline & $N^{0}$ Viagens & 538 & 538 & 538 & 538 & 538 \\
\hline & $\mathbf{N}^{\circ}$ Veículos & 27 & 26 & 26 & 26 & 26 \\
\hline & $\mathbf{N}^{\circ}$ Tripulantes & 58 & 57 & 59 & 56 & 63 \\
\hline \multirow{5}{*}{6} & F. de Avaliação & 107.000 & 105.131 & 116.755 & 112.907 & 110.931 \\
\hline & $\%$ acima MS* & $1,78 \%$ & $0,00 \%$ & $11,06 \%$ & $7,40 \%$ & $5,52 \%$ \\
\hline & $N^{0}$ Viagens & 378 & 378 & 378 & 378 & 378 \\
\hline & $\mathbf{N}^{\circ}$ Veículos & 26 & 25 & 26 & 25 & 25 \\
\hline & $\mathrm{N}^{\circ}$ Tripulantes & 57 & 58 & 59 & 58 & 59 \\
\hline \multirow{5}{*}{7} & F. de Avaliação & 39.046 & 39.165 & 37.836 & 39.744 & 40.939 \\
\hline & $\%$ acima MS* & $3,20 \%$ & $3,51 \%$ & $0,00 \%$ & $5,04 \%$ & $8,20 \%$ \\
\hline & $\mathrm{N}^{0}$ Viagens & 161 & 161 & 161 & 161 & 161 \\
\hline & $\mathrm{N}^{\circ}$ Veículos & 8 & 8 & 8 & 8 & 8 \\
\hline & $\mathbf{N}^{0}$ Tripulantes & 18 & 18 & 18 & 19 & 19 \\
\hline \multirow{5}{*}{8} & F. de Avaliação & 21.207 & 21.447 & 21.207 & 21.279 & 21.207 \\
\hline & $\%$ acima MS* & $0,00 \%$ & $1,13 \%$ & $0,00 \%$ & $0,34 \%$ & $0,00 \%$ \\
\hline & $\mathrm{N}^{0}$ Viagens & 108 & 108 & 108 & 108 & 108 \\
\hline & $\mathbf{N}^{\circ}$ Veículos & 5 & 5 & 5 & 5 & 5 \\
\hline & $\mathbf{N}^{0}$ Tripulantes & 11 & 11 & 11 & 11 & 11 \\
\hline \multirow{5}{*}{ Somatório } & F. de Avaliação & 506.204 & 499.073 & 518.906 & 499.727 & 529.198 \\
\hline & $\%$ acima MS* & $1,43 \%$ & $\mathbf{0 , 0 0 \%}$ & $3,97 \%$ & $0,13 \%$ & $6,04 \%$ \\
\hline & $\mathrm{N}^{0}$ Viagens & 1.914 & 1.914 & 1.914 & 1.914 & 1.914 \\
\hline & $\mathbf{N}^{\circ}$ Veículos & 114 & 112 & 114 & 113 & 111 \\
\hline & $\mathbf{N}^{\circ}$ Tripulantes & 251 & 252 & 252 & 249 & 262 \\
\hline
\end{tabular}

* Desvio porcentual em relação à melhor solução obtida. 
Tabela C.3 - Resultados para o sábado utilizando a abordagem seqüencial tradicional.

\begin{tabular}{|c|c|c|c|c|c|c|}
\hline Instância & Movimentos & $\mathbf{A}$ & B & $\mathrm{C}$ & ABC & NSLO \\
\hline \multirow{5}{*}{1} & F. de Avaliação & 70.179 & 72.357 & 69.284 & 69.884 & 68.124 \\
\hline & $\%$ acima MS* & $3,02 \%$ & $6,21 \%$ & $1,70 \%$ & $2,58 \%$ & $0,00 \%$ \\
\hline & $N^{0}$ Viagens & 172 & 172 & 172 & 172 & 172 \\
\hline & $\mathbf{N}^{\circ}$ Veículos & 23 & 23 & 23 & 23 & 23 \\
\hline & $N^{0}$ Tripulantes & 35 & 35 & 34 & 35 & 34 \\
\hline \multirow{5}{*}{2} & F. de Avaliação & 27.625 & 27.018 & 28.682 & 26.764 & 26.795 \\
\hline & $\%$ acima $\mathrm{MS} *$ & $3,22 \%$ & $0,95 \%$ & $7,17 \%$ & $0,00 \%$ & $0,12 \%$ \\
\hline & $N^{0}$ Viagens & 69 & 69 & 69 & 69 & 69 \\
\hline & $\mathbf{N}^{\circ}$ Veículos & 7 & 7 & 7 & 7 & 7 \\
\hline & $\mathbf{N}^{\circ}$ Tripulantes & 13 & 13 & 12 & 14 & 14 \\
\hline \multirow{5}{*}{3} & F. de Avaliação & 94.350 & 98.204 & 107.999 & 96.171 & 100.087 \\
\hline & $\%$ acima MS* & $0,00 \%$ & $4,08 \%$ & $14,47 \%$ & $1,93 \%$ & $6,08 \%$ \\
\hline & $\mathrm{N}^{0}$ Viagens & 372 & 372 & 372 & 372 & 372 \\
\hline & $\mathrm{N}^{0}$ Veículos & 24 & 24 & 24 & 24 & 24 \\
\hline & $\mathbf{N}^{\mathbf{0}}$ Tripulantes & 53 & 53 & 55 & 52 & 54 \\
\hline \multirow{5}{*}{4} & F. de Avaliação & 87.701 & 94.735 & 92.341 & 93.017 & 87.694 \\
\hline & $\%$ acima MS* & $0,01 \%$ & $8,03 \%$ & $5,30 \%$ & $6,07 \%$ & $0,00 \%$ \\
\hline & $\mathrm{N}^{\mathbf{0}}$ Viagens & 359 & 359 & 359 & 359 & 359 \\
\hline & $\mathbf{N}^{\circ}$ Veículos & 19 & 19 & 19 & 19 & 19 \\
\hline & $\mathbf{N}^{0}$ Tripulantes & 45 & 45 & 45 & 46 & 45 \\
\hline \multirow{5}{*}{5} & F. de Avaliação & 177.614 & 181.607 & 185.062 & 179.754 & 196.684 \\
\hline & $\%$ acima MS* & $0,00 \%$ & $2,25 \%$ & $4,19 \%$ & $1,20 \%$ & $10,74 \%$ \\
\hline & $\mathrm{N}^{0}$ Viagens & 769 & 769 & 769 & 769 & 769 \\
\hline & $\mathrm{N}^{0}$ Veículos & 46 & 46 & 47 & 46 & 46 \\
\hline & $\mathrm{N}^{0}$ Tripulantes & 86 & 88 & 88 & 88 & 94 \\
\hline \multirow{5}{*}{6} & F. de Avaliação & 144.242 & 146.231 & 146.826 & 147.478 & 141.289 \\
\hline & $\%$ acima MS* & $2,09 \%$ & $3,50 \%$ & $3,92 \%$ & $4,38 \%$ & $0,00 \%$ \\
\hline & $N^{0}$ Viagens & 503 & 503 & 503 & 503 & 503 \\
\hline & $\mathrm{N}^{0}$ Veículos & 36 & 36 & 36 & 35 & 36 \\
\hline & $\mathbf{N}^{\circ}$ Tripulantes & 76 & 76 & 73 & 75 & 78 \\
\hline \multirow{5}{*}{7} & F. de Avaliação & 69.368 & 67.867 & 67.527 & 71.784 & 65.996 \\
\hline & $\%$ acima MS* & $5,11 \%$ & $2,84 \%$ & $2,32 \%$ & $8,77 \%$ & $0,00 \%$ \\
\hline & $\mathrm{N}^{0}$ Viagens & 253 & 253 & 253 & 253 & 253 \\
\hline & $\mathbf{N}^{\circ}$ Veículos & 18 & 18 & 18 & 18 & 18 \\
\hline & $\mathbf{N}^{0}$ Tripulantes & 35 & 34 & 34 & 35 & 35 \\
\hline \multirow{5}{*}{8} & F. de Avaliação & 22.917 & 21.894 & 21.894 & 21.894 & 21.909 \\
\hline & $\%$ acima MS* & $4,67 \%$ & $0,00 \%$ & $0,00 \%$ & $0,00 \%$ & $0,07 \%$ \\
\hline & $N^{0}$ Viagens & 121 & 121 & 121 & 121 & 121 \\
\hline & $\mathrm{N}^{0}$ Veículos & 5 & 5 & 5 & 5 & 5 \\
\hline & $\mathbf{N}^{0}$ Tripulantes & 12 & 12 & 12 & 12 & 12 \\
\hline \multirow{5}{*}{ Somatório } & F. de Avaliação & 693.996 & 709.913 & 719.615 & 706.746 & 708.578 \\
\hline & $\%$ acima MS* & $0,00 \%$ & $2,29 \%$ & $3,69 \%$ & $1,84 \%$ & $2,10 \%$ \\
\hline & $N^{0}$ Viagens & 2.618 & 2.618 & 2.618 & 2.618 & 2.618 \\
\hline & $\mathrm{N}^{0}$ Veículos & 178 & 178 & 179 & 177 & 178 \\
\hline & $\mathbf{N}^{0}$ Tripulantes & 355 & 356 & 353 & 357 & 366 \\
\hline
\end{tabular}

* Desvio porcentual em relação à melhor solução obtida. 
Tabela C.4-Resultados para o dia útil utilizando a abordagem seqüencial inversa.

\begin{tabular}{|c|c|c|c|c|c|c|}
\hline Instância & Movimentos & $\mathbf{A}$ & B & $\mathbf{C}$ & ABC & NSLO \\
\hline \multirow{5}{*}{1} & F. de Avaliação & 147.587 & 150.908 & 146.586 & 145.893 & 148.697 \\
\hline & $\%$ acima MS* & $1,16 \%$ & $3,44 \%$ & $0,48 \%$ & $0,00 \%$ & $1,92 \%$ \\
\hline & $\mathrm{N}^{0}$ Viagens & 269 & 269 & 269 & 269 & 269 \\
\hline & $\mathbf{N}^{0}$ Veículos & 45 & 48 & 48 & 48 & 44 \\
\hline & $\mathbf{N}^{\mathbf{0}}$ Tripulantes & 64 & 63 & 62 & 63 & 64 \\
\hline \multirow{5}{*}{2} & F. de Avaliação & 39.677 & 40.183 & 38.708 & 41.405 & 40.760 \\
\hline & $\%$ acima MS* & $2,50 \%$ & $3,81 \%$ & $0,00 \%$ & $6,97 \%$ & $5,30 \%$ \\
\hline & $\mathrm{N}^{0}$ Viagens & 98 & 98 & 98 & 98 & 98 \\
\hline & $\mathbf{N}^{0}$ Veículos & 13 & 13 & 12 & 13 & 14 \\
\hline & $\mathbf{N}^{\mathbf{0}}$ Tripulantes & 20 & 20 & 20 & 20 & 20 \\
\hline \multirow{5}{*}{3} & F. de Avaliação & 171.722 & 169.776 & 168.539 & 179.863 & 184.987 \\
\hline & $\%$ acima MS* & $1,89 \%$ & $0,73 \%$ & $0,00 \%$ & $6,72 \%$ & $9,76 \%$ \\
\hline & $\mathrm{N}^{0}$ Viagens & 507 & 507 & 507 & 507 & 507 \\
\hline & $\mathbf{N}^{0}$ Veículos & 46 & 44 & 45 & 45 & 43 \\
\hline & $\mathbf{N}^{0}$ Tripulantes & 74 & 74 & 73 & 75 & 78 \\
\hline \multirow{5}{*}{4} & F. de Avaliação & 156.067 & 156.391 & 158.024 & 148.913 & 151.367 \\
\hline & $\%$ acima MS* & $4,80 \%$ & $5,02 \%$ & $6,12 \%$ & $0,00 \%$ & $1,65 \%$ \\
\hline & $N^{0}$ Viagens & 468 & 468 & 468 & 468 & 468 \\
\hline & $\mathrm{N}^{0}$ Veículos & 40 & 41 & 42 & 38 & 40 \\
\hline & $\mathbf{N}^{\mathbf{0}}$ Tripulantes & 69 & 69 & 69 & 68 & 68 \\
\hline \multirow{5}{*}{5} & F. de Avaliação & 374.899 & 372.916 & 374.858 & 368.542 & 394.068 \\
\hline & $\%$ acima MS* & $1,72 \%$ & $1,19 \%$ & $1,71 \%$ & $0,00 \%$ & $6,93 \%$ \\
\hline & $\mathrm{N}^{0}$ Viagens & 1.038 & 1.038 & 1.038 & 1.038 & 1.038 \\
\hline & $\mathrm{N}^{\circ}$ Veículos & 91 & 86 & 88 & 90 & 90 \\
\hline & $\mathbf{N}^{\mathbf{0}}$ Tripulantes & 153 & 154 & 153 & 152 & 158 \\
\hline \multirow{5}{*}{6} & F. de Avaliação & 277.314 & 276.478 & 277.173 & 269.985 & 270.934 \\
\hline & $\%$ acima MS* & $2,71 \%$ & $2,40 \%$ & $2,66 \%$ & $0,00 \%$ & $0,35 \%$ \\
\hline & $N^{0}$ Viagens & 706 & 706 & 706 & 706 & 706 \\
\hline & $\mathbf{N}^{0}$ Veículos & 70 & 73 & 73 & 71 & 71 \\
\hline & $\mathbf{N}^{0}$ Tripulantes & 128 & 127 & 127 & 126 & 126 \\
\hline \multirow{5}{*}{7} & F. de Avaliação & 121.087 & 120.048 & 117.965 & 124.277 & 131.558 \\
\hline & $\%$ acima MS* & $2,65 \%$ & $1,77 \%$ & $0,00 \%$ & $5,35 \%$ & $11,52 \%$ \\
\hline & $\mathrm{N}^{0}$ Viagens & 361 & 361 & 361 & 361 & 361 \\
\hline & $\mathrm{N}^{0}$ Veículos & 33 & 36 & 37 & 36 & 35 \\
\hline & $\mathbf{N}^{\mathbf{0}}$ Tripulantes & 58 & 57 & 56 & 58 & 60 \\
\hline \multirow{5}{*}{8} & F. de Avaliação & 61.533 & 56.992 & 57.686 & 61.983 & 66.663 \\
\hline & $\%$ acima MS* & $7,97 \%$ & $0,00 \%$ & $1,22 \%$ & $8,76 \%$ & $16,97 \%$ \\
\hline & $\mathrm{N}^{0}$ Viagens & 207 & 207 & 207 & 207 & 207 \\
\hline & $\mathbf{N}^{0}$ Veículos & 15 & 15 & 15 & 17 & 15 \\
\hline & $\mathbf{N}^{\mathbf{0}}$ Tripulantes & 24 & 23 & 22 & 24 & 25 \\
\hline \multirow{5}{*}{ Somatório } & F. de Avaliação & 1.349 .886 & 1.343.692 & 1.339 .539 & 1.340 .861 & 1.389.034 \\
\hline & $\%$ acima MS* & $0,77 \%$ & $0,31 \%$ & $0,00 \%$ & $0,10 \%$ & $3,69 \%$ \\
\hline & $\mathrm{N}^{0}$ Viagens & 3.654 & 3.654 & 3.654 & 3.654 & 3.654 \\
\hline & $\mathrm{N}^{\circ}$ Veículos & 353 & 356 & 360 & 358 & 352 \\
\hline & $\mathbf{N}^{\mathbf{0}}$ Tripulantes & 590 & 587 & 582 & 586 & 599 \\
\hline
\end{tabular}

* Desvio porcentual em relação à melhor solução obtida. 
Tabela C.5 - Resultados para o domingo utilizando a abordagem seqüencial inversa.

\begin{tabular}{|c|c|c|c|c|c|c|}
\hline Instância & Movimentos & $\mathbf{A}$ & B & $\mathrm{C}$ & $\mathbf{A B C}$ & NSLO \\
\hline \multirow{5}{*}{1} & F. de Avaliação & 36.958 & 38.878 & 39.577 & 38.977 & 39.033 \\
\hline & $\%$ acima $\mathrm{MS} *$ & $0,00 \%$ & $5,20 \%$ & $7,09 \%$ & $5,46 \%$ & $5,61 \%$ \\
\hline & $\mathbf{N}^{0}$ Viagens & 90 & 90 & 90 & 90 & 90 \\
\hline & $\mathbf{N}^{\circ}$ Veículos & 11 & 13 & 13 & 13 & 13 \\
\hline & $\mathrm{N}^{0}$ Tripulantes & 20 & 20 & 20 & 20 & 20 \\
\hline \multirow{5}{*}{2} & F. de Avaliação & 23.042 & 22.703 & 22.655 & 22.433 & 25.470 \\
\hline & $\%$ acima MS* & $2,71 \%$ & $1,20 \%$ & $0,99 \%$ & $0,00 \%$ & $13,54 \%$ \\
\hline & $\mathrm{N}^{0}$ Viagens & 53 & 53 & 53 & 53 & 53 \\
\hline & $\mathbf{N}^{0}$ Veículos & 7 & 7 & 7 & 6 & 7 \\
\hline & $\mathbf{N}^{\circ}$ Tripulantes & 11 & 11 & 10 & 11 & 11 \\
\hline \multirow{5}{*}{3} & F. de Avaliação & 86.769 & 87.987 & 85.182 & 86.109 & 89.880 \\
\hline & $\%$ acima $\mathrm{MS} *$ & $1,86 \%$ & $3,29 \%$ & $0,00 \%$ & $1,09 \%$ & $5,52 \%$ \\
\hline & $\mathrm{N}^{0}$ Viagens & 287 & 287 & 287 & 287 & 287 \\
\hline & $\mathrm{N}^{0}$ Veículos & 20 & 21 & 19 & 20 & 23 \\
\hline & $\mathbf{N}^{0}$ Tripulantes & 42 & 42 & 42 & 42 & 42 \\
\hline \multirow{5}{*}{4} & F. de Avaliação & 121.076 & 103.246 & 99.845 & 101.672 & 111.559 \\
\hline & $\%$ acima MS* & $21,26 \%$ & $3,41 \%$ & $0,00 \%$ & $1,83 \%$ & $11,73 \%$ \\
\hline & $\mathbf{N}^{0}$ Viagens & 299 & 299 & 299 & 299 & 299 \\
\hline & $\mathbf{N}^{\circ}$ Veículos & 24 & 24 & 22 & 24 & 24 \\
\hline & $\mathbf{N}^{0}$ Tripulantes & 43 & 42 & 42 & 42 & 43 \\
\hline \multirow{5}{*}{5} & F. de Avaliação & 180.100 & 167.859 & 174.276 & 211.255 & 180.708 \\
\hline & $\%$ acima MS* & $7,29 \%$ & $0,00 \%$ & $3,82 \%$ & $25,85 \%$ & $7,65 \%$ \\
\hline & $\mathrm{N}^{0}$ Viagens & 538 & 538 & 538 & 538 & 538 \\
\hline & $\mathrm{N}^{0}$ Veículos & 36 & 33 & 35 & 37 & 37 \\
\hline & $\mathbf{N}^{0}$ Tripulantes & 71 & 69 & 70 & 69 & 71 \\
\hline \multirow{5}{*}{6} & F. de Avaliação & 137.157 & 129.533 & 128.900 & 132.416 & 138.675 \\
\hline & $\%$ acima MS* & $6,41 \%$ & $0,49 \%$ & $0,00 \%$ & $2,73 \%$ & $7,58 \%$ \\
\hline & $N^{0}$ Viagens & 378 & 378 & 378 & 378 & 378 \\
\hline & $\mathbf{N}^{0}$ Veículos & 33 & 33 & 33 & 33 & 35 \\
\hline & $\mathrm{N}^{0}$ Tripulantes & 65 & 63 & 63 & 64 & 65 \\
\hline \multirow{5}{*}{7} & F. de Avaliação & 50.293 & 48.031 & 52.233 & 47.212 & 53.586 \\
\hline & $\%$ acima MS* & $6,53 \%$ & $1,73 \%$ & $10,64 \%$ & $0,00 \%$ & $13,50 \%$ \\
\hline & $N^{0}$ Viagens & 161 & 161 & 161 & 161 & 161 \\
\hline & $\mathrm{N}^{0}$ Veículos & 11 & 12 & 12 & 11 & 12 \\
\hline & $\mathbf{N}^{0}$ Tripulantes & 21 & 20 & 21 & 20 & 21 \\
\hline \multirow{5}{*}{8} & F. de Avaliação & 21.180 & 34.156 & 20.192 & 20.424 & 19.800 \\
\hline & $\%$ acima MS* & $6,97 \%$ & $72,51 \%$ & $1,98 \%$ & $3,15 \%$ & $0,00 \%$ \\
\hline & $\mathbf{N}^{0}$ Viagens & 108 & 108 & 108 & 108 & 108 \\
\hline & $\mathbf{N}^{0}$ Veículos & 6 & 7 & 6 & 6 & 6 \\
\hline & $\mathbf{N}^{0}$ Tripulantes & 10 & 11 & 10 & 10 & 10 \\
\hline \multirow{5}{*}{ Somatório } & F. de Avaliação & 656.575 & 632.393 & 622.860 & 660.498 & 658.711 \\
\hline & $\%$ acima MS* & $5,41 \%$ & $1,53 \%$ & $0,00 \%$ & $6,04 \%$ & $5,76 \%$ \\
\hline & $\mathrm{N}^{\mathbf{0}}$ Viagens & 1.914 & 1.914 & 1.914 & 1.914 & 1.914 \\
\hline & $\mathbf{N}^{\circ}$ Veículos & 148 & 150 & 147 & 150 & 157 \\
\hline & $\mathbf{N}^{0}$ Tripulantes & 283 & 278 & 278 & 278 & 283 \\
\hline
\end{tabular}

* Desvio porcentual em relação à melhor solução obtida. 
Tabela C.6 - Resultados para o sábado utilizando a abordagem seqüencial inversa.

\begin{tabular}{|c|c|c|c|c|c|c|}
\hline Instância & Movimentos & $\mathbf{A}$ & B & $\mathrm{C}$ & $\mathbf{A B C}$ & NSLO \\
\hline \multirow{5}{*}{1} & F. de Avaliação & 73.756 & 72.639 & 74.977 & 69.517 & 73.661 \\
\hline & $\%$ acima $\mathrm{MS} *$ & $6,10 \%$ & $4,49 \%$ & $7,85 \%$ & $0,00 \%$ & $5,96 \%$ \\
\hline & $\mathbf{N}^{0}$ Viagens & 172 & 172 & 172 & 172 & 172 \\
\hline & $\mathbf{N}^{\circ}$ Veículos & 25 & 24 & 26 & 25 & 25 \\
\hline & $\mathrm{N}^{0}$ Tripulantes & 36 & 36 & 36 & 35 & 36 \\
\hline \multirow{5}{*}{2} & F. de Avaliação & 28.131 & 26.910 & 27.088 & 26.981 & 29.205 \\
\hline & $\%$ acima MS* & $4,54 \%$ & $0,00 \%$ & $0,66 \%$ & $0,26 \%$ & $8,53 \%$ \\
\hline & $\mathrm{N}^{0}$ Viagens & 69 & 69 & 69 & 69 & 69 \\
\hline & $\mathbf{N}^{0}$ Veículos & 9 & 7 & 8 & 8 & 10 \\
\hline & $\mathbf{N}^{\circ}$ Tripulantes & 14 & 14 & 14 & 14 & 14 \\
\hline \multirow{5}{*}{3} & F. de Avaliação & 118.646 & 116.277 & 117.755 & 113.899 & 123.440 \\
\hline & $\%$ acima $\mathrm{MS} *$ & $4,17 \%$ & $2,09 \%$ & $3,39 \%$ & $0,00 \%$ & $8,38 \%$ \\
\hline & $\mathrm{N}^{0}$ Viagens & 372 & 372 & 372 & 372 & 372 \\
\hline & $\mathbf{N}^{0}$ Veículos & 29 & 27 & 29 & 29 & 33 \\
\hline & $\mathbf{N}^{0}$ Tripulantes & 57 & 57 & 57 & 56 & 57 \\
\hline \multirow{5}{*}{4} & F. de Avaliação & 124.962 & 118.051 & 111.930 & 114.891 & 123.252 \\
\hline & $\%$ acima MS* & $11,64 \%$ & $5,47 \%$ & $0,00 \%$ & $2,65 \%$ & $10,12 \%$ \\
\hline & $\mathbf{N}^{0}$ Viagens & 359 & 359 & 359 & 359 & 359 \\
\hline & $\mathbf{N}^{\circ}$ Veículos & 28 & 26 & 24 & 27 & 27 \\
\hline & $\mathbf{N}^{0}$ Tripulantes & 51 & 52 & 51 & 51 & 53 \\
\hline \multirow{5}{*}{5} & F. de Avaliação & 269.833 & 256.239 & 261.541 & 255.199 & 272.577 \\
\hline & $\%$ acima MS* & $5,73 \%$ & $0,41 \%$ & $2,49 \%$ & $0,00 \%$ & $6,81 \%$ \\
\hline & $\mathrm{N}^{0}$ Viagens & 769 & 769 & 769 & 769 & 769 \\
\hline & $\mathrm{N}^{0}$ Veículos & 55 & 55 & 55 & 54 & 58 \\
\hline & $\mathbf{N}^{0}$ Tripulantes & 109 & 106 & 107 & 106 & 109 \\
\hline \multirow{5}{*}{6} & F. de Avaliação & 170.588 & 179.051 & 170.633 & 167.465 & 180.227 \\
\hline & $\%$ acima MS* & $1,86 \%$ & $6,92 \%$ & $1,89 \%$ & $0,00 \%$ & $7,62 \%$ \\
\hline & $N^{0}$ Viagens & 503 & 503 & 503 & 503 & 503 \\
\hline & $\mathbf{N}^{0}$ Veículos & 41 & 45 & 41 & 42 & 45 \\
\hline & $\mathrm{N}^{0}$ Tripulantes & 84 & 85 & 84 & 83 & 85 \\
\hline \multirow{5}{*}{7} & F. de Avaliação & 87.426 & 78.681 & 74.495 & 78.715 & 88.757 \\
\hline & $\%$ acima MS* & $17,36 \%$ & $5,62 \%$ & $0,00 \%$ & $5,66 \%$ & $19,14 \%$ \\
\hline & \begin{tabular}{|l}
$N^{0}$ Viagens \\
\end{tabular} & 253 & 253 & 253 & 253 & 253 \\
\hline & $\mathrm{N}^{0}$ Veículos & 22 & 22 & 22 & 22 & 22 \\
\hline & $\mathbf{N}^{0}$ Tripulantes & 39 & 37 & 36 & 37 & 39 \\
\hline \multirow{5}{*}{8} & F. de Avaliação & 24.726 & 26.501 & 25.242 & 26.189 & 24.551 \\
\hline & $\%$ acima MS* & $0,71 \%$ & $7,94 \%$ & $2,81 \%$ & $6,67 \%$ & $0,00 \%$ \\
\hline & $\mathbf{N}^{0}$ Viagens & 121 & 121 & 121 & 121 & 121 \\
\hline & $N^{0}$ Veículos & 7 & 7 & 7 & 7 & 7 \\
\hline & $\mathbf{N}^{0}$ Tripulantes & 12 & 12 & 12 & 12 & 12 \\
\hline \multirow{5}{*}{ Somatório } & F. de Avaliação & 898.068 & 874.349 & 863.661 & 852.856 & 915.670 \\
\hline & $\%$ acima MS* & $5,30 \%$ & $2,52 \%$ & $1,27 \%$ & $0,00 \%$ & $7,37 \%$ \\
\hline & $\mathrm{N}^{\mathbf{0}}$ Viagens & 2.618 & 2.618 & 2.618 & 2.618 & 2.618 \\
\hline & $\mathrm{N}^{0}$ Veículos & 216 & 213 & 212 & 214 & 227 \\
\hline & $\mathbf{N}^{0}$ Tripulantes & 402 & 399 & 397 & 394 & 405 \\
\hline
\end{tabular}

* Desvio porcentual em relação à melhor solução obtida. 
Tabela C.7 - Resultados para o dia útil utilizando a abordagem independente.

\begin{tabular}{|c|c|c|c|c|c|c|}
\hline Instância & Movimentos & $\mathbf{A}$ & B & $\mathrm{C}$ & $\mathbf{A B C}$ & NSLO \\
\hline \multirow{5}{*}{ 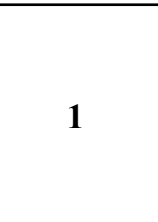 } & F. de Avaliação & 143.998 & 139.088 & 142.540 & 141.999 & 145.114 \\
\hline & $\%$ acima MS* & $3,53 \%$ & $0,00 \%$ & $2,48 \%$ & $2,09 \%$ & $4,33 \%$ \\
\hline & $\mathrm{N}^{0}$ Viagens & 269 & 269 & 269 & 269 & 269 \\
\hline & $\mathbf{N}^{\circ}$ Veículos & 44 & 44 & 44 & 44 & 44 \\
\hline & $\mathbf{N}^{\mathbf{0}}$ Tripulantes & 64 & 62 & 63 & 64 & 64 \\
\hline \multirow{5}{*}{2} & F. de Avaliação & 37.985 & 38.193 & 37.977 & 38.025 & 36.748 \\
\hline & $\%$ acima MS* & $3,37 \%$ & $3,93 \%$ & $3,34 \%$ & $3,48 \%$ & $0,00 \%$ \\
\hline & $\mathrm{N}^{0}$ Viagens & 98 & 98 & 98 & 98 & 98 \\
\hline & $\mathrm{N}^{0}$ Veículos & 11 & 11 & 11 & 11 & 11 \\
\hline & $\mathbf{N}^{0}$ Tripulantes & 20 & 20 & 20 & 20 & 20 \\
\hline \multirow{5}{*}{3} & F. de Avaliação & 155.603 & 160.631 & 164.980 & 164.923 & 173.567 \\
\hline & $\%$ acima MS* & $0,00 \%$ & $3,23 \%$ & $6,03 \%$ & $5,99 \%$ & $11,54 \%$ \\
\hline & $\mathbf{N}^{0}$ Viagens & 507 & 507 & 507 & 507 & 507 \\
\hline & $\mathrm{N}^{0}$ Veículos & 37 & 38 & 38 & 38 & 37 \\
\hline & $\mathbf{N}^{0}$ Tripulantes & 73 & 74 & 75 & 75 & 77 \\
\hline \multirow{5}{*}{4} & F. de Avaliação & 142.895 & 147.194 & 139.817 & 142.943 & 146.887 \\
\hline & $\%$ acima $\mathrm{MS} *$ & $2,20 \%$ & $5,28 \%$ & $0,00 \%$ & $2,24 \%$ & $5,06 \%$ \\
\hline & $N^{0}$ Viagens & 468 & 468 & 468 & 468 & 468 \\
\hline & $\mathbf{N}^{0}$ Veículos & 31 & 31 & 31 & 31 & 31 \\
\hline & $\mathbf{N}^{0}$ Tripulantes & 68 & 69 & 67 & 68 & 69 \\
\hline \multirow{5}{*}{5} & F. de Avaliação & 373.211 & 364.830 & 369.307 & 351.874 & 363.964 \\
\hline & $\%$ acima MS* & $6,06 \%$ & $3,68 \%$ & $4,95 \%$ & $0,00 \%$ & $3,44 \%$ \\
\hline & $\mathrm{N}^{0}$ Viagens & 1.038 & 1.038 & 1.038 & 1.038 & 1.038 \\
\hline & $\mathbf{N}^{\circ}$ Veículos & 74 & 74 & 74 & 74 & 74 \\
\hline & $\mathbf{N}^{\mathbf{0}}$ Tripulantes & 156 & 154 & 155 & 151 & 155 \\
\hline \multirow{5}{*}{6} & F. de Avaliação & 269.213 & 260.651 & 258.142 & 269.013 & 269.373 \\
\hline & $\%$ acima MS* & $4,29 \%$ & $0,97 \%$ & $0,00 \%$ & $4,21 \%$ & $4,35 \%$ \\
\hline & $\mathbf{N}^{0}$ Viagens & 706 & 706 & 706 & 706 & 706 \\
\hline & $\mathbf{N}^{\circ}$ Veículos & 61 & 61 & 62 & 61 & 61 \\
\hline & $\mathrm{N}^{0}$ Tripulantes & 128 & 126 & 125 & 128 & 128 \\
\hline \multirow{5}{*}{7} & F. de Avaliação & 120.020 & 110.806 & 112.100 & 115.173 & 124.438 \\
\hline & $\%$ acima MS* & $8,32 \%$ & $0,00 \%$ & $1,17 \%$ & $3,94 \%$ & $12,30 \%$ \\
\hline & $\mathrm{N}^{0}$ Viagens & 361 & 361 & 361 & 361 & 361 \\
\hline & $\mathbf{N}^{0}$ Veículos & 31 & 30 & 30 & 30 & 30 \\
\hline & $\mathbf{N}^{0}$ Tripulantes & 58 & 56 & 56 & 57 & 59 \\
\hline \multirow{5}{*}{8} & F. de Avaliação & 63.276 & 62.795 & 62.805 & 60.003 & 59.004 \\
\hline & $\%$ acima MS* & $7,24 \%$ & $6,42 \%$ & $6,44 \%$ & $1,69 \%$ & $0,00 \%$ \\
\hline & $\mathbf{N}^{0}$ Viagens & 207 & 207 & 207 & 207 & 207 \\
\hline & $\mathbf{N}^{0}$ Veículos & 13 & 13 & 13 & 13 & 13 \\
\hline & $\mathbf{N}^{0}$ Tripulantes & 25 & 25 & 25 & 24 & 24 \\
\hline \multirow{5}{*}{ Somatório } & F. de Avaliação & 1.306 .201 & 1.284 .188 & 1.287 .668 & 1.283 .953 & 1.319 .095 \\
\hline & $\%$ acima MS* & $1,73 \%$ & $\mathbf{0 , 0 2 \%}$ & $0,29 \%$ & $0,00 \%$ & $2,74 \%$ \\
\hline & $\mathrm{N}^{\mathbf{0}}$ Viagens & 3.654 & 3.654 & 3.654 & 3.654 & 3.654 \\
\hline & $\mathbf{N}^{\circ}$ Veículos & 302 & 302 & 303 & 302 & 301 \\
\hline & $\mathbf{N}^{\mathbf{0}}$ Tripulantes & 592 & 586 & 586 & 587 & 596 \\
\hline
\end{tabular}

* Desvio porcentual em relação à melhor solução obtida. 
Tabela C.8 - Resultados para o domingo utilizando a abordagem independente.

\begin{tabular}{|c|c|c|c|c|c|c|}
\hline Instância & Movimentos & $\mathbf{A}$ & B & $\mathrm{C}$ & $\mathbf{A B C}$ & NSLO \\
\hline \multirow{5}{*}{1} & F. de Avaliação & 40.273 & 35.994 & 36.699 & 36.240 & 39.895 \\
\hline & $\%$ acima MS* & $11,89 \%$ & $0,00 \%$ & $1,96 \%$ & $0,68 \%$ & $10,84 \%$ \\
\hline & $\mathbf{N}^{0}$ Viagens & 90 & 90 & 90 & 90 & 90 \\
\hline & $\mathbf{N}^{\circ}$ Veículos & 10 & 10 & 10 & 10 & 10 \\
\hline & $\mathrm{N}^{0}$ Tripulantes & 21 & 20 & 20 & 20 & 21 \\
\hline \multirow{5}{*}{2} & F. de Avaliação & 20.701 & 20.704 & 18.624 & 18.136 & 20.704 \\
\hline & $\%$ acima MS* & $14,14 \%$ & $14,16 \%$ & $2,69 \%$ & $0,00 \%$ & $14,16 \%$ \\
\hline & $\mathrm{N}^{0}$ Viagens & 53 & 53 & 53 & 53 & 53 \\
\hline & $\mathbf{N}^{\circ}$ Veículos & 5 & 5 & 5 & 5 & 5 \\
\hline & $\mathbf{N}^{\circ}$ Tripulantes & 11 & 11 & 10 & 10 & 11 \\
\hline \multirow{5}{*}{3} & F. de Avaliação & 83.740 & 88.022 & 83.756 & 83.770 & 84.806 \\
\hline & $\%$ acima $\mathrm{MS} *$ & $0,00 \%$ & $5,11 \%$ & $0,02 \%$ & $0,04 \%$ & $1,27 \%$ \\
\hline & $\mathrm{N}^{0}$ Viagens & 287 & 287 & 287 & 287 & 287 \\
\hline & $\mathrm{N}^{0}$ Veículos & 17 & 17 & 17 & 17 & 17 \\
\hline & $\mathbf{N}^{0}$ Tripulantes & 42 & 43 & 42 & 42 & 43 \\
\hline \multirow{5}{*}{4} & F. de Avaliação & 96.660 & 93.539 & 98.054 & 89.161 & 91.353 \\
\hline & $\%$ acima MS* & $8,41 \%$ & $4,91 \%$ & $9,97 \%$ & $0,00 \%$ & $2,46 \%$ \\
\hline & $N^{0}$ Viagens & 299 & 299 & 299 & 299 & 299 \\
\hline & $\mathbf{N}^{\circ}$ Veículos & 16 & 17 & 17 & 17 & 16 \\
\hline & $\mathbf{N}^{0}$ Tripulantes & 43 & 42 & 43 & 41 & 42 \\
\hline \multirow{5}{*}{5} & F. de Avaliação & 175.665 & 167.226 & 167.208 & 171.394 & 172.502 \\
\hline & $\%$ acima MS* & $5,06 \%$ & $0,01 \%$ & $0,00 \%$ & $2,50 \%$ & $3,17 \%$ \\
\hline & $\mathrm{N}^{\mathbf{0}}$ Viagens & 538 & 538 & 538 & 538 & 538 \\
\hline & $\mathrm{N}^{0}$ Veículos & 26 & 26 & 26 & 26 & 26 \\
\hline & $\mathbf{N}^{0}$ Tripulantes & 72 & 70 & 70 & 71 & 72 \\
\hline \multirow{5}{*}{6} & F. de Avaliação & 126.202 & 121.050 & 117.980 & 130.529 & 124.947 \\
\hline & $\%$ acima MS* & $6,97 \%$ & $2,60 \%$ & $0,00 \%$ & $10,64 \%$ & $5,91 \%$ \\
\hline & $N^{0}$ Viagens & 378 & 378 & 378 & 378 & 378 \\
\hline & $\mathbf{N}^{0}$ Veículos & 26 & 25 & 26 & 26 & 25 \\
\hline & $\mathrm{N}^{0}$ Tripulantes & 64 & 63 & 62 & 65 & 64 \\
\hline \multirow{5}{*}{7} & F. de Avaliação & 47.628 & 47.611 & 47.621 & 43.341 & 47.631 \\
\hline & $\%$ acima MS* & $9,89 \%$ & $9,85 \%$ & $9,88 \%$ & $0,00 \%$ & $9,90 \%$ \\
\hline & $N^{0}$ Viagens & 161 & 161 & 161 & 161 & 161 \\
\hline & $\mathrm{N}^{0}$ Veículos & 8 & 8 & 8 & 8 & 8 \\
\hline & $\mathbf{N}^{0}$ Tripulantes & 21 & 21 & 21 & 20 & 21 \\
\hline \multirow{5}{*}{8} & F. de Avaliação & 19.815 & 19.647 & 19.487 & 19.751 & 19.031 \\
\hline & $\%$ acima MS* & $4,12 \%$ & $3,24 \%$ & $2,40 \%$ & $3,78 \%$ & $0,00 \%$ \\
\hline & $\mathrm{N}^{0}$ Viagens & 108 & 108 & 108 & 108 & 108 \\
\hline & $\mathbf{N}^{0}$ Veículos & 5 & 5 & 5 & 5 & 5 \\
\hline & $\mathbf{N}^{0}$ Tripulantes & 10 & 10 & 10 & 10 & 10 \\
\hline \multirow{5}{*}{ Somatório } & F. de Avaliação & 610.684 & 593.793 & 589.429 & 592.322 & 600.869 \\
\hline & $\%$ acima MS* & $3,61 \%$ & $0,74 \%$ & $0,00 \%$ & $0,49 \%$ & $1,94 \%$ \\
\hline & $\mathrm{N}^{\mathbf{0}}$ Viagens & 1.914 & 1.914 & 1.914 & 1.914 & 1.914 \\
\hline & $\mathbf{N}^{\circ}$ Veículos & 113 & 113 & 114 & 114 & 112 \\
\hline & $\mathbf{N}^{0}$ Tripulantes & 284 & 280 & 278 & 279 & 284 \\
\hline
\end{tabular}

* Desvio porcentual em relação à melhor solução obtida. 
Tabela C.9 - Resultados para o sábado utilizando a abordagem independente.

\begin{tabular}{|c|c|c|c|c|c|c|}
\hline Instância & Movimentos & $\overline{\mathbf{A}}$ & $\mathbf{B}$ & $\mathbf{C}$ & $\mathrm{ABC}$ & NSLO \\
\hline \multirow{5}{*}{1} & F. de Avaliação & 72.106 & 69.150 & 72.162 & 72.075 & 72.206 \\
\hline & $\%$ acima MS* & $4,27 \%$ & $0,00 \%$ & $4,36 \%$ & $4,23 \%$ & $4,42 \%$ \\
\hline & $\mathrm{N}^{0}$ Viagens & 172 & 172 & 172 & 172 & 172 \\
\hline & $\mathrm{N}^{\circ}$ Veículos & 23 & 23 & 23 & 23 & 23 \\
\hline & $\mathbf{N}^{0}$ Tripulantes & 36 & 35 & 36 & 36 & 36 \\
\hline \multirow{5}{*}{2} & F. de Avaliação & 26.164 & 26.184 & 26.305 & 25.900 & 23.168 \\
\hline & $\%$ acima MS* & $12,93 \%$ & $13,02 \%$ & $13,54 \%$ & $11,79 \%$ & $0,00 \%$ \\
\hline & $\mathrm{N}^{\circ}$ Viagens & 69 & 69 & 69 & 69 & 69 \\
\hline & $\mathrm{N}^{0}$ Veículos & 7 & 7 & 7 & 7 & 7 \\
\hline & $\mathbf{N}^{0}$ Tripulantes & 14 & 14 & 14 & 14 & 14 \\
\hline \multirow{5}{*}{3} & F. de Avaliação & 112.686 & 107.945 & 112.728 & 112.380 & 111.983 \\
\hline & $\%$ acima MS* & $4,39 \%$ & $0,00 \%$ & $4,43 \%$ & $4,11 \%$ & $3,74 \%$ \\
\hline & $N^{0}$ Viagens & 372 & 372 & 372 & 372 & 372 \\
\hline & $\mathbf{N}^{\circ}$ Veículos & 24 & 23 & 24 & 23 & 23 \\
\hline & $N^{o}$ Tripulantes & 57 & 56 & 57 & 57 & 57 \\
\hline \multirow{5}{*}{4} & F. de Avaliação & 111.769 & 107.512 & 111.732 & 104.364 & 111.874 \\
\hline & $\%$ acima MS* & $7,10 \%$ & $3,02 \%$ & $7,06 \%$ & $0,00 \%$ & $7,20 \%$ \\
\hline & $\mathbf{N}^{0}$ Viagens & 359 & 359 & 359 & 359 & 359 \\
\hline & $\mathrm{N}^{0}$ Veículos & 19 & 19 & 19 & 19 & 19 \\
\hline & $\mathbf{N}^{0}$ Tripulantes & 52 & 51 & 52 & 50 & 52 \\
\hline \multirow{5}{*}{5} & F. de Avaliação & 257.920 & 246.077 & 254.712 & 253.984 & 262.978 \\
\hline & $\%$ acima $\mathrm{MS} *$ & $4,81 \%$ & $0,00 \%$ & $3,51 \%$ & $3,21 \%$ & $6,87 \%$ \\
\hline & $\mathbf{N}^{0}$ Viagens & 769 & 769 & 769 & 769 & 769 \\
\hline & $\mathrm{N}^{\circ}$ Veículos & 45 & 47 & 47 & 46 & 46 \\
\hline & $\mathbf{N}^{0}$ Tripulantes & 108 & 105 & 107 & 107 & 109 \\
\hline \multirow{5}{*}{6} & F. de Avaliação & 166.702 & 171.046 & 158.634 & 166.252 & 170.115 \\
\hline & $\%$ acima $\mathrm{MS} *$ & $5,09 \%$ & $7,82 \%$ & $0,00 \%$ & $4,80 \%$ & $7,24 \%$ \\
\hline & $\mathbf{N}^{0}$ Viagens & 503 & 503 & 503 & 503 & 503 \\
\hline & $\mathrm{N}^{0}$ Veículos & 36 & 36 & 36 & 35 & 35 \\
\hline & $\mathbf{N}^{0}$ Tripulantes & 84 & 85 & 82 & 84 & 86 \\
\hline \multirow{5}{*}{7} & F. de Avaliação & 79.471 & 79.472 & 70.897 & 75.162 & 81.811 \\
\hline & $\%$ acima $\mathrm{MS} *$ & $12,09 \%$ & $12,10 \%$ & $0,00 \%$ & $6,02 \%$ & $15,39 \%$ \\
\hline & $\mathbf{N}^{0}$ Viagens & 253 & 253 & 253 & 253 & 253 \\
\hline & $\mathrm{N}^{\circ}$ Veículos & 18 & 18 & 18 & 18 & 18 \\
\hline & $\mathrm{N}^{\mathrm{o}}$ Tripulantes & 38 & 38 & 36 & 37 & 39 \\
\hline \multirow{5}{*}{8} & F. de Avaliação & 22.909 & 22.933 & 22.909 & 22.902 & 22.102 \\
\hline & $\%$ acima $\mathrm{MS} *$ & $3,65 \%$ & $3,76 \%$ & $3,65 \%$ & $3,62 \%$ & $0,00 \%$ \\
\hline & $\mathbf{N}^{0}$ Viagens & 121 & 121 & 121 & 121 & 121 \\
\hline & $\mathrm{N}^{0}$ Veículos & 5 & 5 & 5 & 5 & 5 \\
\hline & $\mathrm{N}^{\mathrm{o}}$ Tripulantes & 12 & 12 & 12 & 12 & 12 \\
\hline \multirow{5}{*}{ Somatório } & F. de Avaliação & 849.727 & 830.319 & 830.079 & 833.019 & 856.237 \\
\hline & $\%$ acima $\mathrm{MS} *$ & $2,37 \%$ & $0,03 \%$ & $0,00 \%$ & $0,35 \%$ & $3,15 \%$ \\
\hline & $\mathbf{N}^{0}$ Viagens & 2.618 & 2.618 & 2.618 & 2.618 & 2.618 \\
\hline & $\mathrm{N}^{0}$ Veículos & 177 & 178 & 179 & 176 & 176 \\
\hline & $\mathrm{N}^{0}$ Tripulantes & 401 & 396 & 396 & 397 & 405 \\
\hline
\end{tabular}

* Desvio porcentual em relação à melhor solução obtida. 
Tabela C.10 - Resultados para o dia útil utilizando a abordagem integrada nível 1.

\begin{tabular}{|c|c|c|c|c|c|c|}
\hline Instância & Movimentos & $\mathbf{A}$ & B & $\mathrm{C}$ & $\mathbf{A B C}$ & NSLO \\
\hline \multirow{5}{*}{1} & F. de Avaliação & 145.930 & 148.220 & 148.474 & 147.014 & 162.374 \\
\hline & $\%$ acima MS* & $0,00 \%$ & $1,57 \%$ & $1,74 \%$ & $0,74 \%$ & $11,27 \%$ \\
\hline & $\mathrm{N}^{0}$ Viagens & 269 & 269 & 269 & 269 & 269 \\
\hline & $\mathbf{N}^{\circ}$ Veículos & 45 & 45 & 45 & 46 & 66 \\
\hline & $\mathbf{N}^{0}$ Tripulantes & 58 & 58 & 57 & 58 & 57 \\
\hline \multirow{5}{*}{2} & F. de Avaliação & 36.385 & 36.347 & 36.546 & 35.948 & 40.193 \\
\hline & $\%$ acima MS* & $1,22 \%$ & $1,11 \%$ & $1,66 \%$ & $0,00 \%$ & $11,81 \%$ \\
\hline & $\mathrm{N}^{0}$ Viagens & 98 & 98 & 98 & 98 & 98 \\
\hline & $\mathbf{N}^{0}$ Veículos & 11 & 11 & 11 & 11 & 15 \\
\hline & $\mathrm{N}^{0}$ Tripulantes & 19 & 19 & 19 & 19 & 19 \\
\hline \multirow{5}{*}{3} & F. de Avaliação & 130.580 & 128.170 & 133.449 & 131.454 & 137.367 \\
\hline & $\%$ acima MS* & $1,88 \%$ & $0,00 \%$ & $4,12 \%$ & $2,56 \%$ & $7,18 \%$ \\
\hline & $\mathrm{N}^{0}$ Viagens & 507 & 507 & 507 & 507 & 507 \\
\hline & $\mathbf{N}^{\circ}$ Veículos & 37 & 37 & 36 & 36 & 48 \\
\hline & $\mathbf{N}^{0}$ Tripulantes & 66 & 64 & 64 & 66 & 66 \\
\hline \multirow{5}{*}{4} & F. de Avaliação & 114.466 & 127.974 & 130.008 & 125.974 & 133.069 \\
\hline & $\%$ acima MS* & $0,00 \%$ & $11,80 \%$ & $13,58 \%$ & $10,05 \%$ & $16,25 \%$ \\
\hline & $N^{0}$ Viagens & 468 & 468 & 468 & 468 & 468 \\
\hline & $\mathbf{N}^{0}$ Veículos & 31 & 31 & 31 & 31 & 38 \\
\hline & $\mathrm{N}^{0}$ Tripulantes & 60 & 63 & 61 & 62 & 63 \\
\hline \multirow{5}{*}{5} & F. de Avaliação & 254.945 & 262.093 & 265.761 & 254.893 & 266.823 \\
\hline & $\%$ acima MS* & $0,02 \%$ & $2,82 \%$ & $4,26 \%$ & $0,00 \%$ & $4,68 \%$ \\
\hline & $\mathrm{N}^{0}$ Viagens & 1.038 & 1.038 & 1.038 & 1.038 & 1.038 \\
\hline & $\mathbf{N}^{\circ}$ Veículos & 74 & 73 & 74 & 75 & 95 \\
\hline & $\mathbf{N}^{0}$ Tripulantes & 124 & 123 & 124 & 123 & 122 \\
\hline \multirow{5}{*}{6} & F. de Avaliação & 208.607 & 213.134 & 217.552 & 212.692 & 223.613 \\
\hline & $\%$ acima MS* & $0,00 \%$ & $2,17 \%$ & $4,29 \%$ & $1,96 \%$ & $7,19 \%$ \\
\hline & $N^{0}$ Viagens & 706 & 706 & 706 & 706 & 706 \\
\hline & $\mathbf{N}^{\circ}$ Veículos & 62 & 62 & 62 & 61 & 82 \\
\hline & $\mathrm{N}^{0}$ Tripulantes & 113 & 113 & 113 & 115 & 113 \\
\hline \multirow{5}{*}{7} & F. de Avaliação & 110.370 & 110.815 & 109.347 & 109.913 & 113.075 \\
\hline & $\%$ acima MS* & $0,94 \%$ & $1,34 \%$ & $0,00 \%$ & $0,52 \%$ & $3,41 \%$ \\
\hline & $N^{0}$ Viagens & 361 & 361 & 361 & 361 & 361 \\
\hline & $\mathbf{N}^{0}$ Veículos & 30 & 31 & 31 & 31 & 38 \\
\hline & $\mathbf{N}^{0}$ Tripulantes & 54 & 53 & 53 & 54 & 55 \\
\hline \multirow{5}{*}{8} & F. de Avaliação & 47.638 & 48.505 & 44.076 & 46.003 & 51.170 \\
\hline & $\%$ acima MS* & $8,08 \%$ & $10,05 \%$ & $0,00 \%$ & $4,37 \%$ & $16,09 \%$ \\
\hline & $\mathrm{N}^{0}$ Viagens & 207 & 207 & 207 & 207 & 207 \\
\hline & $\mathbf{N}^{0}$ Veículos & 13 & 13 & 13 & 13 & 20 \\
\hline & $\mathrm{N}^{0}$ Tripulantes & 19 & 19 & 19 & 18 & 19 \\
\hline \multirow{5}{*}{ Somatório } & F. de Avaliação & 1.048 .921 & 1.075 .258 & 1.085 .213 & 1.063 .891 & 1.127 .684 \\
\hline & $\%$ acima MS* & $0,00 \%$ & $2,51 \%$ & $3,46 \%$ & $1,43 \%$ & $7,51 \%$ \\
\hline & $\mathrm{N}^{0}$ Viagens & 3.654 & 3.654 & 3.654 & 3.654 & 3.654 \\
\hline & $\mathbf{N}^{\circ}$ Veículos & 303 & 303 & 303 & 304 & 402 \\
\hline & $\mathbf{N}^{0}$ Tripulantes & 513 & 512 & 510 & 515 & 514 \\
\hline
\end{tabular}

* Desvio porcentual em relação à melhor solução obtida. 
Tabela C.11 - Resultados para o domingo utilizando a abordagem integrada nível 1.

\begin{tabular}{|c|c|c|c|c|c|c|}
\hline Instância & Movimentos & $\mathbf{A}$ & B & $\mathrm{C}$ & $\mathbf{A B C}$ & NSLO \\
\hline \multirow{5}{*}{1} & F. de Avaliação & 36.256 & 36.204 & 36.204 & 35.795 & 37.888 \\
\hline & $\%$ acima MS* & $1,29 \%$ & $1,14 \%$ & $1,14 \%$ & $0,00 \%$ & $5,85 \%$ \\
\hline & $\mathrm{N}^{0}$ Viagens & 90 & 90 & 90 & 90 & 90 \\
\hline & $\mathbf{N}^{\circ}$ Veículos & 10 & 10 & 10 & 10 & 11 \\
\hline & $\mathbf{N}^{0}$ Tripulantes & 20 & 20 & 20 & 20 & 20 \\
\hline \multirow{5}{*}{2} & F. de Avaliação & 19.547 & 19.763 & 20.267 & 20.067 & 19.803 \\
\hline & $\%$ acima MS* & $0,00 \%$ & $1,11 \%$ & $3,68 \%$ & $2,66 \%$ & $1,31 \%$ \\
\hline & $\mathrm{N}^{0}$ Viagens & 53 & 53 & 53 & 53 & 53 \\
\hline & $\mathbf{N}^{\circ}$ Veículos & 5 & 5 & 5 & 5 & 5 \\
\hline & $\mathbf{N}^{\circ}$ Tripulantes & 10 & 10 & 10 & 10 & 10 \\
\hline \multirow{5}{*}{3} & F. de Avaliação & 72.321 & 74.555 & 74.983 & 71.091 & 70.555 \\
\hline & $\%$ acima MS* & $2,50 \%$ & $5,67 \%$ & $6,28 \%$ & $0,76 \%$ & $0,00 \%$ \\
\hline & $N^{0}$ Viagens & 287 & 287 & 287 & 287 & 287 \\
\hline & $\mathbf{N}^{0}$ Veículos & 17 & 18 & 17 & 17 & 17 \\
\hline & $\mathbf{N}^{0}$ Tripulantes & 39 & 39 & 39 & 39 & 39 \\
\hline \multirow{5}{*}{4} & F. de Avaliação & 78.449 & 82.044 & 86.086 & 81.735 & 85.747 \\
\hline & $\%$ acima MS* & $0,00 \%$ & $4,58 \%$ & $9,73 \%$ & $4,19 \%$ & $9,30 \%$ \\
\hline & $N^{0}$ Viagens & 299 & 299 & 299 & 299 & 299 \\
\hline & $\mathbf{N}^{0}$ Veículos & 16 & 17 & 18 & 17 & 16 \\
\hline & $\mathbf{N}^{\circ}$ Tripulantes & 38 & 38 & 37 & 36 & 40 \\
\hline \multirow{5}{*}{5} & F. de Avaliação & 130.055 & 119.781 & 140.906 & 123.706 & 127.187 \\
\hline & $\%$ acima MS* & $8,58 \%$ & $0,00 \%$ & $17,64 \%$ & $3,28 \%$ & $6,18 \%$ \\
\hline & $N^{0}$ Viagens & 538 & 538 & 538 & 538 & 538 \\
\hline & $\mathrm{N}^{\circ}$ Veículos & 26 & 25 & 26 & 26 & 25 \\
\hline & $\mathrm{N}^{0}$ Tripulantes & 61 & 58 & 61 & 57 & 60 \\
\hline \multirow{5}{*}{6} & F. de Avaliação & 109.871 & 113.092 & 118.093 & 111.556 & 110.511 \\
\hline & $\%$ acima MS* & $0,00 \%$ & $2,93 \%$ & $7,48 \%$ & $1,53 \%$ & $0,58 \%$ \\
\hline & $\mathrm{N}^{0}$ Viagens & 378 & 378 & 378 & 378 & 378 \\
\hline & $\mathbf{N}^{\circ}$ Veículos & 26 & 26 & 26 & 26 & 26 \\
\hline & $\mathbf{N}^{0}$ Tripulantes & 58 & 57 & 57 & 58 & 59 \\
\hline \multirow{5}{*}{7} & F. de Avaliação & 39.828 & 37.965 & 39.075 & 39.069 & 39.690 \\
\hline & $\%$ acima MS* & $4,91 \%$ & $0,00 \%$ & $2,92 \%$ & $2,91 \%$ & $4,54 \%$ \\
\hline & $N^{0}$ Viagens & 161 & 161 & 161 & 161 & 161 \\
\hline & $\mathrm{N}^{0}$ Veículos & 8 & 8 & 8 & 8 & 8 \\
\hline & $\mathbf{N}^{0}$ Tripulantes & 19 & 18 & 17 & 18 & 19 \\
\hline \multirow{5}{*}{8} & F. de Avaliação & 21.228 & 18.901 & 21.228 & 21.228 & 21.228 \\
\hline & $\%$ acima MS* & $12,31 \%$ & $0,00 \%$ & $12,31 \%$ & $12,31 \%$ & $12,31 \%$ \\
\hline & $\mathrm{N}^{0}$ Viagens & 108 & 108 & 108 & 108 & 108 \\
\hline & $\mathbf{N}^{0}$ Veículos & 5 & 5 & 5 & 5 & 5 \\
\hline & $\mathrm{N}^{0}$ Tripulantes & 11 & 10 & 11 & 11 & 11 \\
\hline \multirow{5}{*}{ Somatório } & F. de Avaliação & 507.555 & 502.305 & 536.842 & 504.247 & 512.609 \\
\hline & $\%$ acima MS* & $1,05 \%$ & $0,00 \%$ & $6,88 \%$ & $0,39 \%$ & $2,05 \%$ \\
\hline & $N^{0}$ Viagens & 1.914 & 1.914 & 1.914 & 1.914 & 1.914 \\
\hline & $\mathrm{N}^{0}$ Veículos & 113 & 114 & 115 & 114 & 113 \\
\hline & $\mathbf{N}^{0}$ Tripulantes & 256 & 250 & 252 & 249 & 258 \\
\hline
\end{tabular}

* Desvio porcentual em relação à melhor solução obtida. 
Tabela C.12 - Resultados para o sábado utilizando a abordagem integrada nível 1.

\begin{tabular}{|c|c|c|c|c|c|c|}
\hline Instância & Movimentos & $\mathbf{A}$ & B & $\mathrm{C}$ & ABC & NSLO \\
\hline \multirow{5}{*}{1} & F. de Avaliação & 69.192 & 69.848 & 70.389 & 71.296 & 68.756 \\
\hline & $\%$ acima MS* & $0,63 \%$ & $1,59 \%$ & $2,38 \%$ & $3,69 \%$ & $0,00 \%$ \\
\hline & $\mathbf{N}^{0}$ Viagens & 172 & 172 & 172 & 172 & 172 \\
\hline & $\mathbf{N}^{\circ}$ Veículos & 23 & 23 & 23 & 23 & 23 \\
\hline & $\mathbf{N}^{0}$ Tripulantes & 35 & 34 & 34 & 35 & 34 \\
\hline \multirow{5}{*}{2} & F. de Avaliação & 25.992 & 26.996 & 25.957 & 26.257 & 26.548 \\
\hline & $\%$ acima MS* & $0,13 \%$ & $4,00 \%$ & $0,00 \%$ & $1,16 \%$ & $2,28 \%$ \\
\hline & $\mathrm{N}^{0}$ Viagens & 69 & 69 & 69 & 69 & 69 \\
\hline & $\mathbf{N}^{0}$ Veículos & 7 & 7 & 7 & 7 & 8 \\
\hline & $\mathbf{N}^{0}$ Tripulantes & 13 & 13 & 13 & 13 & 13 \\
\hline \multirow{5}{*}{3} & F. de Avaliação & 94.394 & 96.932 & 103.043 & 98.014 & 93.601 \\
\hline & $\%$ acima MS* & $0,85 \%$ & $3,56 \%$ & $10,09 \%$ & $4,71 \%$ & $0,00 \%$ \\
\hline & $N^{0}$ Viagens & 372 & 372 & 372 & 372 & 372 \\
\hline & $\mathbf{N}^{0}$ Veículos & 24 & 24 & 24 & 24 & 25 \\
\hline & $\mathbf{N}^{0}$ Tripulantes & 53 & 52 & 53 & 53 & 52 \\
\hline \multirow{5}{*}{4} & F. de Avaliação & 94.342 & 87.563 & 92.418 & 94.393 & 93.013 \\
\hline & $\%$ acima MS* & $7,74 \%$ & $0,00 \%$ & $5,54 \%$ & $7,80 \%$ & $6,22 \%$ \\
\hline & $\mathrm{N}^{0}$ Viagens & 359 & 359 & 359 & 359 & 359 \\
\hline & $\mathbf{N}^{0}$ Veículos & 19 & 19 & 19 & 19 & 19 \\
\hline & $\mathbf{N}^{\mathbf{0}}$ Tripulantes & 46 & 43 & 44 & 45 & 47 \\
\hline \multirow{5}{*}{5} & F. de Avaliação & 182.543 & 182.335 & 196.663 & 183.125 & 182.961 \\
\hline & $\%$ acima MS* & $0,11 \%$ & $0,00 \%$ & $7,86 \%$ & $0,43 \%$ & $0,34 \%$ \\
\hline & $\mathbf{N}^{\mathbf{0}}$ Viagens & 769 & 769 & 769 & 769 & 769 \\
\hline & $\mathbf{N}^{0}$ Veículos & 46 & 46 & 46 & 46 & 46 \\
\hline & $\mathbf{N}^{0}$ Tripulantes & 87 & 88 & 92 & 88 & 89 \\
\hline \multirow{5}{*}{6} & F. de Avaliação & 151.188 & 139.974 & 147.734 & 147.765 & 140.123 \\
\hline & $\%$ acima MS* & $8,01 \%$ & $0,00 \%$ & $5,54 \%$ & $5,57 \%$ & $0,11 \%$ \\
\hline & $N^{0}$ Viagens & 503 & 503 & 503 & 503 & 503 \\
\hline & $\mathbf{N}^{0}$ Veículos & 36 & 37 & 36 & 36 & 35 \\
\hline & $\mathbf{N}^{0}$ Tripulantes & 76 & 75 & 74 & 78 & 76 \\
\hline \multirow{5}{*}{7} & F. de Avaliação & 65.378 & 68.106 & 73.071 & 68.955 & 69.198 \\
\hline & $\%$ acima MS* & $0,00 \%$ & $4,17 \%$ & $11,77 \%$ & $5,47 \%$ & $5,84 \%$ \\
\hline & $\mathrm{N}^{0}$ Viagens & 253 & 253 & 253 & 253 & 253 \\
\hline & $\mathbf{N}^{0}$ Veículos & 18 & 18 & 18 & 18 & 18 \\
\hline & $\mathbf{N}^{0}$ Tripulantes & 34 & 34 & 34 & 34 & 34 \\
\hline \multirow{5}{*}{8} & F. de Avaliação & 22.532 & 22.492 & 22.300 & 23.100 & 22.300 \\
\hline & $\%$ acima MS* & $1,04 \%$ & $0,86 \%$ & $0,00 \%$ & $3,59 \%$ & $0,00 \%$ \\
\hline & $N^{0}$ Viagens & 121 & 121 & 121 & 121 & 121 \\
\hline & $\mathbf{N}^{0}$ Veículos & 5 & 5 & 5 & 5 & 5 \\
\hline & $\mathbf{N}^{0}$ Tripulantes & 12 & 12 & 12 & 12 & 12 \\
\hline \multirow{5}{*}{ Somatório } & F. de Avaliação & 705.561 & 694.246 & 731.575 & 712.905 & 696.500 \\
\hline & $\%$ acima MS* & $1,63 \%$ & $0,00 \%$ & $5,38 \%$ & $2,69 \%$ & $0,32 \%$ \\
\hline & $N^{0}$ Viagens & 2.618 & 2.618 & 2.618 & 2.618 & 2.618 \\
\hline & $\mathbf{N}^{0}$ Veículos & 178 & 179 & 178 & 178 & 179 \\
\hline & $\mathbf{N}^{0}$ Tripulantes & 356 & 351 & 356 & 358 & 357 \\
\hline
\end{tabular}

* Desvio porcentual em relação à melhor solução obtida. 
Tabela C.13 - Resultados para o dia útil utilizando a abordagem integrada nível 2.

\begin{tabular}{|c|c|c|c|c|c|c|}
\hline Instância & Movimentos & $\mathbf{A}$ & B & $\mathrm{C}$ & $\mathbf{A B C}$ & NSLO \\
\hline \multirow{5}{*}{1} & F. de Avaliação & 161.367 & 165.780 & 164.048 & 162.956 & 161.457 \\
\hline & $\%$ acima MS* & $0,00 \%$ & $2,73 \%$ & $1,66 \%$ & $0,98 \%$ & $0,06 \%$ \\
\hline & $\mathbf{N}^{0}$ Viagens & 269 & 269 & 269 & 269 & 269 \\
\hline & $\mathbf{N}^{\circ}$ Veículos & 43 & 43 & 43 & 44 & 43 \\
\hline & $\mathbf{N}^{0}$ Tripulantes & 61 & 63 & 62 & 62 & 61 \\
\hline \multirow{5}{*}{2} & F. de Avaliação & 32.467 & 32.134 & 32.275 & 32.158 & 32.137 \\
\hline & $\%$ acima MS* & $1,04 \%$ & $0,00 \%$ & $0,44 \%$ & $0,07 \%$ & $0,01 \%$ \\
\hline & $\mathbf{N}^{\circ}$ Viagens & 98 & 98 & 98 & 98 & 98 \\
\hline & $\mathrm{N}^{0}$ Veículos & 11 & 11 & 11 & 11 & 11 \\
\hline & $N^{0}$ Tripulantes & 18 & 17 & 17 & 17 & 17 \\
\hline \multirow{5}{*}{3} & F. de Avaliação & 120.253 & 119.247 & 116.624 & 117.685 & 118.526 \\
\hline & $\%$ acima MS* & $3,11 \%$ & $2,25 \%$ & $0,00 \%$ & $0,91 \%$ & $1,63 \%$ \\
\hline & $\mathbf{N}^{0}$ Viagens & 507 & 507 & 507 & 507 & 507 \\
\hline & $\mathbf{N}^{0}$ Veículos & 37 & 37 & 37 & 37 & 37 \\
\hline & $\mathrm{N}^{\mathbf{0}}$ Tripulantes & 73 & 72 & 69 & 70 & 71 \\
\hline \multirow{5}{*}{4} & F. de Avaliação & 105.694 & 108.505 & 108.580 & 105.746 & 108.600 \\
\hline & $\%$ acima MS* & $0,00 \%$ & $2,66 \%$ & $2,73 \%$ & $0,05 \%$ & $2,75 \%$ \\
\hline & $\mathbf{N}^{0}$ Viagens & 468 & 468 & 468 & 468 & 468 \\
\hline & $\mathbf{N}^{0}$ Veículos & 30 & 30 & 30 & 30 & 30 \\
\hline & $\mathrm{N}^{\mathbf{0}}$ Tripulantes & 66 & 68 & 68 & 66 & 68 \\
\hline \multirow{5}{*}{5} & F. de Avaliação & 243.389 & 249.112 & 251.316 & 247.834 & 247.508 \\
\hline & $\%$ acima $\mathrm{MS} *$ & $0,00 \%$ & $2,35 \%$ & $3,26 \%$ & $1,83 \%$ & $1,69 \%$ \\
\hline & $\mathrm{N}^{0}$ Viagens & 1038 & 1038 & 1038 & 1038 & 1038 \\
\hline & $\mathbf{N}^{0}$ Veículos & 73 & 73 & 73 & 73 & 73 \\
\hline & $N^{0}$ Tripulantes & 145 & 149 & 150 & 148 & 148 \\
\hline \multirow{5}{*}{6} & F. de Avaliação & 195.364 & 198.971 & 201.733 & 198.554 & 196.871 \\
\hline & $\%$ acima MS* & $0,00 \%$ & $1,85 \%$ & $3,26 \%$ & $1,63 \%$ & $0,77 \%$ \\
\hline & $N^{0}$ Viagens & 706 & 706 & 706 & 706 & 706 \\
\hline & $\mathbf{N}^{0}$ Veículos & 60 & 61 & 61 & 61 & 60 \\
\hline & $\mathrm{N}^{\mathbf{0}}$ Tripulantes & 118 & 119 & 122 & 119 & 119 \\
\hline \multirow{5}{*}{7} & F. de Avaliação & 90.577 & 93.635 & 93.328 & 92.596 & 92.271 \\
\hline & $\%$ acima MS* & $0,00 \%$ & $3,38 \%$ & $3,04 \%$ & $2,23 \%$ & $1,87 \%$ \\
\hline & $\mathbf{N}^{0}$ Viagens & 361 & 361 & 361 & 361 & 361 \\
\hline & $\mathbf{N}^{0}$ Veículos & 30 & 30 & 30 & 30 & 30 \\
\hline & $N^{0}$ Tripulantes & 53 & 55 & 55 & 55 & 55 \\
\hline \multirow{5}{*}{8} & F. de Avaliação & 45.893 & 46.268 & 46.547 & 46.319 & 46.094 \\
\hline & $\%$ acima $\mathrm{MS} *$ & $0,00 \%$ & $0,82 \%$ & $1,43 \%$ & $0,93 \%$ & $0,44 \%$ \\
\hline & $\mathbf{N}^{\mathbf{0}}$ Viagens & 207 & 207 & 207 & 207 & 207 \\
\hline & $\mathbf{N}^{0}$ Veículos & 13 & 13 & 13 & 13 & 13 \\
\hline & $\mathbf{N}^{0}$ Tripulantes & 21 & 21 & 21 & 21 & 21 \\
\hline \multirow{5}{*}{ Somatório } & F. de Avaliação & 995.004 & 1.013 .652 & 1.014 .451 & 1.003 .848 & 1.003 .464 \\
\hline & $\%$ acima $\mathrm{MS}^{*}$ & $\mathbf{0 , 0 0 \%}$ & $1,87 \%$ & $1,95 \%$ & $0,89 \%$ & $0,85 \%$ \\
\hline & $\mathbf{N}^{0}$ Viagens & 3.654 & 3.654 & 3.654 & 3.654 & 3.654 \\
\hline & $\mathbf{N}^{\circ}$ Veículos & 297 & 298 & 298 & 299 & 297 \\
\hline & $\mathrm{N}^{0}$ Tripulantes & 555 & 564 & 564 & 558 & 560 \\
\hline
\end{tabular}

* Desvio porcentual em relação à melhor solução obtida. 
Tabela C.14 - Resultados para o domingo utilizando a abordagem integrada nível 2.

\begin{tabular}{|c|c|c|c|c|c|c|}
\hline Instância & Movimentos & $\mathbf{A}$ & B & $\mathrm{C}$ & $\mathrm{ABC}$ & NSLO \\
\hline \multirow{5}{*}{1} & F. de Avaliação & 30.816 & 30.524 & 30.450 & 30.492 & 30.476 \\
\hline & $\%$ acima MS* & $1,20 \%$ & $0,24 \%$ & $0,00 \%$ & $0,14 \%$ & $0,09 \%$ \\
\hline & $\mathrm{N}^{0}$ Viagens & 90 & 90 & 90 & 90 & 90 \\
\hline & $\mathbf{N}^{0}$ Veículos & 10 & 10 & 10 & 10 & 10 \\
\hline & $\mathrm{N}^{\mathbf{0}}$ Tripulantes & 18 & 17 & 17 & 17 & 17 \\
\hline \multirow{5}{*}{2} & F. de Avaliação & 15.841 & 15.841 & 15.841 & 15.841 & 15.841 \\
\hline & $\%$ acima MS* & $0,00 \%$ & $0,00 \%$ & $0,00 \%$ & $0,00 \%$ & $0,00 \%$ \\
\hline & $\mathrm{N}^{0}$ Viagens & 53 & 53 & 53 & 53 & 53 \\
\hline & $\mathrm{N}^{0}$ Veículos & 5 & 5 & 5 & 5 & 5 \\
\hline & $\mathrm{N}^{0}$ Tripulantes & 9 & 9 & 9 & 9 & 9 \\
\hline \multirow{5}{*}{3} & F. de Avaliação & 58.764 & 60.018 & 59.969 & 59.745 & 61.168 \\
\hline & $\%$ acima MS* & $0,00 \%$ & $2,13 \%$ & $2,05 \%$ & $1,67 \%$ & $4,09 \%$ \\
\hline & $\mathrm{N}^{0}$ Viagens & 287 & 287 & 287 & 287 & 287 \\
\hline & $\mathbf{N}^{0}$ Veículos & 17 & 17 & 17 & 17 & 17 \\
\hline & $\mathbf{N}^{0}$ Tripulantes & 37 & 38 & 38 & 38 & 39 \\
\hline \multirow{5}{*}{4} & F. de Avaliação & 60.970 & 63.672 & 65.075 & 65.065 & 66.668 \\
\hline & $\%$ acima MS* & $0,00 \%$ & $4,43 \%$ & $6,73 \%$ & $6,72 \%$ & $9,35 \%$ \\
\hline & $N^{0}$ Viagens & 299 & 299 & 299 & 299 & 299 \\
\hline & $\mathbf{N}^{0}$ Veículos & 15 & 15 & 15 & 15 & 15 \\
\hline & $\mathrm{N}^{\mathbf{0}}$ Tripulantes & 39 & 41 & 42 & 42 & 43 \\
\hline \multirow{5}{*}{5} & F. de Avaliação & 117.570 & 112.047 & 114.901 & 113.405 & 120.307 \\
\hline & $\%$ acima MS* & $4,93 \%$ & $0,00 \%$ & $2,55 \%$ & $1,21 \%$ & $7,37 \%$ \\
\hline & $\mathrm{N}^{0}$ Viagens & 538 & 538 & 538 & 538 & 538 \\
\hline & $\mathbf{N}^{\circ}$ Veículos & 25 & 25 & 25 & 25 & 25 \\
\hline & $\mathrm{N}^{0}$ Tripulantes & 75 & 71 & 73 & 72 & 77 \\
\hline \multirow{5}{*}{6} & F. de Avaliação & 87.924 & 89.317 & 89.089 & 88.913 & 88.149 \\
\hline & $\%$ acima MS* & $0,00 \%$ & $1,58 \%$ & $1,33 \%$ & $1,12 \%$ & $0,26 \%$ \\
\hline & $\mathrm{N}^{0}$ Viagens & 378 & 378 & 378 & 378 & 378 \\
\hline & $\mathbf{N}^{0}$ Veículos & 25 & 25 & 25 & 25 & 25 \\
\hline & $N^{0}$ Tripulantes & 55 & 56 & 55 & 56 & 55 \\
\hline \multirow{5}{*}{7} & F. de Avaliação & 29.888 & 29.069 & 28.954 & 28.980 & 31.303 \\
\hline & $\%$ acima MS* & $3,23 \%$ & $0,40 \%$ & $0,00 \%$ & $0,09 \%$ & $8,11 \%$ \\
\hline & $\mathrm{N}^{0}$ Viagens & 161 & 161 & 161 & 161 & 161 \\
\hline & $\mathrm{N}^{0}$ Veículos & 9 & 9 & 8 & 8 & 9 \\
\hline & $\mathbf{N}^{0}$ Tripulantes & 18 & 17 & 18 & 18 & 19 \\
\hline \multirow{5}{*}{8} & F. de Avaliação & 16.699 & 16.735 & 16.402 & 16.699 & 16.714 \\
\hline & $\%$ acima MS* & $1,81 \%$ & $2,03 \%$ & $0,00 \%$ & $1,81 \%$ & $1,90 \%$ \\
\hline & $\mathrm{N}^{0}$ Viagens & 108 & 108 & 108 & 108 & 108 \\
\hline & $\mathbf{N}^{0}$ Veículos & 5 & 5 & 5 & 5 & 5 \\
\hline & $\mathbf{N}^{0}$ Tripulantes & 10 & 10 & 9 & 10 & 10 \\
\hline \multirow{5}{*}{ Somatório } & F. de Avaliação & 418.472 & 417.223 & 420.681 & 419.140 & 430.626 \\
\hline & $\%$ acima MS* & $\mathbf{0 , 3 0} \%$ & $0,00 \%$ & $0,83 \%$ & $0,46 \%$ & $3,21 \%$ \\
\hline & $\mathrm{N}^{0}$ Viagens & 1.914 & 1.914 & 1.914 & 1.914 & 1.914 \\
\hline & $\mathrm{N}^{\circ}$ Veículos & 111 & 111 & 110 & 110 & 111 \\
\hline & $\mathbf{N}^{0}$ Tripulantes & 261 & 259 & 261 & 262 & 269 \\
\hline
\end{tabular}

* Desvio porcentual em relação à melhor solução obtida. 
Tabela C.15 - Resultados para o sábado utilizando a abordagem integrada nível 2.

\begin{tabular}{|c|c|c|c|c|c|c|}
\hline Instância & Movimentos & $\mathbf{A}$ & B & $\mathrm{C}$ & $\mathbf{A B C}$ & NSLO \\
\hline \multirow{5}{*}{1} & F. de Avaliação & 81.316 & 81.489 & 81.034 & 81.559 & 80.988 \\
\hline & $\%$ acima $M S^{*}$ & $0,40 \%$ & $0,62 \%$ & $0,06 \%$ & $0,71 \%$ & $0,00 \%$ \\
\hline & $\mathrm{N}^{0}$ Viagens & 172 & 172 & 172 & 172 & 172 \\
\hline & $\mathbf{N}^{0}$ Veículos & 23 & 23 & 23 & 23 & 23 \\
\hline & $\mathbf{N}^{0}$ Tripulantes & 36 & 36 & 37 & 36 & 37 \\
\hline \multirow{5}{*}{2} & F. de Avaliação & 22.214 & 22.214 & 22.204 & 22.235 & 22.181 \\
\hline & $\%$ acima $\mathrm{MS} *$ & $0,15 \%$ & $0,15 \%$ & $0,10 \%$ & $0,24 \%$ & $0,00 \%$ \\
\hline & $\mathrm{N}^{0}$ Viagens & 69 & 69 & 69 & 69 & 69 \\
\hline & $\mathrm{N}^{0}$ Veículos & 7 & 7 & 7 & 7 & 7 \\
\hline & $\mathbf{N}^{o}$ Tripulantes & 12 & 12 & 12 & 12 & 12 \\
\hline \multirow{5}{*}{3} & F. de Avaliação & 82.700 & 86.978 & 88.010 & 83.694 & 85.538 \\
\hline & $\%$ acima MS* & $0,00 \%$ & $5,17 \%$ & $6,42 \%$ & $1,20 \%$ & $3,43 \%$ \\
\hline & $N^{0}$ Viagens & 372 & 372 & 372 & 372 & 372 \\
\hline & $\mathrm{N}^{0}$ Veículos & 24 & 24 & 23 & 23 & 24 \\
\hline & $\mathbf{N}^{0}$ Tripulantes & 53 & 56 & 57 & 54 & 55 \\
\hline \multirow{5}{*}{4} & F. de Avaliação & 69.059 & 71.861 & 73.410 & 70.409 & 76.100 \\
\hline & $\%$ acima MS* & $0,00 \%$ & $4,06 \%$ & $6,30 \%$ & $1,95 \%$ & $10,20 \%$ \\
\hline & $\mathbf{N}^{0}$ Viagens & 359 & 359 & 359 & 359 & 359 \\
\hline & $\mathbf{N}^{0}$ Veículos & 19 & 19 & 19 & 19 & 19 \\
\hline & $\mathbf{N}^{0}$ Tripulantes & 44 & 46 & 47 & 45 & 49 \\
\hline \multirow{5}{*}{5} & F. de Avaliação & 171.532 & 173.857 & 178.307 & 175.026 & 175.264 \\
\hline & $\%$ acima MS* & $0,00 \%$ & $1,36 \%$ & $3,95 \%$ & $2,04 \%$ & $2,18 \%$ \\
\hline & $\mathrm{N}^{0}$ Viagens & 769 & 769 & 769 & 769 & 769 \\
\hline & $\mathbf{N}^{0}$ Veículos & 45 & 45 & 45 & 46 & 45 \\
\hline & $\mathbf{N}^{0}$ Tripulantes & 106 & 108 & 111 & 108 & 109 \\
\hline \multirow{5}{*}{6} & F. de Avaliação & 119.830 & 121.687 & 122.600 & 120.228 & 118.928 \\
\hline & $\%$ acima MS* & $0,76 \%$ & $2,32 \%$ & $3,09 \%$ & $1,09 \%$ & $0,00 \%$ \\
\hline & $\mathbf{N}^{0}$ Viagens & 503 & 503 & 503 & 503 & 503 \\
\hline & $\mathbf{N}^{0}$ Veículos & 35 & 35 & 35 & 35 & 35 \\
\hline & $\mathbf{N}^{0}$ Tripulantes & 74 & 75 & 76 & 74 & 73 \\
\hline \multirow{5}{*}{7} & F. de Avaliação & 57.860 & 58.194 & 59.259 & 58.370 & 57.953 \\
\hline & $\%$ acima MS* & $0,00 \%$ & $0,58 \%$ & $2,42 \%$ & $0,88 \%$ & $0,16 \%$ \\
\hline & $\mathrm{N}^{0}$ Viagens & 253 & 253 & 253 & 253 & 253 \\
\hline & $\mathbf{N}^{0}$ Veículos & 18 & 18 & 18 & 18 & 18 \\
\hline & $\mathbf{N}^{\mathbf{0}}$ Tripulantes & 35 & 35 & 36 & 35 & 35 \\
\hline \multirow{5}{*}{8} & F. de Avaliação & 17.665 & 17.737 & 17.713 & 17.752 & 17.671 \\
\hline & $\%$ acima $\mathrm{MS}^{*}$ & $0,00 \%$ & $0,41 \%$ & $0,27 \%$ & $0,49 \%$ & $0,03 \%$ \\
\hline & $\mathbf{N}^{0}$ Viagens & 121 & 121 & 121 & 121 & 121 \\
\hline & $N^{0}$ Veículos & 5 & 5 & 5 & 5 & 5 \\
\hline & $\mathbf{N}^{0}$ Tripulantes & 11 & 11 & 11 & 11 & 11 \\
\hline \multirow{5}{*}{ Somatório } & F. de Avaliação & 622.176 & 634.017 & 642.537 & 629.273 & 634.623 \\
\hline & $\%$ acima MS* & $0,00 \%$ & $1,90 \%$ & $3,27 \%$ & $1,14 \%$ & $2,00 \%$ \\
\hline & $\mathbf{N}^{0}$ Viagens & 2.618 & 2.618 & 2.618 & 2.618 & 2.618 \\
\hline & $\mathrm{N}^{0}$ Veículos & 176 & 176 & 175 & 176 & 176 \\
\hline & $\mathbf{N}^{0}$ Tripulantes & 371 & 379 & 387 & 375 & 381 \\
\hline
\end{tabular}

* Desvio porcentual em relação à melhor solução obtida. 